Florida International University

FIU Digital Commons

FIU Electronic Theses and Dissertations

University Graduate School

$11-12-2019$

\title{
Mechanical Behavior of Ternary Metallic Glasses and Their Composites
}

Xue Liang

xlian002@fiu.edu

Follow this and additional works at: https://digitalcommons.fiu.edu/etd

Part of the Structural Materials Commons

\section{Recommended Citation}

Liang, Xue, "Mechanical Behavior of Ternary Metallic Glasses and Their Composites" (2019). FIU Electronic Theses and Dissertations. 4317.

https://digitalcommons.fiu.edu/etd/4317

This work is brought to you for free and open access by the University Graduate School at FIU Digital Commons. It has been accepted for inclusion in FIU Electronic Theses and Dissertations by an authorized administrator of FIU Digital Commons. For more information, please contact dcc@fiu.edu. 


\title{
FLORIDA INTERNATIONAL UNIVERSITY
}

Miami, Florida

\section{MECHANICAL BEHAVIOR OF TERNARY METALLIC GLASSES AND THEIR COMPOSITES}

\author{
A dissertation submitted in partial fulfillment of \\ the requirements for the degree of \\ DOCTOR OF PHILOSOPHY \\ in \\ MATERIALS SCIENCE AND ENGINEERING \\ by
}

Xue Liang 


\section{To: Dean John L. Volakis}

College of Engineering and Computing

This dissertation, written by Xue Liang, and entitled Mechanical Behavior Of Ternary Metallic Glasses And Their Composites, having been approved in respect to style and intellectual content, is referred to you for judgment.

We have read this dissertation and recommend that it be approved.

\section{Zhe Cheng}

Chunlei Wang

Benjamin Boesl

Wenzhi Li

Date of Defense: November 12, 2019

Jiuhua Chen, Major Professor

The dissertation of Xue Liang is approved.

Dean John L. Volakis

College of Engineering and Computing

Andrés G. Gil

Vice President for Research and Economic Development and Dean of the University Graduate School

Florida International University, 2019 
(C) Copyright 2019 by Xue Liang

All rights reserved. 


\section{DEDICATION}

To my wife Qixiu and parents, I couldn't have done this without you. Thank you for all your support and encouragement along the way. 


\section{ACKNOWLEDGMENTS}

First and foremost, I greatly appreciate the help from my major professor Dr. Jiuhua Chen - for his advice, support, and guidance throughout the entire dissertation period. I thank him for making a lot of opportunities available to me during my dissertation, such as attending several conferences and workshops and conducting experiments in national synchrotron facilities. The accumulated experience from these opportunities helped me reach my goal and enriched my knowledge.

I am also indebted to my dissertation committee members: Dr. Zhe Cheng, Dr. Chunlei Wang, Dr. Benjamin Boesl, and Dr. Wenzhi Li for their suggestions and encouragement at different stages of my dissertation. I also would like to thank Dr. Qiaoshi Zeng for his help with metallic glasses sample preparation, Dr. George Dulikravich for his advice and help with multi-objective optimization of MG composition, Dr. Vadym Drozd for their guidance and help with my experiments, and Dr. Andriy Durygin for familiarizing me with the lab instruments.

Furthermore, this dissertation will not be completed without the financial support from Florida International University graduate school-their doctoral evidence acquisition fellowship and dissertation year fellowship. Also, the work was partially supported by NSF Grant EAR-1723185.

Last but not least, I would like to thank the support of my wife Qixiu Xin and my parents for their support and for their invaluable assistance during my study. Moreover, I thank all my friends especially Dr. Guang Cheng for encouraging me and giving me many valuable suggestions and advice during my graduate study. 


\title{
ABSTRACT OF THE DISSERTATION \\ MECHANICAL BEHAVIOR OF TERNARY METALLIC GLASSES \\ AND THEIR COMPOSITES
}

\author{
by \\ Xue Liang \\ Florida International University, 2019 \\ Miami, Florida \\ Professor Jiuhua Chen, Major Professor
}

The vast demands for advanced materials have been putting tremendous pressure on materials scientists and engineers to discover and produce novel lighter and stiffer materials. This dissertation is devoted to the development and fundamental understanding of the strength and the structures within Aluminum ternary metallic glasses (MGs) and their composites, which have a low density and promising high strength. The dissertation focuses on the following content: The multi-objective optimization algorithm predicted the $\mathrm{Al}_{16.5} \mathrm{Ni}_{8} \mathrm{Ce}_{75.5}$ ternary metallic glass composition with an improved glass-forming ability (supercooled liquid region $\Delta T x=29 \mathrm{~K}$ ), based on the provided dataset. Inoue Criteria can predict the $\mathrm{Al}_{46} \mathrm{Ni}_{10} \mathrm{Ce}_{44}$ metallic glass concentration with the highest supercooled liquid region $\Delta T x=40 \mathrm{~K}$ and best initial hardness $389(\mathrm{Hv})$. The highest hardness value, $853(\mathrm{Hv})$, was achieved when annealed $\mathrm{Al}_{46} \mathrm{Ni}_{10} \mathrm{Ce}_{44}$ at $573 \mathrm{~K}$ for 30 mins. This value is significantly high compared to the published hardness of bulk MG systems, such as Zr-based, Pd-based and Mg-based metallic glasses, as well as conventional alloys such as stainless steel and super high strength steel. The relationship between the hardness of Al-Ni-Ce MGs and the annealing temperatures was investigated by high energy synchrotron X-ray diffraction 
(HEXRD) and Transmission Electron Microscopy (TEM). Obtained HEXRD and TEM results and microindentation values show that when the annealing temperature is close to the onset temperature of crystallization, the hardness reaches the highest value.

Annealing treatment of the $\mathrm{Al}_{23} \mathrm{Ce}_{75} \mathrm{Si}_{2} \mathrm{MG}$ at a temperature above $473 \mathrm{~K}$ introduced 30$40 \mathrm{~nm} \mathrm{AlCe} 3$ crystalline precipitations, which enhanced the hardness of the annealed alloy. The number of such nano-precipitations increased with the annealing temperature within the range of $473 \mathrm{~K}-563 \mathrm{~K}$. Consequently, the hardness increased with the annealing temperature. From transmission electron microscopy images, the mixed area of the crystalline and non-crystalline structure was identified, the increased density of grain boundary improved the mechanical property of the sample.

The pair distribution function (PDF) analyses based on the HEXRD of $\mathrm{Al}_{20} \mathrm{Ni}_{10} \mathrm{Ce}_{70}$, $\mathrm{Al}_{46} \mathrm{Ni}_{10} \mathrm{Ce}_{44}, \mathrm{Al}_{86.5} \mathrm{Ni}_{9.5} \mathrm{Ce}_{5}$, and $\mathrm{Al}_{85.8} \mathrm{Ni}_{9.1} \mathrm{Ce}_{5.1}$ were conducted, and the results demonstrate that there is an atom amount balance for $\mathrm{Al}$ atoms' closest $\mathrm{Ni}$ and $\mathrm{Ce}$. Also, this balance influenced glass forming ability (GFA). The PDF results from $\mathrm{Al}_{86.5} \mathrm{Ni}_{9.5} \mathrm{Ce}_{5}$ and $\mathrm{Al}_{85.8} \mathrm{Ni}_{9.1} \mathrm{Ce}_{5.1}$ indicate that a slight difference in concentration would not significantly affect the final GFA performance.

The current research suggests a possible way to design, synthesize, and improve Al-based bulk metallic glass (BMG). 
CHAPTER 1.INTRODUCTION............................................................................................. 1

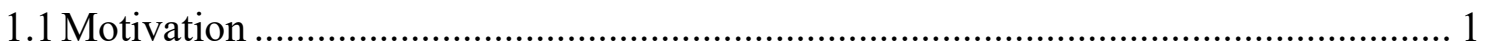

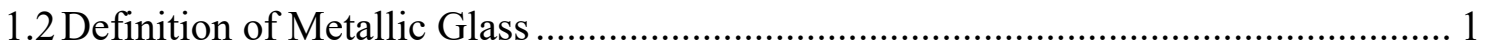

1.3 Processing Methods of Metallic Glass .................................................................. 3

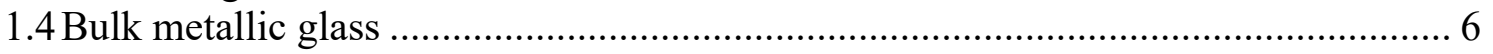

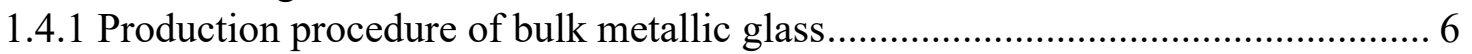

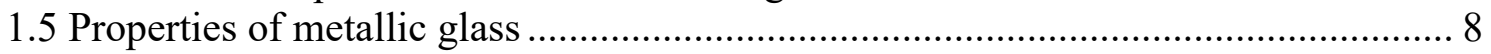

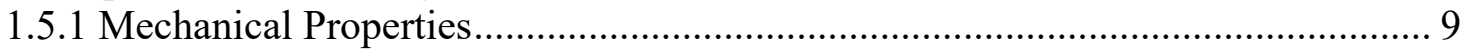

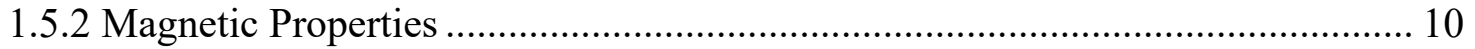

1.5.3 Corrosion and Wear Resistance Properties........................................................ 11

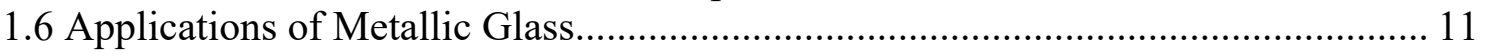

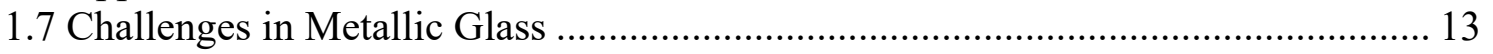

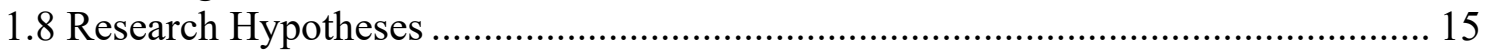

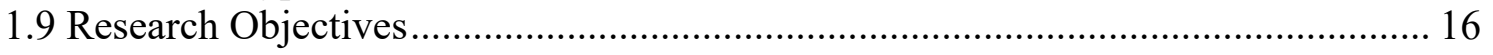

CHAPTER 2.LITERATURE REVIEW ................................................................18

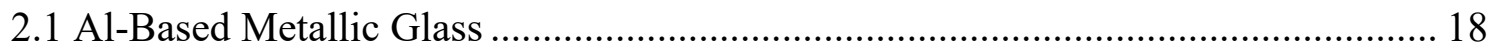

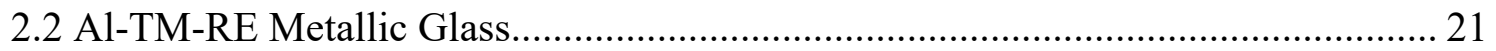

2.3 Glass-Forming Ability of Al-Re-Tm Metallic Glass ................................................. 23

CHAPTER 3.EXPERIMENTAL METHODS ...............................................................27

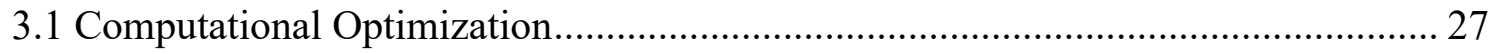

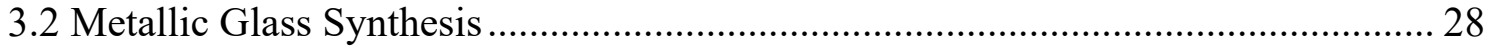

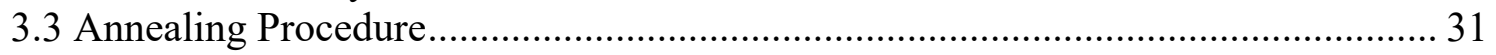

3.4 Total X-ray Scattering Measurement ................................................................. 32

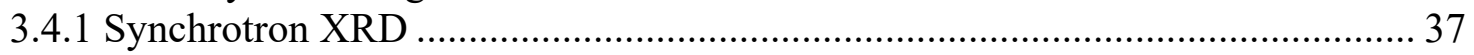

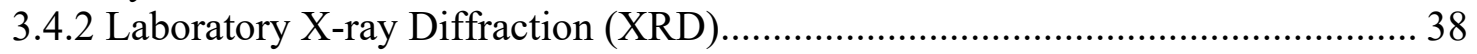

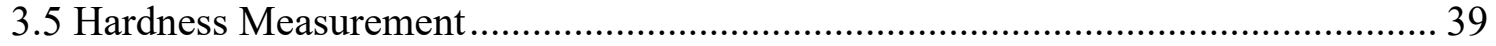

3.6 Transmission Electron Microscopy (TEM) ……………......................................... 40

CHAPTER 4.EFFECT OF PRECIPITATION ON THE HARDNESS OF TERNARY METALLIC GLASS.......................................................................................................41

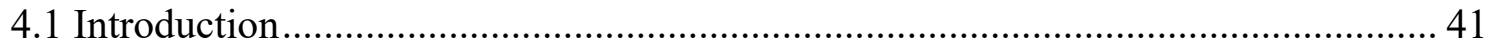

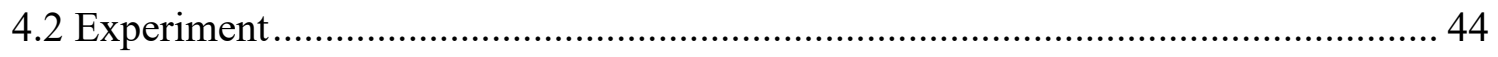

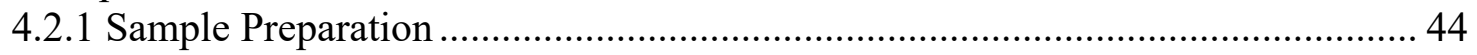

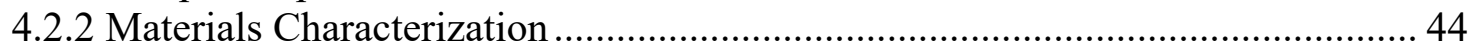

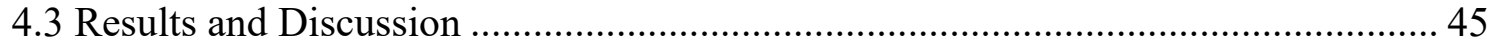

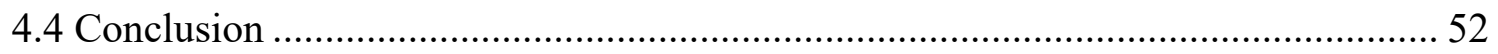

CHAPTER 5.OPTIMIZING COMPOSITION OF AL-NI-CE TERNARY ALLOY FOR IMPROVED GLASS-FORMING ABILITY AND MECHANICAL PROPERTIES ........53

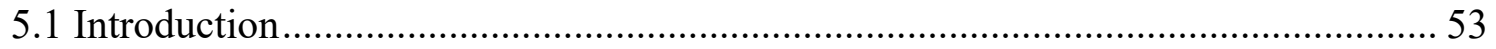




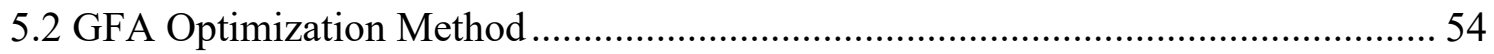

5.2.1 Multi-objective Optimization Algorithm ....................................................... 55

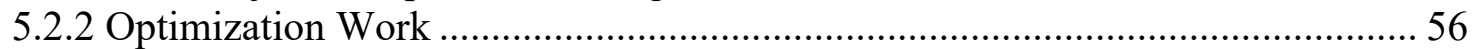

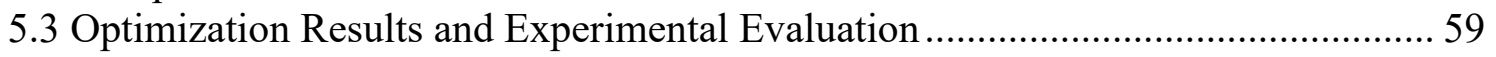

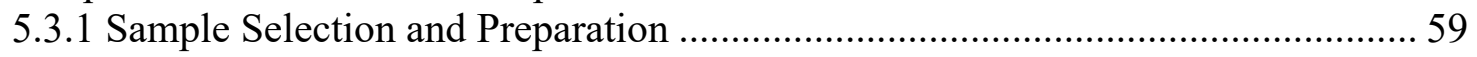

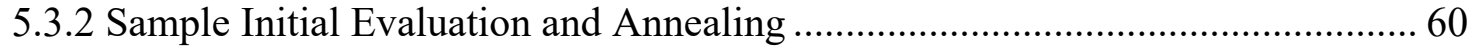

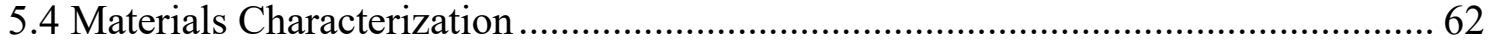

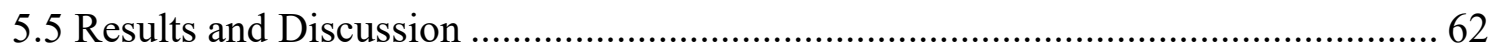

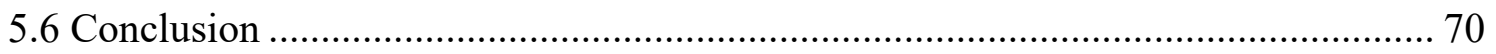

CHAPTER 6.SHORT-RANGE ORDER RESEARCH IN AL-NI-CE METALLIC GLASSES AND THEIR COMPOSITES ..................................................................72

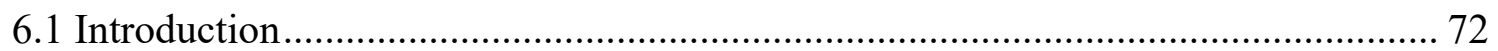

6.2 Experimental process and data analyses ....................................................... 74

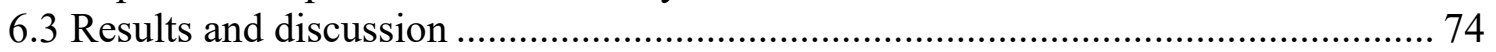

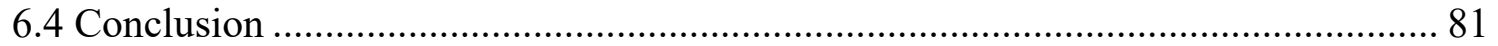

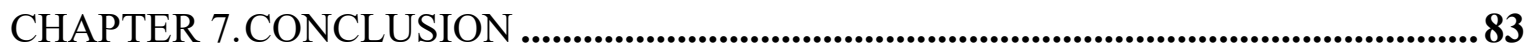

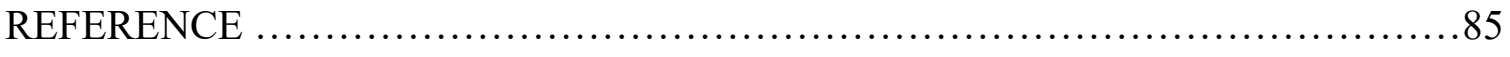

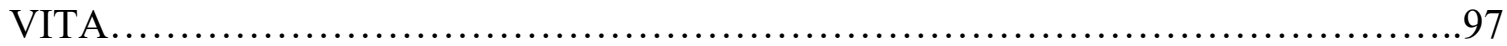


Table 1 Difference between crystalline materials and amorphous materials ..................... 3

Table 2 The size development of metallic glass with different compositions ..................... 5

Table 3 Current and future application fields for metallic glass. [45] ............................. 13

Table 4 Comparison of structural Al-based BMG with conventional engineering Al-

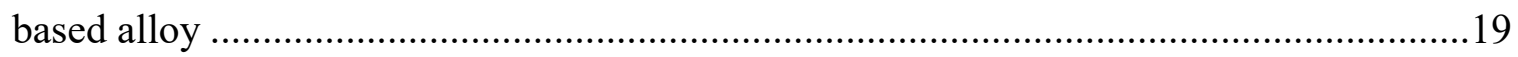

Table 5 Metallic glass experimental data collection........................................................ 57

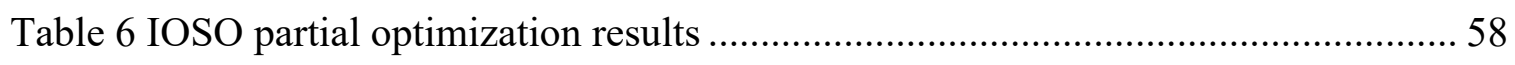

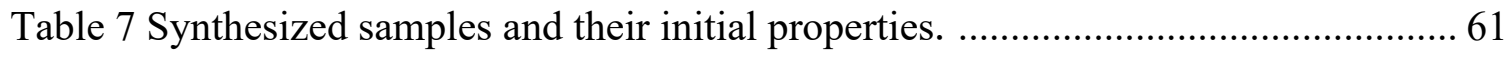

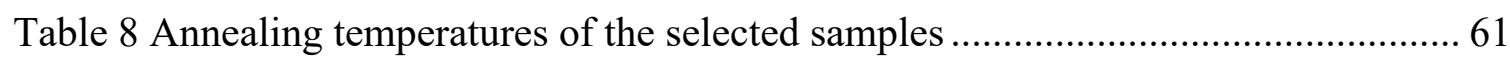

Table 9 The properties of four samples $\left(\mathrm{Al}_{20} \mathrm{Ni}_{10} \mathrm{Ce}_{70}, \mathrm{Al}_{46} \mathrm{Ni}_{10} \mathrm{Ce}_{44}, \mathrm{Al}_{86.5} \mathrm{Ni}_{9.5} \mathrm{Ce}_{5}\right.$ and $\mathrm{Al}_{85.8} \mathrm{Ni}_{9.1} \mathrm{Ce}_{5.1}$ ): experimental measured super-cooled liquid region ( $\mathrm{Tx}-\mathrm{Tg}$ ), initial

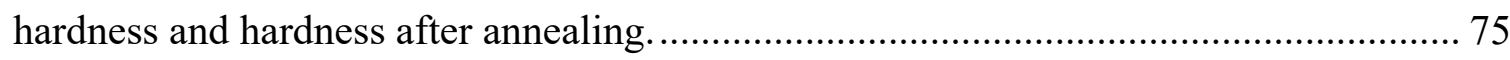

Table 10 Peak positions of the pair distribution function, G(r), for the Al-based MGs .... 79 
Figure 1 (a) Crystalline (left), (b) Amorphous (right) [6]............................................... 2

Figure 2 Schematic time-temperature-transformation (TTT) diagram of processing methods: path (1) is Direct Casting and path (2) is Thermoplastic Forming [134]............ 8

Figure 3 Metallic glass combines higher strength than crystalline metal with the

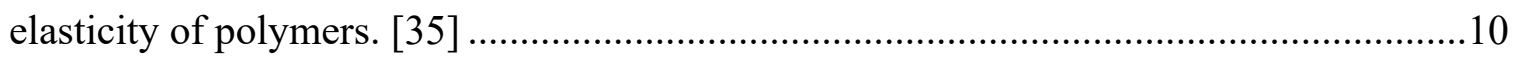

Figure $4 \mathrm{BMG} \mathrm{Al}{ }_{86} \mathrm{Ni}_{7} \mathrm{Y}_{5} \mathrm{Co}_{1} \mathrm{La}_{1}$ rod sample with a $1 \mathrm{~mm}$ diameter [44] ...................... 12

Figure 5 The ideal metallic glass with desired properties.............................................. 15

Figure 6 Coordination number as a function of bond distance in Al-based MG [67] ...... 22

Figure 7 Diagram of the relationship between critical cooling rate and free energy of

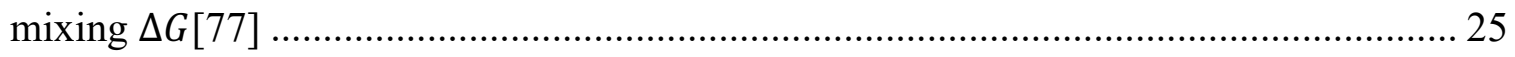

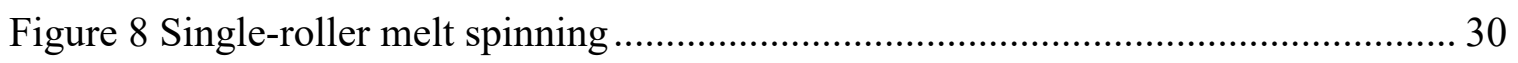

Figure 9 Annealing procedure of samples in the current study ......................................... 31

Figure 10 Annealing facility. Annealing oven (left), Vacuum system (right)................. 32

Figure 11 The National Synchrotrons Light Sources II (NSLS-II), Brookhaven

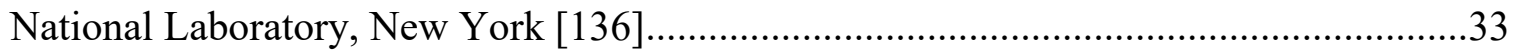

Figure 12 (a) NSLS-II 28-IDC and (b) NSLS-II 28-IDC workstation. Beam Status (Red), Motor control (Yellow), Camera Status (Blue) ........................................................34

Figure 13 Inside of the hutch and PDF sample holder................................................ 35

Figure 14 Schematic illustration of $\mathrm{g}(\mathrm{r})$ dependence on radius [88] ................................ 37

Figure 15 X-ray diffractometer (XRD) at CeSMEC....................................................... 39

Figure 16 Hardness test equipment at Advanced Materials Engineering Research

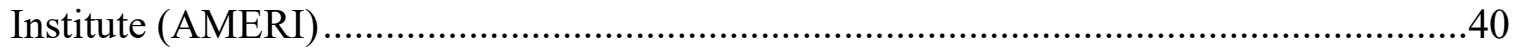

Figure 17 Processing of $\mathrm{Ce}_{75} \mathrm{Al}_{23} \mathrm{Si}_{2}$ metallic glass mechanical properties and structure

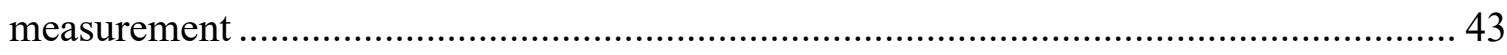

Figure 18 The average hardness values (Hv) of each sample with different annealing temperatures (The points from left to right were the as received sample and samples annealing at $373 \mathrm{~K}, 473 \mathrm{~K}, 523 \mathrm{~K}, 543 \mathrm{~K}$ and $563 \mathrm{~K}$ ). Bars attached to the symbols represent the experimental uncertainty. 
Figure 19 The XRD patterns of each samples: (a) as received (AR) sample, (b) sample annealed at $373 \mathrm{~K}$, (c) sample annealed at $473 \mathrm{~K}$, (d) sample annealed at 523K, (e) sample annealed at $543 \mathrm{~K}$, and (f) sample annealed at $563 \mathrm{~K}$ (Wavelength $\lambda$ is $0.7093 \AA$,

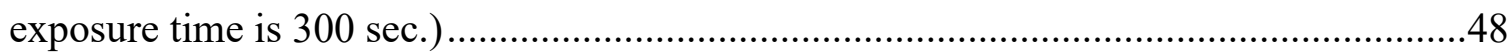

Figure 20 (a) microstructures of $\mathrm{Ce}_{75} \mathrm{Al}_{23} \mathrm{Si}_{2}$ sample annealed at $473 \mathrm{~K}$......................... 50

Figure 21 (b) magnified images of $\mathrm{Ce}_{75} \mathrm{Al}_{23} \mathrm{Si}_{2}$ sample annealed at $473 \mathrm{~K}$..................... 50

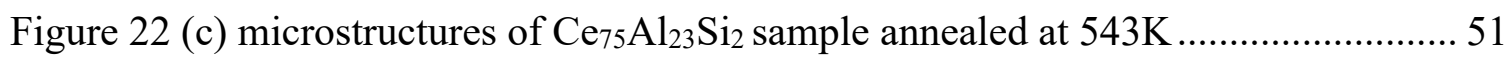

Figure $23(\mathrm{~d})$ magnified images of $\mathrm{Ce}_{75} \mathrm{Al}_{23} \mathrm{Si}_{2}$ sample annealed at $543 \mathrm{~K} \ldots \ldots \ldots \ldots \ldots \ldots . . . . . . . . . .51$

Figure 24 (a) the XRD patterns of $\mathrm{Al}_{20} \mathrm{Ni}_{10} \mathrm{Ce}_{70}$ (Wavelength $\lambda$ is $0.3344 \AA$ and exposure time is $10 \mathrm{sec}$ ), and (b) the average hardness values ( $\mathrm{Hv}$ ) of the $\mathrm{Al}_{20} \mathrm{Ni}_{10} \mathrm{Ce}_{70}$ sample with annealing temperatures at $363 \mathrm{~K}, 393 \mathrm{~K}, 423 \mathrm{~K}, 453 \mathrm{~K}, 483 \mathrm{~K}$, respectively...64 Figure 25 (a) the XRD patterns of $\mathrm{Al}_{85.5} \mathrm{Ni}_{9.5} \mathrm{Ce}_{5}$ (Wavelength $\lambda$ is $0.3344 \AA$, exposure time is $10 \mathrm{sec}$ ) and (b)the average hardness values ( $\mathrm{Hv}$ ) of the $\mathrm{Al}_{20} \mathrm{Ni}_{10} \mathrm{Ce}_{70}$ sample with annealing temperatures at $373 \mathrm{~K}, 473 \mathrm{~K}, 513 \mathrm{~K}, 543 \mathrm{~K}, 573 \mathrm{~K}$, respectively.

Figure 26 Top is the XRD patterns of $\mathrm{Al}_{85.8} \mathrm{Ni}_{9.1} \mathrm{Ce}_{5.1}$ (Wavelength $\lambda$ is $0.3344 \AA$, exposure time is $10 \mathrm{sec}$ ); Bottom are the average hardness values (HV) of the $\mathrm{Al}_{20} \mathrm{Ni}_{10} \mathrm{Ce}_{70}$ sample with annealing temperatures at $373 \mathrm{~K}, 423 \mathrm{~K}, 483 \mathrm{~K}, 523 \mathrm{~K}, 553 \mathrm{~K}$, respectively. 66

Figure 27 Top is the XRD patterns of $\mathrm{Al}_{46} \mathrm{Ni}_{10} \mathrm{Ce}_{44}$ (Wavelength $\lambda$ is $0.3344 \AA$, exposure time is $10 \mathrm{sec}$ ); Bottom are the average hardness values (HV) of the $\mathrm{Al}_{20} \mathrm{Ni}_{10} \mathrm{Ce}_{70}$ sample with annealing temperatures at $373 \mathrm{~K}, 473 \mathrm{~K}, 523 \mathrm{~K}, 573 \mathrm{~K}, 603 \mathrm{~K}$, respectively.

Figure 28 The composition map for Al-based MG alloys areas. 68

Figure 29 The hardness of the metallic glass $\mathrm{Al}_{46} \mathrm{Ni}_{10} \mathrm{Ce}_{44}$ after annealing shows the excellent mechanical property compared to other MG system or other crystalline alloys [126].

Figure 30 Total structure factors $\mathrm{S}(\mathrm{Q})$ obtained from X-ray diffraction for amorphous $\mathrm{Al}_{20} \mathrm{Ni}_{10} \mathrm{Ce}_{70}, \mathrm{Al}_{46} \mathrm{Ni}_{10} \mathrm{Ce}_{44}, \mathrm{Al}_{86.5} \mathrm{Ni}_{9.5} \mathrm{Ce}_{5}$ and $\mathrm{Al}_{85.8} \mathrm{Ni}_{9.1} \mathrm{Ce}_{5.1}$ 76

Figure 31 Reduced atomic distribution function, G(r), for four amorphous alloys. The vertical blue dash line is used to mark the position of Al-Ni pair, yellow dash line is 
marked the position of Al-Al pair and green dash line is for Al-Ce pair. The intensity of Al-Ni and Al-Ce are shifted with different composition...............................................78 Figure 32 Reduced atomic distribution function, $\mathrm{G}(\mathrm{r})$, for amorphous $\mathrm{Al}_{46} \mathrm{Ni}_{10} \mathrm{Ce}_{44}$ at room temperature (RT) and after annealing at $373 \mathrm{~K}, 473 \mathrm{~K}, 543 \mathrm{~K}, 643 \mathrm{~K}$ and $673 \mathrm{~K}$, respectively. The vertical blue dash line is the position of first main peak, red dash line is the position of the second peak for each sample........................................................... 


\section{CHAPTER 1.INTRODUCTION}

\subsection{Motivation}

With the rapid progress of technologies and industries, the huge demands and higher requirements for new advanced materials right now have been putting tremendous pressure on materials scientists and engineers to find and produce novel materials with further improved properties, such as a lower density as well as an improved stiffness. These efforts have resulted in the design and development of advanced materials that are "lighter and stiffer" than those existing materials. With the development of new equipment and new synthesis techniques since last century, some completely state-of-the-art materials have been found and produced, such as the Au-Si metallic glass produced by Duwez et al in 1967 [1], Al-Mg quasicrystals found and produced by Shechtman et al. in 1982 [2], and barium-doped compound superconductors synthesized by Bednorz and Muller in 1986 [3]. After continuing studies and developments of these materials, scientists and engineers found metallic glass is one of the best candidates to meet all those requirements mentioned above.

\subsection{Definition of Metallic Glass}

Solids are usually divided into two different types: one is crystalline matter, such as metals and diamonds, and the other is amorphous matter, such as glass. A crystalline solid is characterized by its freezing of the atoms in a particular structure that is uniform across the whole solid [4]. Figure 1 shows the structural difference between crystalline materials and amorphous materials. Figure 1 (a) shows that all of the atoms are packed with a regularly repeating pattern. While Figure 1 (b), atoms are arranged randomly, although they appear to be arranged periodically when viewed in a local area. The small crystal structure (unit 
cell) is reproducible within the space when we observe the matter from the atom scale. In other words, we can predict the structure of any part of the crystalline material based on a small volume containing the unit cell. An amorphous solid, on the other hand, is a solid material obtained from a liquid that does not crystallize during cooling; thus, the atoms are packed in a random pattern. For the amorphous materials, however, we can only know the local structure and cannot predict its structure from the local arrangement because of its random organization when viewed in a whole. Amorphous materials, such as glass, are usually manufactured by rapid cooling from the liquid state. Metallic glass (MG), as an amorphous material, is different from traditional glass, because they possess metallic behavior such as conducting electricity and high durability [5].
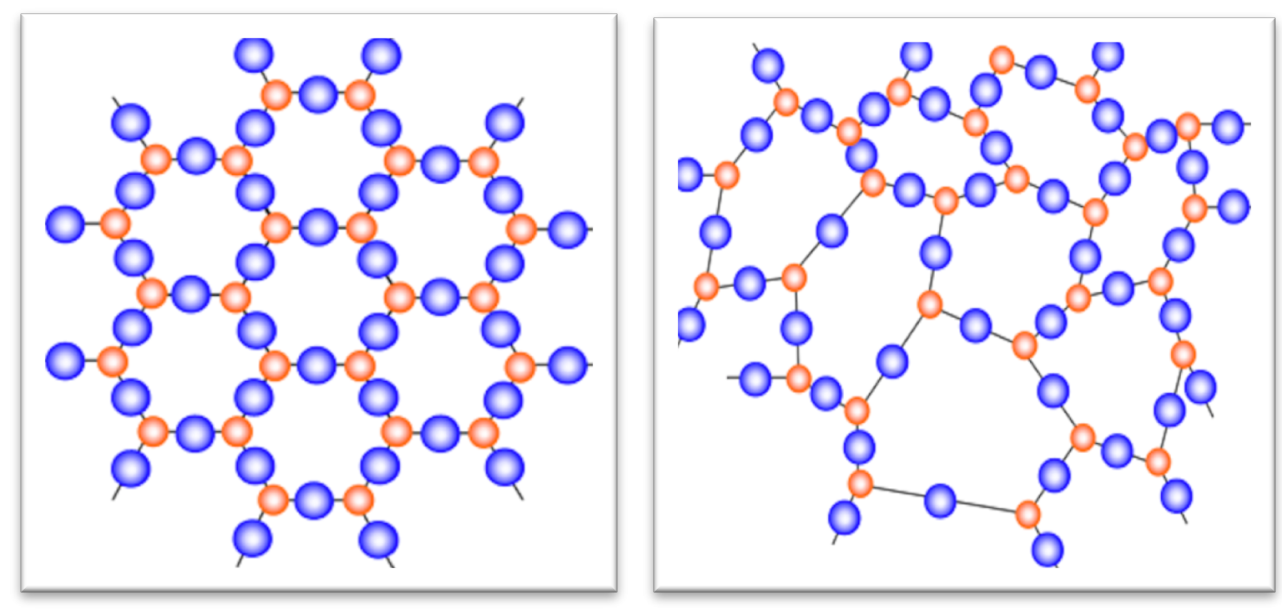

Figure 1 (a) Crystalline (left), (b) Amorphous (right) [6]

Crystalline materials and amorphous materials have different properties in various aspects, such as shape, melting point, and anisotropy.

Table 1 introduced the main difference between crystalline materials and amorphous materials [7]. The first and foremost difference between these two kinds of materials is how the atoms are arranged. For the crystalline materials, the atoms are arranged in a 
periodic manner. If the unit cell of such materials has already been known, it is possible to predict the whole structure of the crystalline materials. For the amorphous materials, since the atoms are arranged randomly, it is hard to identify the atoms' position and distance far away, the atoms are just arranged locally. In other words, the distance between the atoms are not fixed. The second difference is that a crystalline material has a specific melting point, but one amorphous material does not. Thirdly, because anisotropy is relative to the crystal symmetry, different crystal orientations can lead to different physical properties, such as Young's modulus or hardness in crystalline materials. Since the atoms are arranged randomly for amorphous materials, they are isotropic. The mechanical behavior of crystalline materials mainly depends on the dislocation density. The high density of dislocation would result in a low strength and a high plastic deformation ability. Amorphous materials, on the other hand, would have a high strength and a low ductility because there is no dislocation there.

Table 1 Difference between crystalline materials and amorphous materials

\begin{tabular}{cc}
\hline Crystalline Materials & Amorphous Materials \\
\hline Long-range order & Short-range order \\
Melt at sharp temperature & $\begin{array}{c}\text { Do not have a fixed melting point, but a } \\
\text { range of temperature }\end{array}$ \\
Anisotropic & Isotropic \\
Low Strength & High Strength \\
High ductility & Low ductility \\
\hline
\end{tabular}

\subsection{Processing Methods of Metallic Glass}

In order to achieve a better performance and properties, scientists found that the synthesized materials need to be manufactured under far from equilibrium conditions [8]. 
This realization has led to a quick development of nonequilibrium processing techniques and facilities. Among these, rapid solidification processing (RSP) is one of the most critical procedures. Pol Duwez and his research team produced the first Au-Si MG by using RSP [1]. The typical cooling rate of RSP should be higher than $10^{4} \mathrm{~K} / \mathrm{s}$, and the value is usually $\sim 10^{6} \mathrm{~K} / \mathrm{s}$. RSP is realized by three main methods: droplet method, jet method, and surface melting method.

So far, there are several methods to synthesize MG [9-15]:

- Physical vapor deposition (PVD): The original materials can be deposited via physical heating or sputtering, then depositing on the surface as thin film.

- Chemical vapor deposition (CVD): The target material is exposed to the chemical reagent, then the material is synthesized with the MG coating.

- Ion implantation: The ions of original material are deposited on the surface of the substrate under an electric field.

- Droplet methods: The molten alloy is formed into small droplets and then exposed to an inert gas environment.

- Jet method: Steam of molten alloy is solidified by transferring it to a cold surface. This is the most popular and primary method of manufacturing the MG ribbon.

- Splat quenching: This method is a liquid rolling technique and involves rapid solidification of a molten alloy between two cooling rollers.

- Mechanical alloying: A powder metallurgy method in which blended elemental powder and grinding part are placed in a container. Then, the container is agitated at a high speed so that the powders of element get crushed and shaped with a thin cross-section. 
When a metal or alloy was cooled down to a solid-state, the atoms have enough time to pack and arrange their positions. However, if the metal is cooled down in a short time, the atoms do not have sufficient time to get arranged uniformly. This kind of rapid cooling decreases the movement ability of the metal's molecules before they pack into a more thermodynamically promising crystalline state [16]. One requirement to achieve high solidification rates via RSP is that one of the dimensions of the sample should be small enough[17]. This requirement leads to a result that all the synthesized products by RSP are either ribbon, wire, or powder. The problem is that the application for the one-dimension, or two-dimension products are very limited. Thus, the size of MG is one of the biggest issues that prevent its widespread implementation. However, if MG could be manufactured at a slower solidification rate, then its size could be much larger. To increase the size of MG, materials scientists and engineers need to find either suitable materials or new process to manufacture thicker MG under a low solidification rate.

Scientists have been working toward developing the manufacturing method and optimizing the composition of MG to produce thicker products, and they have achieved significant progress. Table 2 shows the thickness development of MG. From Table 2, we can see that the new processing techniques kept increasing the thickness of BMG.

Table 2 The size development of metallic glass with different compositions

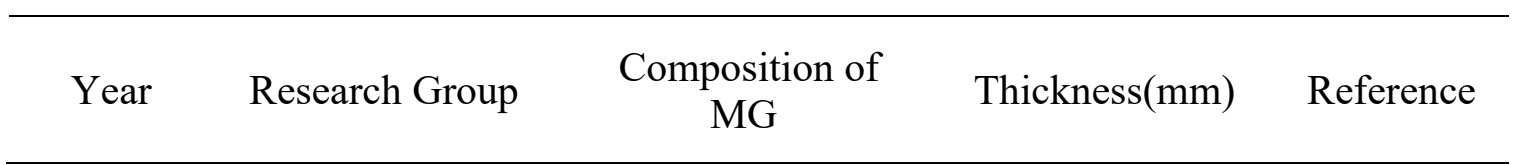




\begin{tabular}{lcccc}
\hline 1960 & Duwez et al & $\mathrm{Au-Si}$ & $\begin{array}{c}\text { several of } \\
\text { microns }\end{array}$ & {$[1]$} \\
1969 & Chen, Turnbull & $\mathrm{Pd}-\mathrm{Cu}-\mathrm{Si}$ & 0.5 & {$[19]$} \\
1974 & Chen & $\mathrm{Au}-\mathrm{Pb}-\mathrm{Sb}$ & $>0.5$ & {$[20]$} \\
1988 & Inoue & La-Al-TM & 5 & {$[21]$} \\
$1980 \mathrm{~s}$ & Turnbul & Pd-Ni-P & 10 & {$[22]$} \\
1991 & Inoue, A & Ze-Al-Ni-Cu & 15 & {$[23]$} \\
1992 & Johnson, Peker & Zr-Ti-Cu-Ni-Be & 14 & {$[24]$} \\
1996 & Inoue, A & Pd-Ni-Cu-P & 40 & {$[25]$} \\
1997 & Inoue, A & Pd-Ni-Cu-P & 70 & {$[26]$} \\
\hline
\end{tabular}

\subsection{Bulk metallic glass}

When the thickness or the diameter of one MG is more than $1 \mathrm{~mm}$, it is named as bulk metallic glass (BMG) [27]. Compared with thin film or ribbon $\mathrm{MG}$, a BMG has some specific characteristics: on the one hand, a BMG is usually a multi-component alloy that needs at least three different elements in its composition; on the other, it is produced at a lower solidification rate than thin film or ribbon $\mathrm{MG}$, with a rate less than $10^{3} \mathrm{~K} / \mathrm{s}$.

\subsubsection{Production procedure of bulk metallic glass}

The manufacture of BMG is different from the general method for thin film or ribbon MG. The methods for manufacturing BMG are listed as following:

- Direct Casting: A main method for BMG production, and this method can be used for the BMG net-shape fabrication process. While processing BMG, the metastable character of its amorphous state has to avoid crystallization as well as solidification. In Figure 2, path (1) is designed for direct casting. The cooling rate following path (1) is much faster than path (2). Only if a cooling rate is equal to or faster than that 
of path (1), it will satisfy the requirements for direct casting. Otherwise, the alloy cannot avoid crystallization.

- Thermoplastic Forming: This is an alternative processing technique to the direct casting method. It includes hot pressing, viscous flow forming, superplastic forming, and viscous flow working [28]. In Figure 2, path (2) is the processing path for the thermoplastic forming method. This method requires fast cooling, so the BMG is reheated into the supercooled liquid region. The processing window of this method is wider than that of direct casting.

- Other methods: There are some other processing procedures, which are based on thermoplastic forming, such as compression, injection molding, rolling, and blow molding. The injection molding method is the most suitable way for mass production, and blow forming is the appropriate method for producing threedimensional components. 


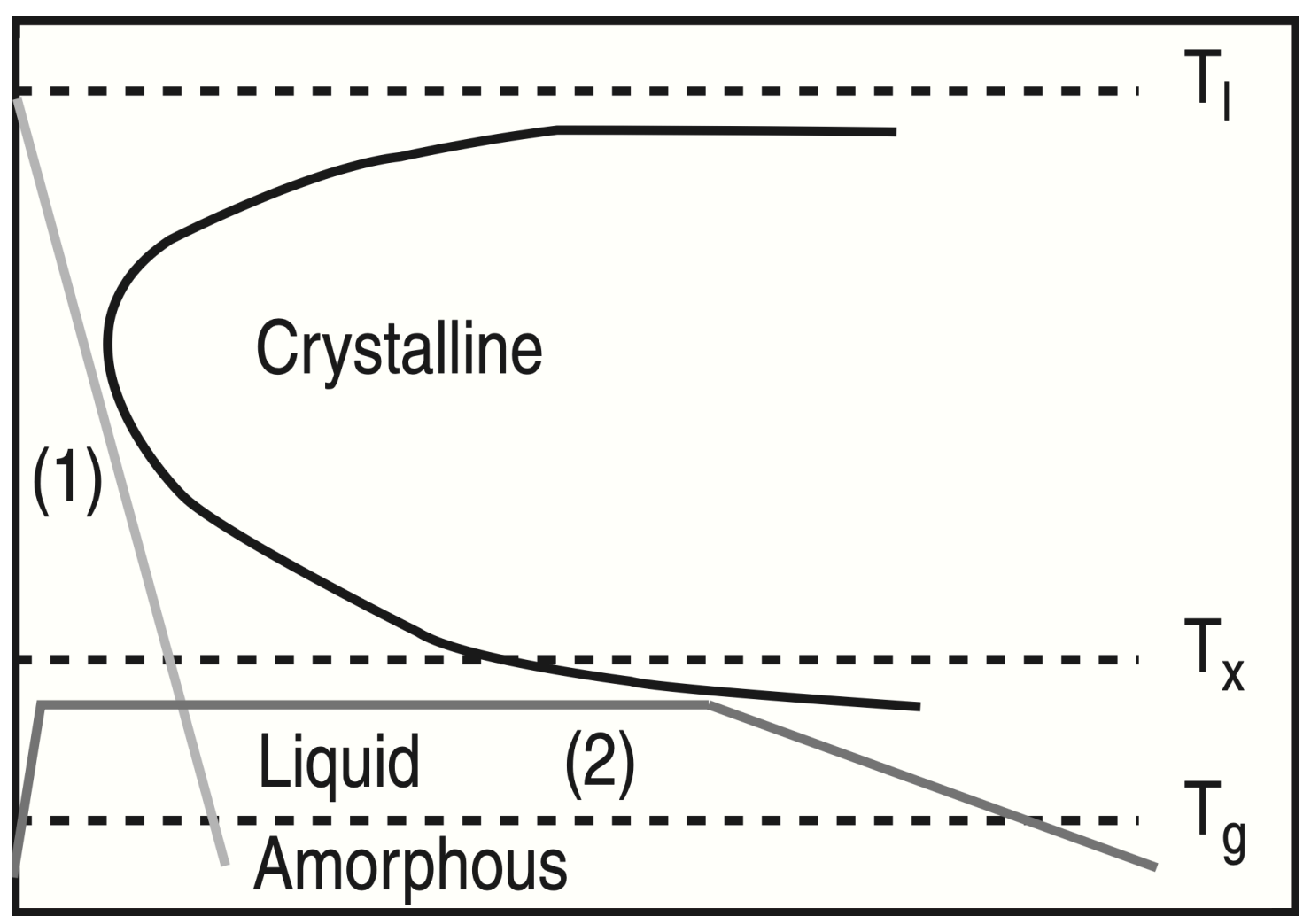

Figure 2 Schematic time-temperature-transformation (TTT) diagram of processing methods: path (1) is Direct Casting and path (2) is Thermoplastic Forming [134]

\subsection{Properties of metallic glass}

After the first Au-Si MG was found and synthesized, its amorphous structure attracted huge interest from both the academy and industries. Scientists and engineers tried to investigate whether there are some unique properties with these materials. MGs with different compositions were produced and various research was conducted. Several significant properties of MG have been found since then, for example, the yield strength of $\mathrm{Zr}_{55} \mathrm{Cu}_{30} \mathrm{Al}_{10} \mathrm{Ni}{ }_{5}$ is over $1 \mathrm{GPa}$, and its strain at yielding is around $2 \%$ [29]. In addition, some MGs, such as $\mathrm{Fe}_{76} \mathrm{Si}_{9} \mathrm{~B}_{10} \mathrm{P}_{5}$ [30], $\mathrm{Fe}_{78} \mathrm{Ga}_{2} \mathrm{P}_{12} \mathrm{C}_{4} \mathrm{~B}_{4}$ [31] and $\mathrm{Fe}_{76} \mathrm{Al}_{4} \mathrm{P}_{12} \mathrm{~B}_{4} \mathrm{Si}_{4}$ [32], have very high magnetic properties, and the magnetic flus density of all these MGs are over 1 Tesla. Thirdly, MGs is highly resistant to corrosion and wear. For example, the corrosion 
rate of $\mathrm{Zr}_{65} \mathrm{Al}_{7.5} \mathrm{Ni}_{10} \mathrm{Cu}_{17.5} \mathrm{MG}$ is as low as $0.001 \mu \mathrm{m} /$ year [33]. More details on $\mathrm{MG}$ properties will be introduced in the following sections.

\subsubsection{Mechanical Properties}

MG, especially BMG, has lower Young's moduli and higher tensile strengths compared to traditional structural materials. As shown in Figure 3, MG can have both high strengths and high elastic limits at the same time [34]. Compared to crystalline alloys, plastic deformation of MG is mainly relative to inhomogeneous flow in highly localized shear bands. The plastic deformation of crystalline alloys is relative to the movement of dislocation, so they generally exhibit significant plastic strains, with yielding under tension. The reason lies in its high fracture toughness and impact resistance. But MGs always exhibit less plasticity than normal crystalline alloys. Metallic glasses have a high tensile strength; however, MGs' ductility at the room temperature is poor. The MG would fail soon after yielding. The yielding procedure does not show any sign of plastic deformation. When $\mathrm{MG}$ is tested at a high temperature, its deformation behavior differs. The deformation behavior of MG is homogeneous at a high temperature and inhomogeneous at a low temperature. It is noted that the "high temperature" means the temperature is higher than half of the glass transition temperature (Tg). In the "high temperature," MG undergoes viscous flow, the plastic strain within MG is distributed continuously, and each volume element of the sample contributes to the strain. The yield strength of MG is determined by the cooperative shear motion of shear transformation zone, which is similar to the movement of dislocation in the crystalline structure. 


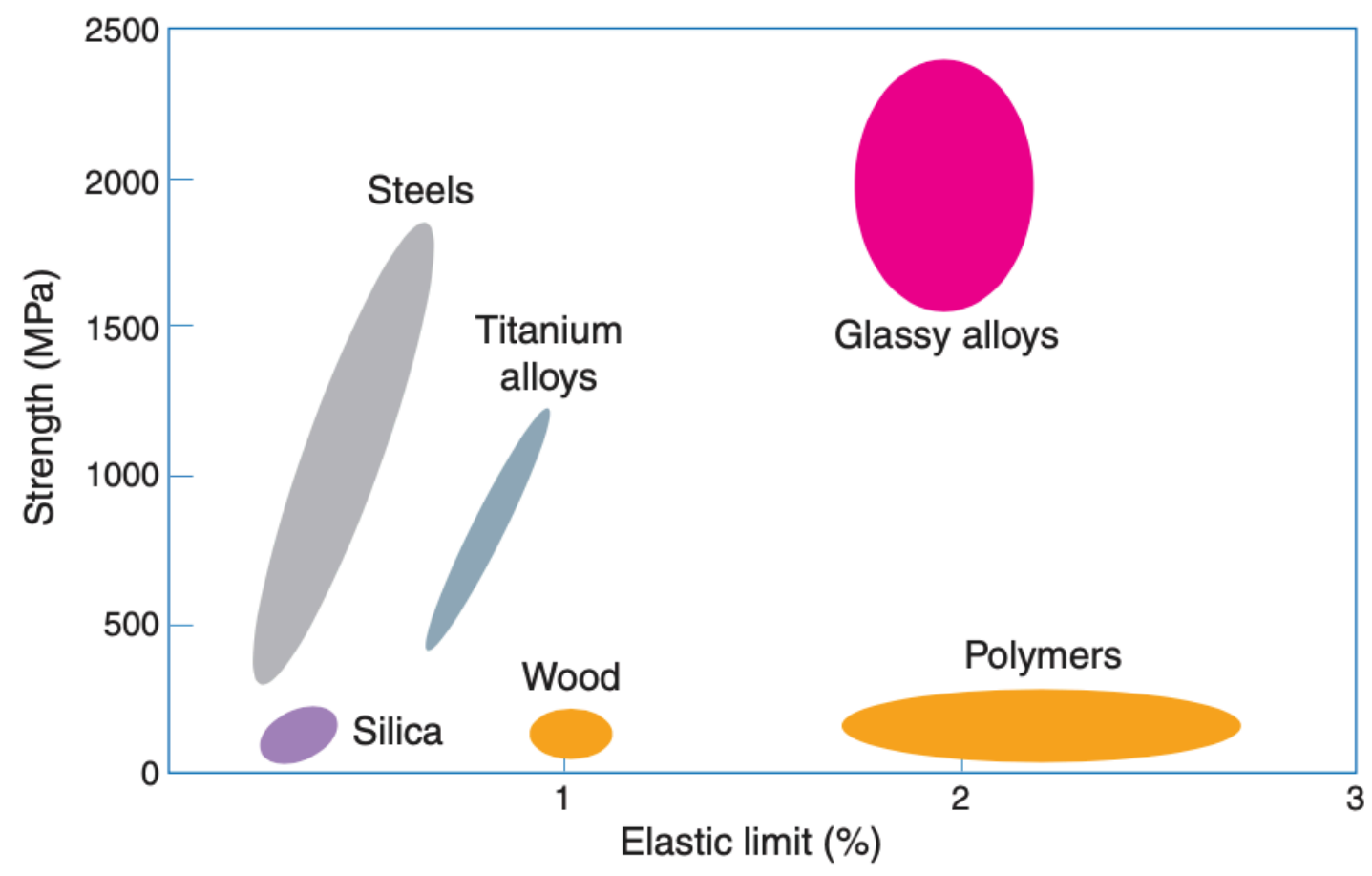

Figure 3 Metallic glass combines higher strength than crystalline metal with the elasticity of polymers. [35]

\subsubsection{Magnetic Properties}

Magnetic property is one of the key features for serious applications in the electrical and electronic areas. And magnetic metallic glasses can be divided into two types: one is soft magnetic materials, and the other one is hard magnetic materials. Soft magnetic materials will not make an excellent permanent magnet since they will remain magnetization after being switched off. And permanent magnets are made from hard magnetic materials. Soft magnetic materials have three key factors, high saturation magnetization, high electrical resistivity, and low coercivity. Fe-based and Co-based MGs, such as the Fe-C-P and CoFe-B-Si systems, are the most widely studied and used soft magnetic materials. The highest saturation magnetization (Is) of Fe-based MG can reach $1.51 \mathrm{~T}$, and the maximum value 
in ferromagnetic-core electromagnets is around 2T [36]. Few hard magnetic MG materials have been developed, besides Nd-Fe and Pr-Fe MGs. Since the addition of Al could enhance the GFA for $\mathrm{Nd}-\mathrm{Fe} \mathrm{GM}, \mathrm{Nd}_{70} \mathrm{Al}_{10} \mathrm{Fe}_{20}$ and $\mathrm{Nd}_{60} \mathrm{Al}_{10} \mathrm{Fe}_{30} \mathrm{BMG}$ were made and considered as that they could exhibit hard magnetic properties at the room temperature [37]. Fe-based or Co-based BMGs are soft magnetic materials, and they have some unique advantages, such as high electrical resistivity, higher initial permeability, lower coercive force, controllable organization of domain wall structure, and good micro-forming ability. Meanwhile, they have some disadvantages, such as higher materials cost and lower saturated magnetic flux density [38,39].

\subsubsection{Corrosion and Wear Resistance Properties}

MGs have outstanding corrosion resistance properties. Some researchers have demonstrated that even under extremely tough conditions, BMG can behave passively [40]. Phosphorus-containing BMG has the highest reported corrosion resistance so far, while Febased BMG also has great corrosion resistance, and both of them can be implemented as corrosion resistance materials [41]. Currently, researchers have found that if $M G$ is synthesized with different-sized atoms (such as $\mathrm{Al}=1.25 \AA ̊$ and $\mathrm{Ce}=1.85 \AA$ ), its high viscosity results in a low free volume. The low free volume prevents the atoms from moving over each other and yields a high wear and corrosion resistance $[42,43]$.

\subsection{Applications of Metallic Glass}

Since MGs have unique and excellent properties, they are appropriate for many applications. Currently, some BMGs have already been utilized as die materials, such as Pd-Cu-Ni-P BMG. Other BMGs, such as Zr-Ti-Cu-Ni-Be, can be used as sports gear. Figure 4 shows the $\mathrm{BMG}$ of $\mathrm{Al}_{86} \mathrm{Ni}_{7} \mathrm{Y}_{5} \mathrm{Co}_{1} \mathrm{La}_{1}$.[44] Al-based MGs, because of their low 
density, high strength properties, low elastic modulus, and excellent corrosion resistance property, the Al-based BMGs are used in a wide range of industries, such as aerospace, automotive and nautical [45]. The desire for low-density, high-strength, high corrosion resistance BMG is mainly driven by reducing energy consumption and keeping stability in extreme environments. Al-based BMGs can meet nearly all the requirements mentioned above. Moreover, compared to other low-density elements, the cost of $\mathrm{Al}$ is much lower than the others such as $\mathrm{Mg}, \mathrm{Ca}$, and Ti. Thus, the Al-based BMG is one of the best candidates.

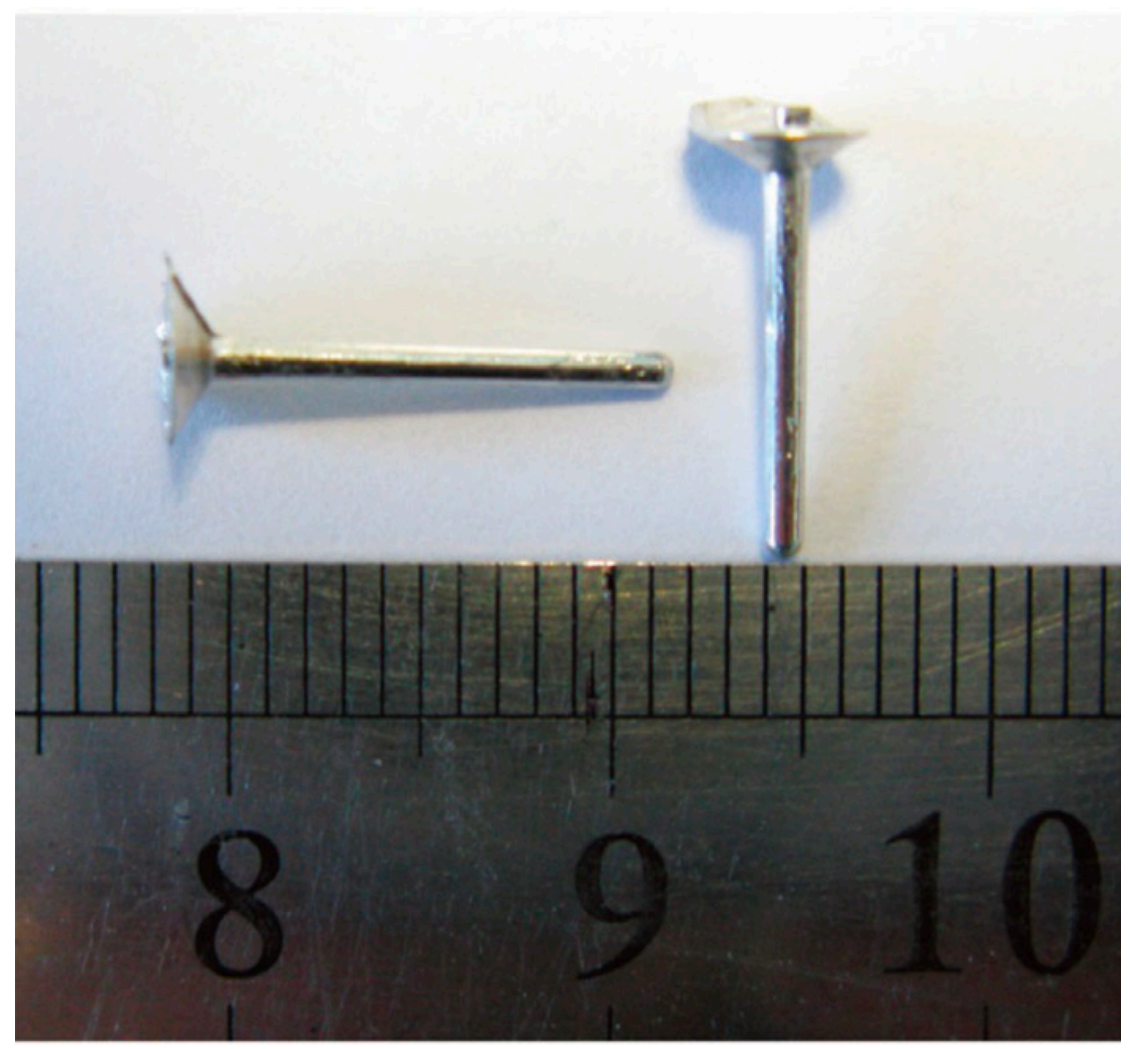

Figure $4 \mathrm{BMG} \mathrm{Al}_{86} \mathrm{Ni}_{7} \mathrm{Y}_{5} \mathrm{Co}_{1} \mathrm{La}_{1}$ rod sample with a $1 \mathrm{~mm}$ diameter [44]

Another important application of BMGs is medical components. They can be used in surgical instruments as well as prosthetic implants because of the following reasons: (1) they are biocompatible - they will not interact with the body or any organs; (2) they have 
great wear resistance, which is an essential requirement for joint parts of the body; (3) they have an excellent strength-to-weight ratio, much better than stainless steel or titanium alloys; (4) they have at least twice the strength compared to traditional medically-used alloys such as titanium; (5) BMG can be produced as net-shape with desirable surface texture, reducing the cost of post-processing. Table 3 summarizes the current and future potential applications for MG, especially in engineering. With its easier and lower-cost processing, BMG has many good prospects for broad applications.

Table 3 Current and future application fields for metallic glass. [45]

\begin{tabular}{cc}
\hline Properties & Potential application \\
High strength & Machinery structural materials \\
High hardness & Cutting materials \\
High fracture toughness & Die materials \\
High impact fracture energy & Tool materials \\
High fatigue strength & Bonding materials \\
High elastic energy & Sporting goods materials \\
High corrosion resistance & Corrosion resistance materials \\
High wear resistance & Writing appliance materials \\
High reflection ratio & Optical precision materials \\
High hydrogen storage & Hydrogen storage materials \\
Good soft magnetism & Soft magnetic materials \\
High-frequency permeability & High magnetostrictive materials \\
Efficient electrode & Electrode materials \\
High viscous flowability & Composite materials \\
High acoustic attenuation & Acoustic absorption materials \\
Self-sharping property & Penetrator materials \\
High wear resistance and manufacturability & Medical device materials \\
\hline
\end{tabular}

\subsection{Challenges in Metallic Glass}

Although MGs especially Al-based BMGs have many promising properties, there are still several challenges in regard to producing them and improving their applications [46,47]:

- The glass-forming ability of Al MGs is very low. That is the main reason why manufacturing Al-based BMG is very difficult. 
- The performances of a BMG are very sensitive to composition. A very small change in MG composition might results in a significant impact on glass-forming ability (GFA). Researchers are still attempting to understand and control this issue, which is critical for successful commercialization.

- The cost of BMG manufacture is still high. MG, especially BMG, needs a cheaper and easier manufacturing procedure. A mixed structure of nanocrystalline and glassy will promote a combination of high strength and ductility; however, it is very challenging to realize precipitates in the as-cast state without following annealing steps.

Figure 5 shows the ideal MG with desired properties. To utilize the MGs, several requirements and standards are proposed to define an ideal MG [48], which should have good mechanical properties such as high hardness and good elasticity. Also, MG should have an excellent GFA to be easily manufactured in a bulk size. Furthermore, the manufacture and composition of MG should be at a low density and low cost. Lastly, MG should have outstanding wear and corrosion-resistant capabilities to survive in tough service environments or under extreme conditions. 


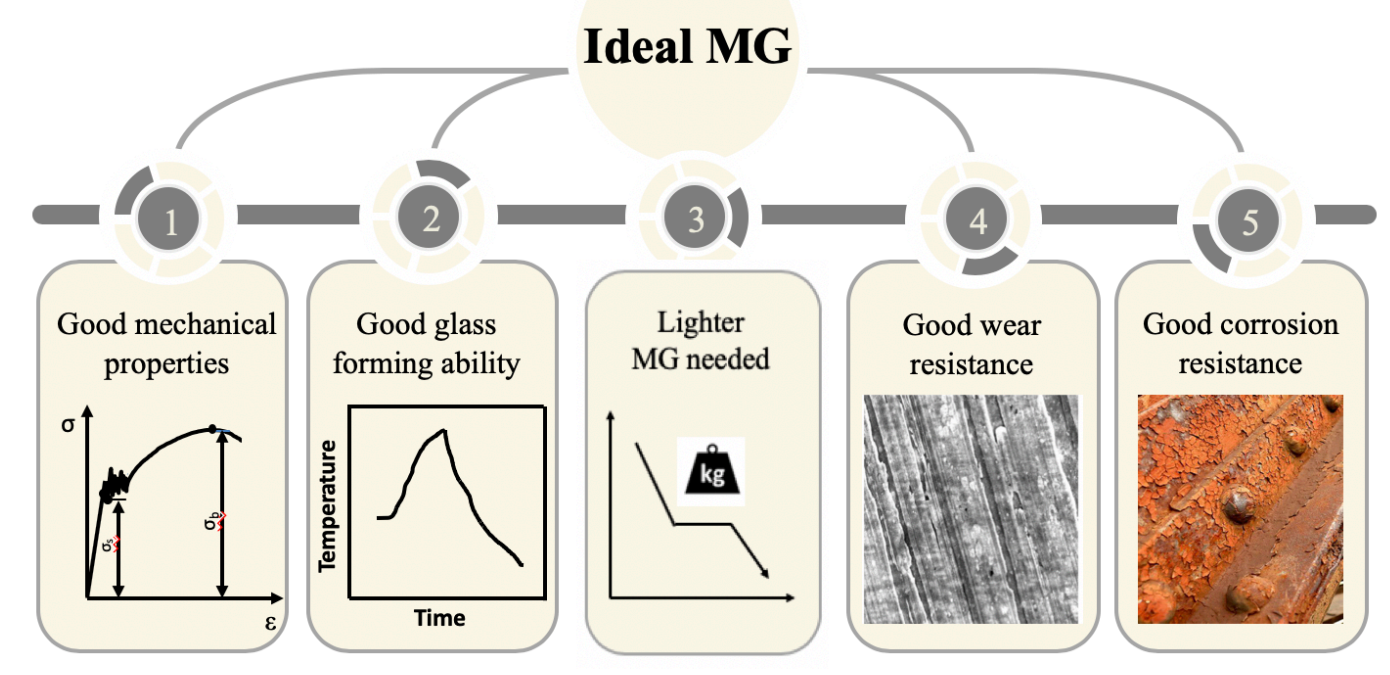

Figure 5 The ideal metallic glass with desired properties

\subsection{Research Hypotheses}

- To design and synthesis BMG successfully, from Inoue Criteria, several rules should be followed: (1) the MG should contain at least three components. The formation of glass would become easier when adding more components in the system; (2) the major atomic size difference should above $12 \%$ between the main component elements; (3) there also would be negative enthalpy of mixing for the elements in the MG system. The first rule is based on both the thermodynamic and kinetic aspects of MG formation, the second is on the topological aspects, and the third is on formation of the homogeneous glassy phase. The MG composition we chose to study-Al-Ni-Ce-fulfills Inoue Criteria and therefore should be a promising MG system. Single and multi-objective methods can be used to optimize the composition of MGs for turning their properties towards the desirableness GFA. Here, we emphasized the Al-Ni-Ce ternary system. The composition of each 
element will be predicted/optimized by using these algorithms to maximize the supercooled liquid region $(\Delta T x)$. Then the optimized sample will be prepared, and the accuracy of the prediction will be evaluated.

- Appropriate annealing treatment can improve the hardness of the MG through relaxation, glassy phase separation, or nanocrystalline. Combination of composition optimization and annealing treatment will help improve the mechanical properties of Al-Ni-Ce alloy to a new level.

- Pair distribution function (PDF) analysis will unveil the short-range ordering in the Al-Ni-Ce MGs and illustrate how each element influences the initial supercooled liquid region $\left(\Delta T_{x}\right)$, and hardness. In addition, how the annealing procedure influences the short-range order will be revealed.

\subsection{Research Objectives}

- A systematic study will be conducted on multiple MG samples within a wide supercooled liquid region to find compelling evidence for the connection between structure change and improvement of mechanical behaviors. Inoue Criteria and multi-objective optimization algorithms through further annealing procedure will be used to find the best composition candidates for high glass-forming ability (indicated as $\Delta T X$ ) and improved the mechanical properties.

- The relationship between microstructure (i.e., nano-precipitation), composition, and annealing temperature will be investigated. Furthermore, evidence for the hardness enhancement in MGs and their composites will be demonstrated by its correlation with the annealing process. X-ray diffraction and indentation would be used to investigate the procedure. 
- The relationship between glass-forming ability and the change of short atomic distance will be found and proposed using the pair-distribution function analysis.

To realize the research objectives, I need to (1) optimize the composition of MG to improve the glass forming ability (GFA) and initial mechanical properties, (2) characterize the mechanical behaviors of series ternary MG and their composites after annealing treatment, and (3) develop a fundamental understanding about the effect of nanoprecipitation in hardness improvement. 


\section{CHAPTER 2. LITERATURE REVIEW}

\subsection{Al-Based Metallic Glass}

The first Al-based metallic glass (MG) ribbon was synthesized in 1988 by Hafner and Jaswal [49] with the composition of $\mathrm{Ca}_{\mathrm{x}} \mathrm{Al}_{1-\mathrm{x}}(\mathrm{x}=0.7,0.6,0.5$ and 0.33$)$. Since then, Albased amorphous alloy has become very attractive due to their highly specific strength and good corrosion resistance [50-54]. As presented in the previous section, dramatic progress has been made with a variety of MGs. Because the glass-forming composition in Al-based MGs is located somewhat far from their eutectic points, which is quite different from most of the other known MGs, the achievement of an Al-based amorphous alloy is not very significant. The nucleation theory indicates that a larger value of reduced glass transition temperature $\left(\mathrm{T}_{\mathrm{rg}}\right)$ yields a slow homogeneous nucleation rate, and therefore it should be relatively easy for the glass formation to occur at slow solidification rates. Al-based MGs exhibit a low $\mathrm{T}_{\mathrm{rg}}$, and the lower the $\mathrm{T}_{\mathrm{rg}}$ means the lower the glass-forming ability (GFA).

Table 4 summarizes the comparison of main properties between Al-based BMG and conventional Al-based alloys [55]. Al-based BMG exhibits ultra-high strengths (800-1500 $\mathrm{MPa}$ ) whereas Al-based alloys' strengths are ranging from 200 to $300 \mathrm{MPa}$. The excellent property of high strength and low density offers the tremendous possibilities for applications in aircraft industry and medical implants. However, it should be noticed that some properties of Al-based BMG, such as toughness and plastic strain, are lower than crystallized Al-based alloy. 
Table 4 Comparison of structural Al-based BMG with conventional engineering Al-based alloy

\begin{tabular}{lcc}
\hline & $\begin{array}{c}\text { Coventional } \\
\text { Metals(Al-based) }\end{array}$ & BMG(Al-based) \\
\hline $\begin{array}{l}\text { Strength(MPa) } \\
\begin{array}{l}\text { Stiffness(Youngs } \\
\text { Modulus, GPa) }\end{array}\end{array}$ & $200-300$ & $800-1500$ \\
$\begin{array}{l}\text { Density(gram/cm^3 } \\
\begin{array}{l}\text { Toughness(Mpa- } \\
\left.\mathrm{m}^{\wedge} 1 / 2\right)\end{array}\end{array}$ & $60-80$ & $60-80$ \\
& $20-120$ & $3-4$ \\
$\begin{array}{l}\text { Plastic Strain to } \\
\begin{array}{l}\text { Failure } \\
\text { Cost of raw ingot } \\
\text { material(\$ per Kg) }\end{array}\end{array}$ & $\begin{array}{l}\text { Typical large in all } \\
\text { loading geometries }\end{array}$ & $\begin{array}{c}\text { less than } 1 \%, \\
\text { extended to } 5 \% \text { if } \\
\text { add second phase } \\
\text { additions }\end{array}$ \\
\hline
\end{tabular}

Al-based MGs' outstanding strength can be further improved through a thermal treatment procedure [56]. The strength of Al-Ni-Y-Co-La MG can be increased to $1.34 \mathrm{GPa}$ after annealing [57]. Al-based MGs also hold great potential for applications that require high corrosion or wear resistance. Some novel Al-based MGs show ultra-high corrosion resistance; for example, the corrosion loss of $\mathrm{Al}_{85} \mathrm{Y}_{10} \mathrm{Ni}_{5}$ is below $2.5 \mathrm{~mm}$ per year in a $\mathrm{NaOH}$ environment [60]. The mechanical and corrosion properties of Al-based MGs with partially crystallized structure have a strong relationship with their microstructure: the short-range order of atoms [58].

Features regarding glass forming ability of Al-based MG are summarized below [59]:

- Most Al-based MGs are marginal glass formers. This is significantly different from general BMG. Because Al-based MG requires higher critical cooling rates (higher 
than $10^{5} \mathrm{~K} / \mathrm{s}$ ), it is very difficult to prepare Al-based MG using typical BMG manufacturing methods. Melt spinning is the primary method used to produce Albased MG.

- Most Al-based MGs do not show a significant glass transition signal $\mathrm{T}_{\mathrm{g}}$ when they are tested using differential scanning calorimetry (DSC). During the Al-based MGs DSC testing, it can be found that the onset of crystallization peak $T_{x}$ almost coincides with the glass transition temperature $T_{g}$; it is difficult to obtain the supercooled liquid region $\Delta T_{x}\left(=\mathrm{T}_{\mathrm{x}}-\mathrm{T}_{\mathrm{g}}\right)$. Also, $\Delta T_{x}$ is the most critical indicator to predict the glass-forming ability (GFA). Thus, only temperature-modulated DSC can be used to investigate $\mathrm{T}_{\mathrm{g}}$ of Al MGs.

- There are often a high number of face center cubic (FCC) Al nanoparticles in Albased MG. Al is the principal crystallization phase. Any small change in the composition may lead to a change in the crystallization pathway.

Understanding the crystallization behavior of Al-based MG is important. It can be used to control the microstructure of the MGs and then optimize its physical and mechanical properties. In addition, its poor glass-forming ability (GFA) presents a great challenge for manufacturing bulk metallic glass, and this challenge would limit the applications of Albased MG. It is the first and foremost step for Al-based MG improvement to raise its low GFA, which is the bottleneck problem for Al-based MGs. Even with a very small amount of element added to the Al-based MG, the glass forming ability and crystallization behavior will be changed greatly. For the mechanism of this change, three aspects should be considered: structure, kinetic, and thermodynamic. 


\subsection{Al-TM-RE Metallic Glass}

Al-based MGs with rare earth elements (e.g., Ce, La, and Y) and transition metals (e.g., Ti, $\mathrm{Ni}$, and $\mathrm{Sc}$ ) could possess excellent strength properties and outstanding corrosion properties at the same time [61]. Their great mechanical properties, such as high hardness, can even be improved when nanoparticles are dispersed in their amorphous structure. However, intermetallic compounds are easily generated during this process, which would lead the prepared Al-TM-RE MG to become brittle. Researchers have been attending to those challenges in controlling the intermetallic compounds, both its GFA and primary crystallization process [62-65].

The glass forming ability of the Al-Ni-RE MGs has a strong relationship with the size of those rear earth atoms. For example, larger RE atoms will promote GFA. Ce atom has a larger atomic radius $(0.1825 \mathrm{~nm})$ compared to other RE elements, and this radius is just slightly smaller than La. Moreover, the Pauling electronegativity of Ce is larger than any other RE elements (which is 1.12) [66]. Meanwhile, compared to other RE atoms in Al-Ni MG systems, Ce could have much stronger interactions with $\mathrm{Al}$ atoms and $\mathrm{Ni}$ atoms. Thus, Al-Ni-Ce MGs could be the best Al-TM-RE system at this moment to study the GFA and properties of Al-TM-RE MGs.

The relationship between coordination number and Al-X bond distance is shown in Figure 6 , where $\mathrm{X}$ is the solute elements. This plot presents a broader size distribution of various clusters that will be formed with the higher $\mathrm{Al}$ in the closest atoms shell. When the sizes of other elements in Al-based MG differ greatly, the formability and stability of Al-based 
MG will be improved. Ce has a large cluster size as well as a long bond distance, which corresponds to the theory we mentioned early.

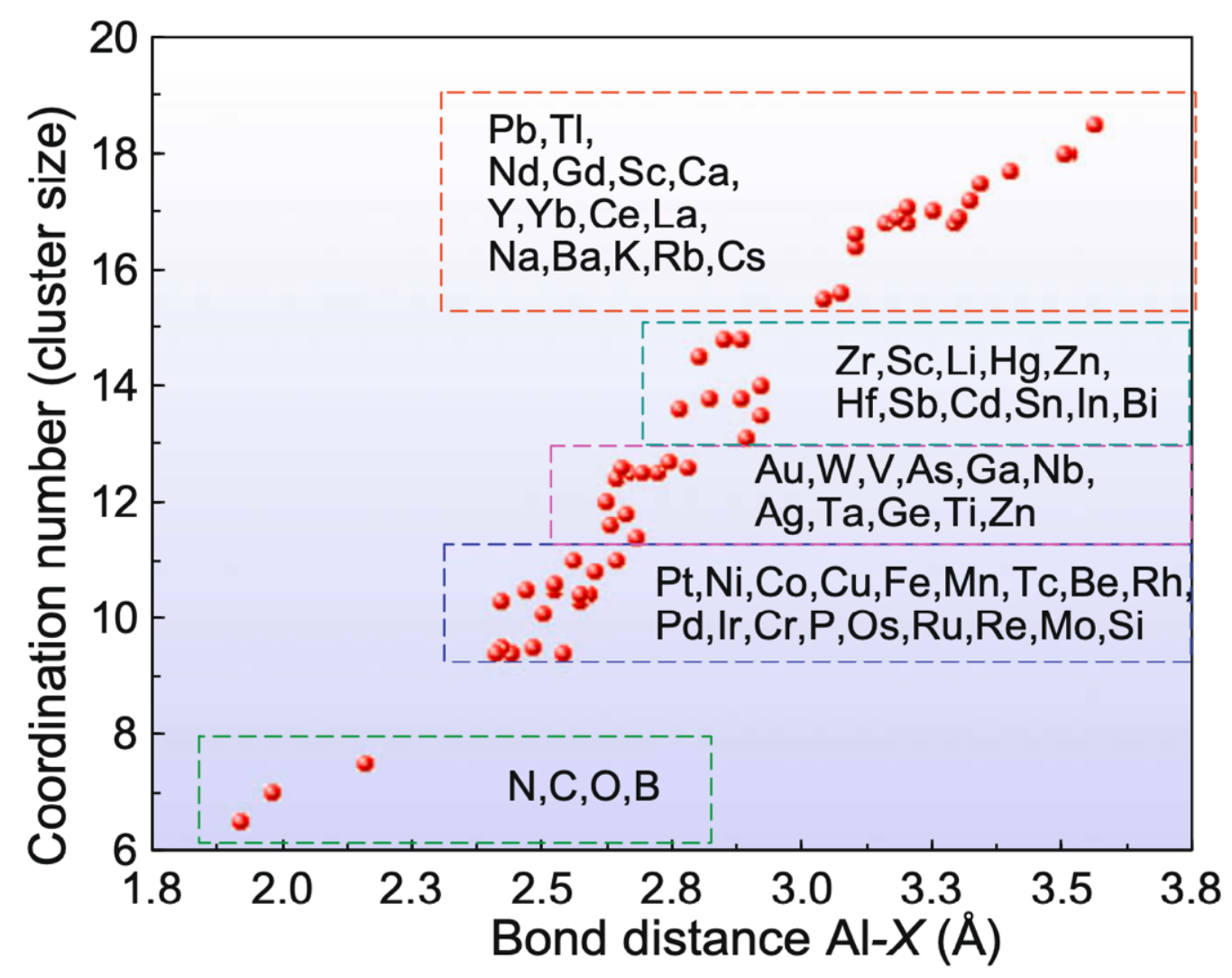

Figure 6 Coordination number as a function of bond distance in Al-based MG [67]

Microstructural studies were conducted to study the effect of RE elements $(\mathrm{Ce})$ on the morphology of Al-Ni-Ce MG. Moreover, the mechanical properties of the amorphous AlNi-Ce ribbon was investigated by a hardness test. The influence of crystallization on strength improvement was found and discussed by Liang et al [68] and Kim et al [69]. The effect of RE elements on the GFA of Al-based MG has been investigated by Belov et al [70] and Munoz-Morris et al [71]. Mixtures of Re elements with Tm elements are still popular in both academy and industry because they are more accessible and cost-effective 
compared to adding only Re elements [72].

Based on the literature survey, evaluation of the microstructural features and mechanical properties of Al-TM-RE MG is essential and crucial for controlled crystallization. My study aims to investigate the effect of rare earth elements (Ce) and transfer elements (Ni) on the glass forming ability improvement. Also, the mechanism of the mechanical property changes in amorphous Al-Ni-Ce alloys during different annealing.

\subsection{Glass-Forming Ability of Al-Re-Tm Metallic Glass}

Glass forming ability (GFA) is a critical factor for understanding the mechanism of glass formation. GFA is one of the most important consideration factors in new MG design and development. Critical cooling rate is the most import parameter to evaluate GFA. And this rate is the smallest rate for melt keeping its amorphous states and avoiding precipitation of crystal structure during solidification. As a result, when the cooling rate is low, the GFA is high. Although crystal cooling rate is critical, it is very difficult to obtain its precise value. A lot of effort has been applied to find another easily measured parameter for evaluating GFA. Since then, several parameters have been proposed by different research groups, such as reduced glass transition temperature $T_{\mathrm{rg}}$ and supercooled liquid region $\Delta T_{x}$. [73]. In these parameters, $\Delta T_{x}$ is the most widely used.

In the early days, the manufacturing of MG mostly used trial-and-error method. No theory or rule could be used to guide synthesizing MG. With more experiments and experience, researchers and engineers began to formulate some rules for MG elements selection. Moreover, they found that when they manufacture MG (especially BMG), a larger size of 
BMG could be achieved if they apply a slower cooling rate. With the development of thermodynamic and kinetic, researchers and engineers currently understand that the factors inside the alloys are much more important than their external factors during the MG solidification.

The concept "confusion principle" means when more components are added into MG, the GFA of such MG becomes better [74]—resulting in the destabilization of components during cooling without forming crystalline phases. And the nucleation rate is decided by the thermodynamic and kinetic factors. [75,76]

There are two parameters we need to consider for glass formation, and the first parameter is:

$$
\mathrm{T}_{\mathrm{rg}}=\mathrm{T}_{\mathrm{g}} / \mathrm{T}_{\mathrm{m}}
$$

here, $\mathrm{T}_{\mathrm{g}}$ is the glass transition temperature and $\mathrm{Tm}$ is the melting point. Another parameter is:

$$
\Delta T x=\mathrm{T}_{\mathrm{x}}-\mathrm{T}_{\mathrm{g}}
$$

where $\mathrm{Tx}$ is the crystallization temperature.

The $\Delta T x$ for GFA is equal to the difference between the onset temperature of the first crystallization peak and the glass transition temperature. A larger value of $\Delta T_{x}$ would lead to a higher GFA because amorphous alloys near the stoichiometric composition have a more compact atomic configuration and a stronger bonding force, which result from the optimization of atomic size and the electronic bonding state. The amorphous structure increases the difficulty of the diffusivity of constituent atoms and the stability of the 
supercooled liquid. The large $\Delta T x$ values imply that the supercooled liquid can exist in a wide temperature range without crystallization and have a strong resistance to the possible nucleation and growth of crystalline phases. Therefore, the supercooled liquid obtained by melt spinning also has a high resistance to the nucleation and growth of crystalline phases, leading to a high glass-forming capacity.

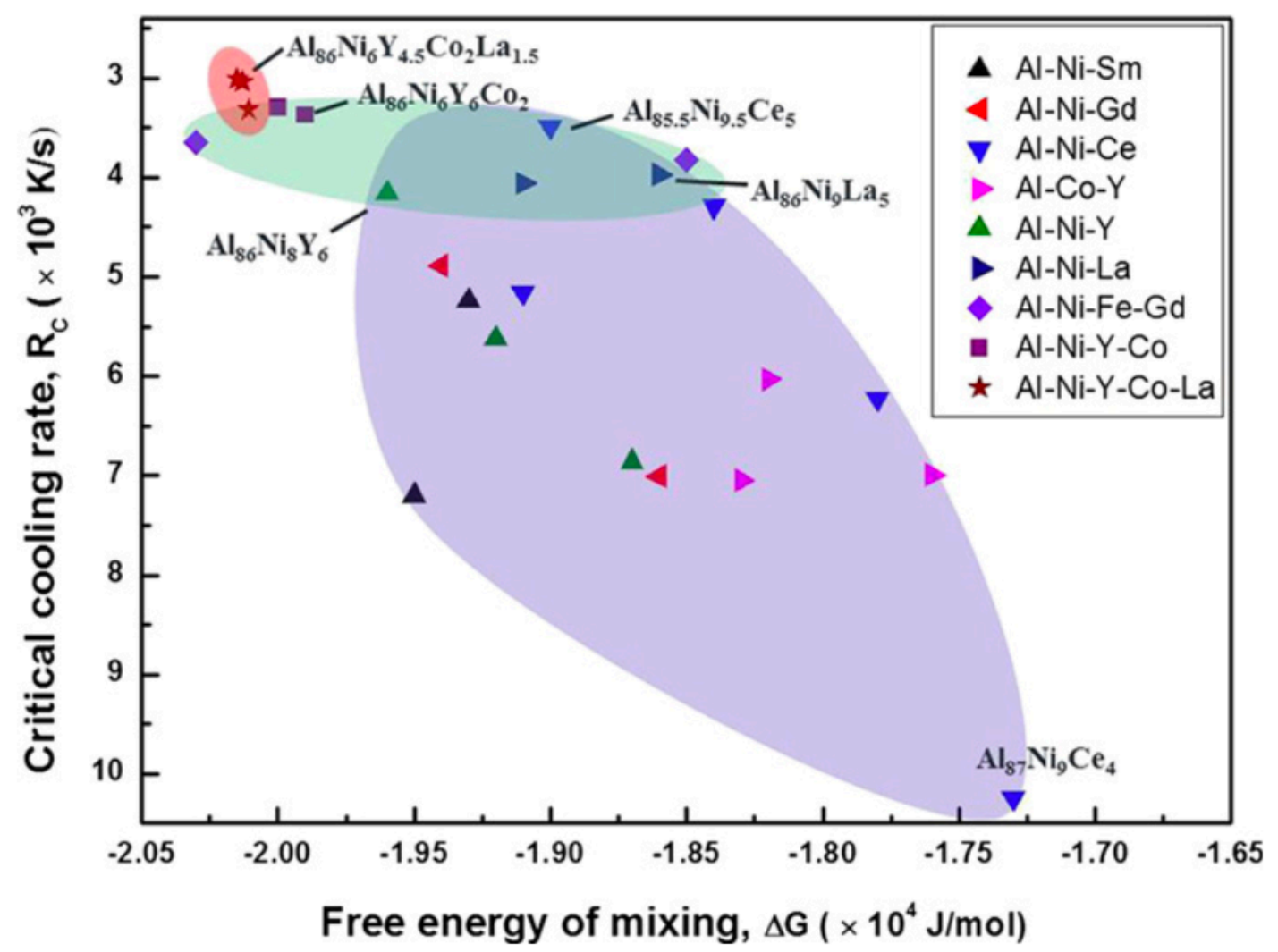

Figure 7 Diagram of the relationship between critical cooling rate and free energy of mixing $\Delta G[77]$

Figure 7 shows Liao et al. studied the relationship between the critical cooling rate $R c$ and free energy of mixing $\Delta G$, which asserted that for Al-based ternary systems. They found $\mathrm{Al}_{85.5} \mathrm{Ni}_{9.5} \mathrm{Ce}_{5}$ would have the best GFA. In the following chapters, we will compare this 
result with our single/multi-objective optimization method by maximizing $\Delta T x$, and more details will be provided. 


\section{CHAPTER 3.EXPERIMENTAL METHODS}

\subsection{Computational Optimization}

'Trial-and-error' is a commonly used method to find the best GFA in a specific MG system in previous studies. However, this method is time-consuming and expensive. Right now, researcher found that multi-objective optimization algorithm is an efficient and economical way to find the solution for the problem. This algorithm is based on the self-adapting response surface methodology. Dulikravich et al. have demonstrated that multi-objective optimization algorithm is an accessible method to optimize the chemical concentrations of metallic glass with superior properties [78].

The multi-objective optimization problem generally includes a serious of conflicting objectives and a group of complex objective functions. The method is used to conduct analytical fits of those available experimental datasets and applies the datasets to build multi-dimensional response surfaces. Theoretically, this method could be regarded as a one-parameter look-up table or a multi-dimensional curve fitting process used by research and industry [79]. Each objective needs to create one response surface. Here, the dimensionality of response surface is the number of the object variables.

The multi-objective method was implemented by using a commercial software IOSO developed by Sigma Technology $[80,81]$. The main advantage of the IOSO algorithm is using the minimum number of data to design the most accurate results.

Two steps are taken to conduct the optimization on the IOSO: 
- First, design the approximations of the objective functions. In each iteration, divide those initial approximation functions into a serious of simple approximation functions. And the final response surface functions is multi-level structures.

- Second, using the optimization of coefficients in step one, decompose simple approximation functions to fit the response surface as precisely as possible via the collected and organized experimental dataset.

\subsection{Metallic Glass Synthesis}

To design a metallic glass with excellent GFA, researchers have proposed many approaches. Because all of these approaches are based on a trial-and-error method, there is still no widely accepted justified theory and general scientific rule.[82] From previous study, there are several ways to predict the best glass forming ability for metallic glass, such as GFA linear regression analysis[83]. Also, $\Delta T x$ represents the stability of glass, it means how far is the temperature of crystallization from the temperature of glass transition. A greater value of $\Delta T x$ represents the greater stability of glass against crystallization. Therefor, $\Delta T x$ can be used as a GFA parameter for Al-Tm-Re metallic glass. In my study, I used single-objective and multi-objective optimization algorithm to predict the GFA of Al-Ni-Ce metallic glass. For the single-objective method, I maximized the width of the super-cooled liquid region $\Delta T x=T x-T g(T x$ is crystallization temperature, $T g$ is glass

transformation temperature). For the multi-objective method, I maximized both $\Delta T x$ and crystallization temperature $T x .[84,85]$

From the published record, researchers asserted that the ideal glass forming composition in Al-Ni-Ce system is located at $\mathrm{Al}_{85.5} \mathrm{Ni}_{9.5} \mathrm{Ce}_{5}$, but the GFA parameters such as $\mathrm{T}_{\mathrm{rg}}=\mathrm{T}_{\mathrm{g}} / \mathrm{T}_{1}$ 
( $\mathrm{T}_{1}$ is liquidus temperature) is the highest in $\mathrm{Al}_{85} \mathrm{Ni}_{8} \mathrm{Ce}_{7}(\Delta T x=20.0)$ [86]. However, this value is very different from another published paper $(\Delta T x=12.5)$ [87], so we have to confirm which one is the correct value first (investigate the samples $\mathrm{Al}_{85.5} \mathrm{Ni}_{9.5} \mathrm{Ce}_{5}$ and $\mathrm{Al}_{85} \mathrm{Ni}_{8} \mathrm{Ce}_{7}$ via $\left.\mathrm{DSC}\right)$. The best single-object optimized result we get is $\mathrm{Al}_{20} \mathrm{Ni}_{10} \mathrm{Ce}_{70}$ ( $\Delta T x=49.6)$. The best multi-object optimized result is $\mathrm{Al}_{16.5} \mathrm{Ni}_{8} \mathrm{Ce}_{75.5}(\Delta T x=55.17)$. For the samples $\mathrm{Al}_{46} \mathrm{Ni}_{10} \mathrm{Ce}_{44}$, because this sample's information cannot be found from published papers and database of optimization software.

For the sample preparation, each master ingot was prepared by arc-melting a mixture of pure elements, such as Ce (99.5 at.\%), Al (99.95 at.\%), Ni(99.95 at.\%), Si (99.99 at.\%) in argon atmosphere. All the ingots were melted five times to ensure homogeneity in composition. Using the master ingots, ribbon metallic glass (the numbers present atomic percentage) with a thickness of about $\sim 35 \mu \mathrm{m}$ and a width of $2 \sim 3 \mathrm{~mm}$ prepared via singleroller melt-spinning with a $\mathrm{Cu}$ wheel surface rotating speed of 40m/s (Figure.8). 


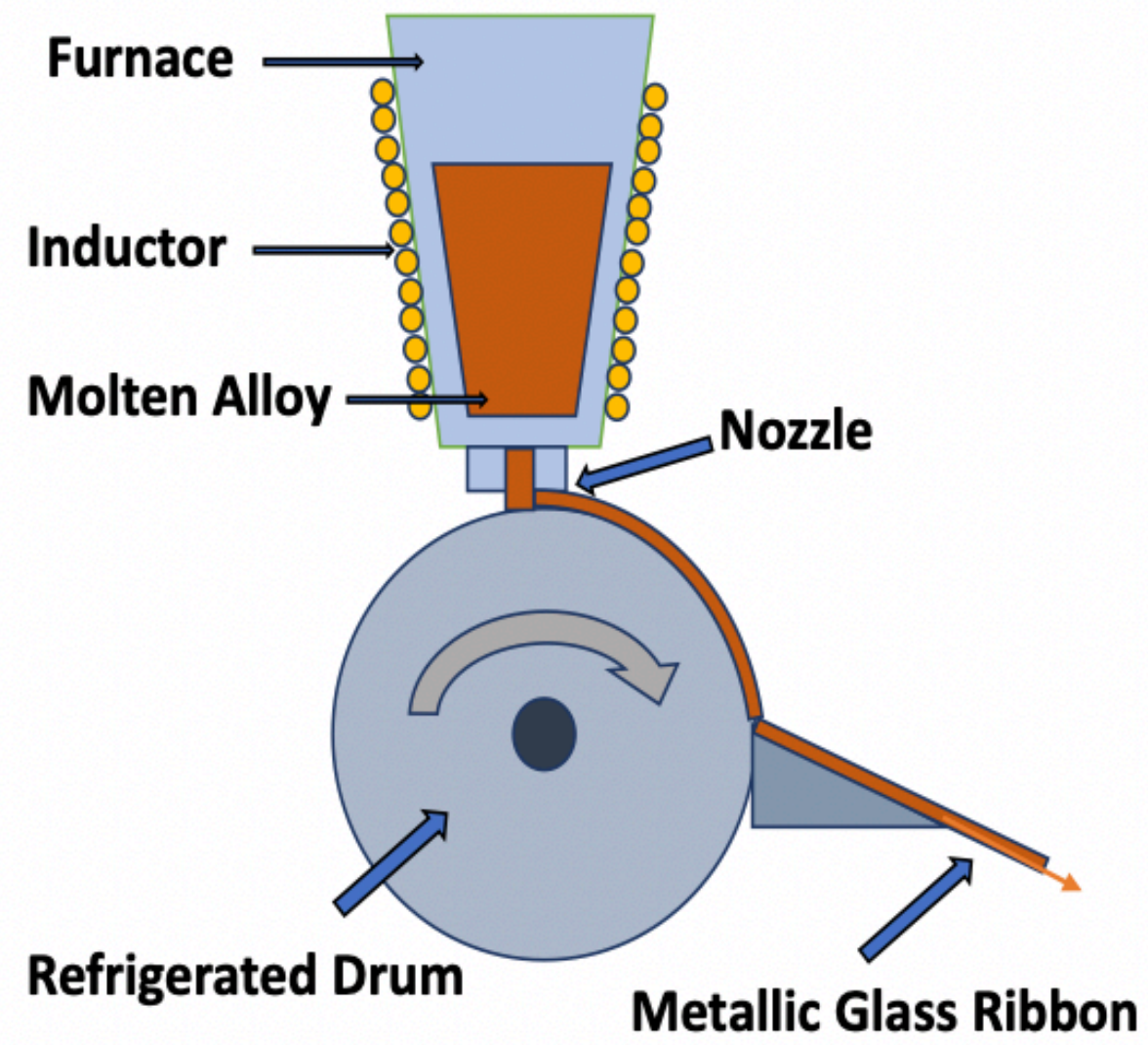

Figure 8 Single-roller melt spinning

The final synthesized samples are,

- $\mathrm{Ce}_{75} \mathrm{Al}_{23} \mathrm{Si}_{2}$

- $\mathrm{Al}_{89} \mathrm{Ce}_{5} \mathrm{Ni}_{6}$

- $\mathrm{Al}_{16.5} \mathrm{Ni}_{8} \mathrm{Ce}_{75.5}$

- $\mathrm{Al}_{20} \mathrm{Ni}_{10} \mathrm{Ce}_{70}$

- $\mathrm{Al}_{85} \mathrm{Ni}_{8} \mathrm{Ce}_{7}$

- $\mathrm{Al}_{85.5} \mathrm{Ni}_{9.5} \mathrm{Ce}_{5}$

- $\mathrm{Al}_{85.8} \mathrm{Ni}_{9.1} \mathrm{Ce}_{5.1}$ 
- $\mathrm{Al}_{46} \mathrm{Ni}_{10} \mathrm{Ce}_{44}$

\subsection{Annealing Procedure}

The metallic glass sample after synthesis was cut into several pieces with the same size (each piece $5 \mathrm{~mm} * 2 \mathrm{~mm} * 35 \mu \mathrm{m}$ ). Each cut sample was loaded into a quartz capillary and kept under vacuum (at $4 \times 10-4$ Torr, figure 10 right) to reduce the possibility of oxidation during annealing heat treatment. A Fisher Scientific oven (Figure 10 left) was used to heat the sample at different temperatures. The annealing temperatures for each sample are determined based on the glass transforming temperature of original metallic glasses. Figure 9 shows the standard procedure for annealing. All the annealing experiments were performed at the Center for the Study of Matter at Extreme Condition (CeSMEC), FIU.

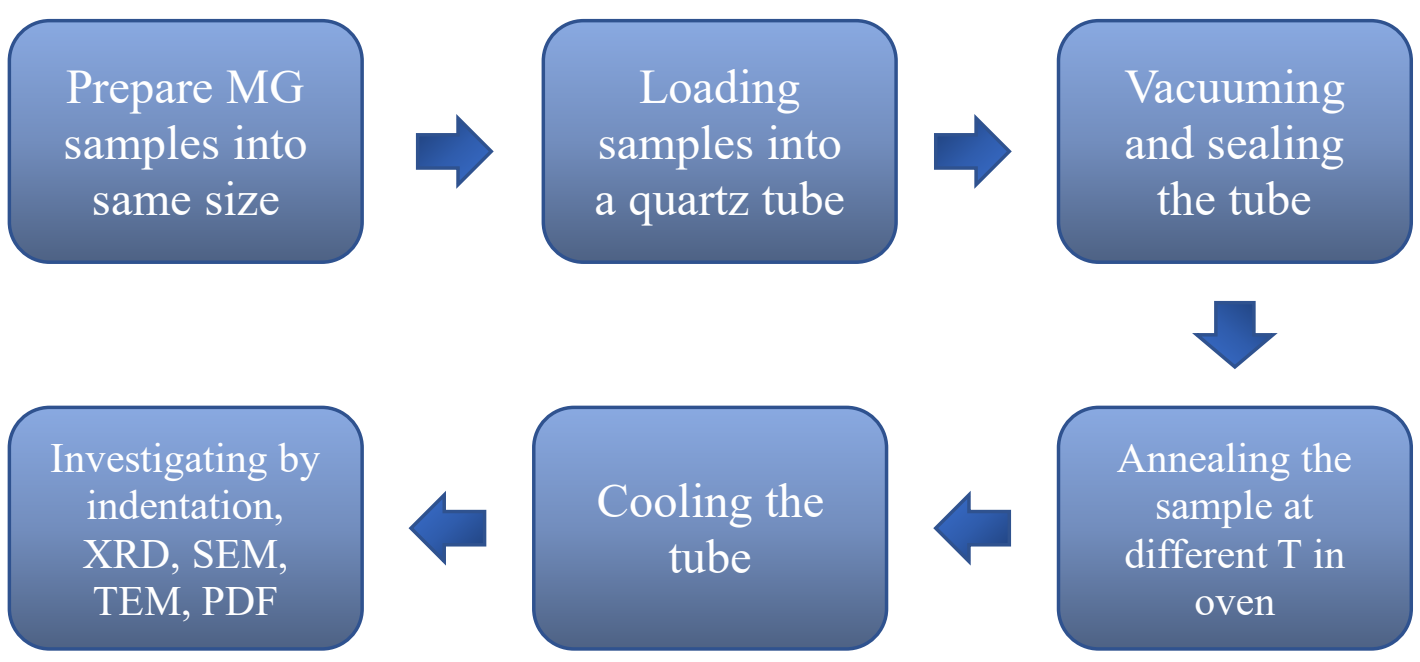

Figure 9 Annealing procedure of samples in the current study 

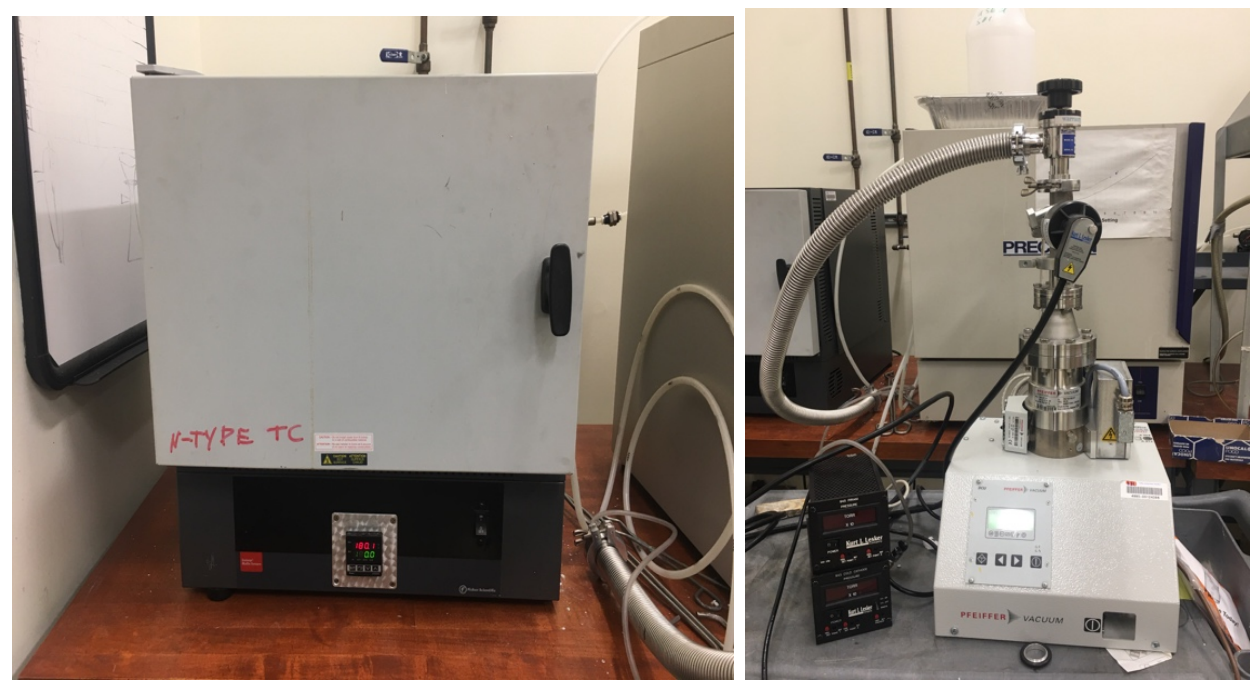

Figure 10 Annealing facility. Annealing oven (left), Vacuum system (right)

\subsection{Total X-ray Scattering Measurement}

Total x-ray scattering of the MG sample was conducted at synchrotron radiation facilities to study short-range ordering in the sample through pair distribution function (PDF) analysis. Synchrotron light source is an electromagnetic radiation source, which is produced by a storage ring of charged particles (e.g., electrons). In a synchrotron facility, an electron beam is firstly generated and accelerated in a Linear Accelerator (LINAC), then directed into a storage ring which consists of auxiliary components (bending magnets and insertion devices, such as undulators or wigglers). Finally, when high-energy electrons change their motion direction in the strong magnetic fields of bending magnets or insertion devices, brilliant $\mathrm{x}$-rays are emitted to be used as an analytical radiation source. Synchrotron light has the character of showing its advantage in the samples with light elements and small quantities, high brilliance, high polarization, high collimation 
low emittance, wide tunability in energy/wavelength, and pulsed light emission. It is widely used for scientific research in condensed matter physics, materials sciences, biology, medicine, and many other fields.

Our experiments were carried out at the National Synchrotron Light Source II (NSLS-II) at Brookhaven National Laboratory (BNL) (shown in Figure 11)

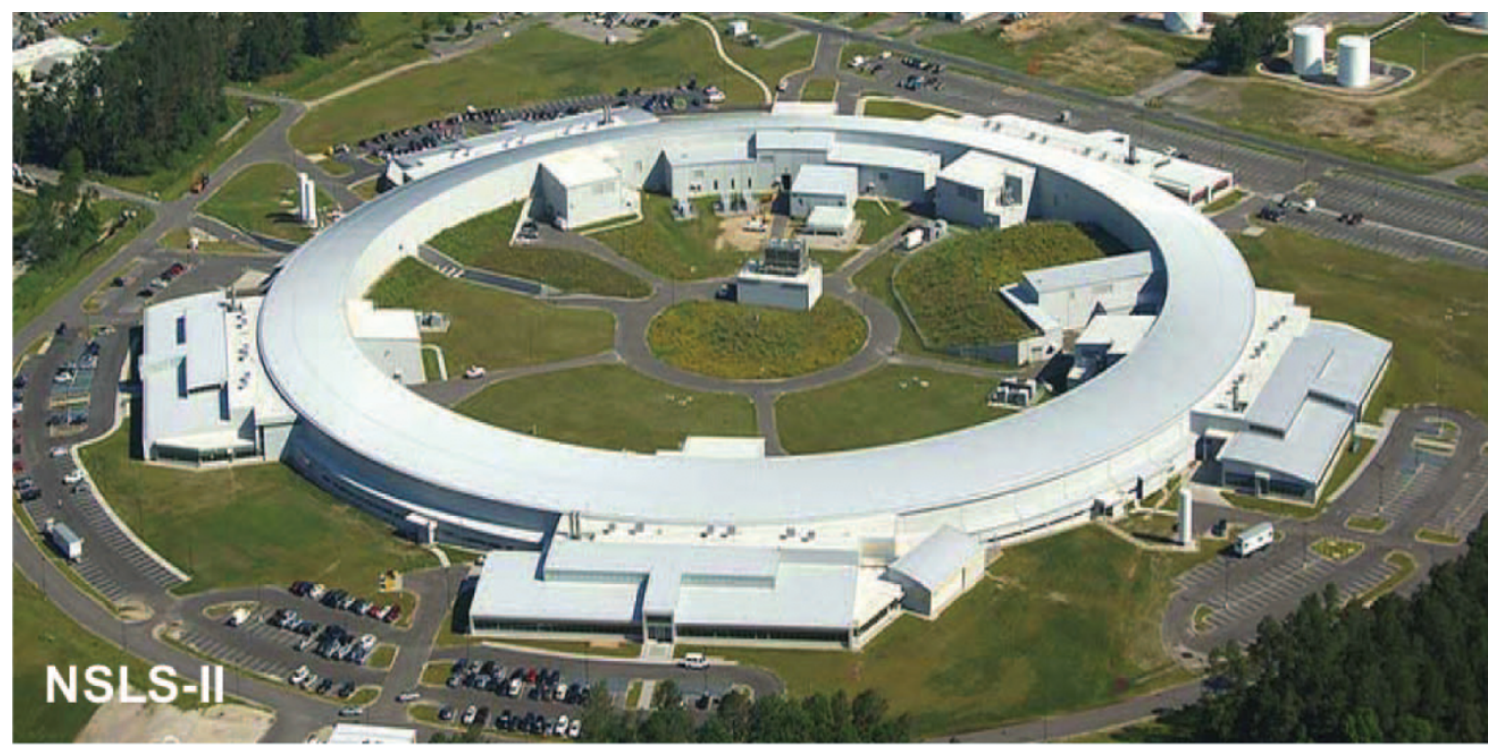

Figure 11 The National Synchrotrons Light Sources II (NSLS-II), Brookhaven National Laboratory, New York [136]

The XPD (X-ray Powder Diffraction) beamline has two independent branch lines and three end-stations. The 28-ID-B end station is used for pair distribution function (PDF) investigation (shown in figure 12). The sample should be fixed on the holder (shown in figure 13), when the X-ray beam is on; the CCD collector would collect the diffraction data from the samples. 

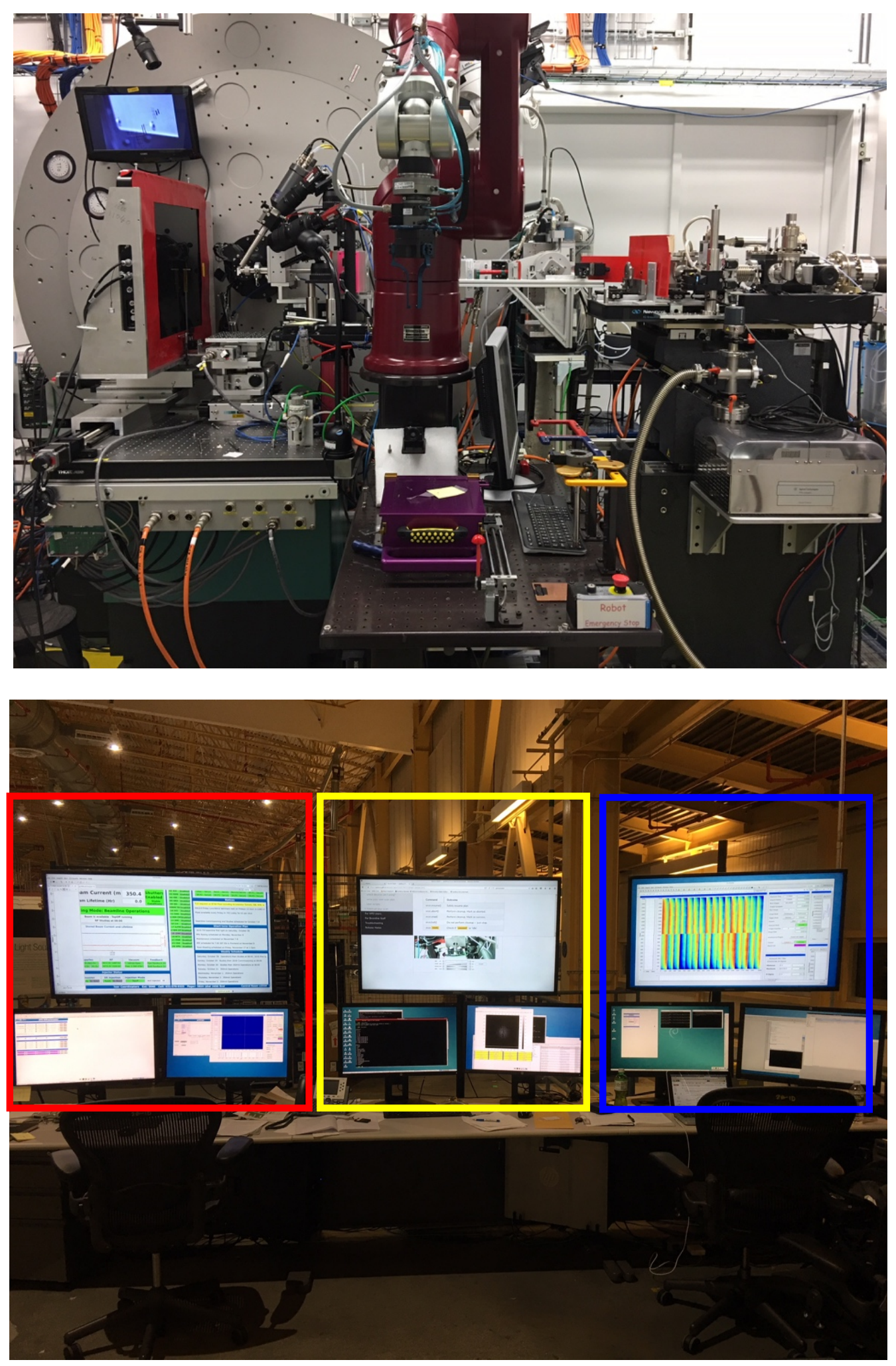

Figure 12 (a) NSLS-II 28-IDC and (b) NSLS-II 28-IDC workstation. Beam Status (Red), Motor control (Yellow), Camera Status (Blue) 


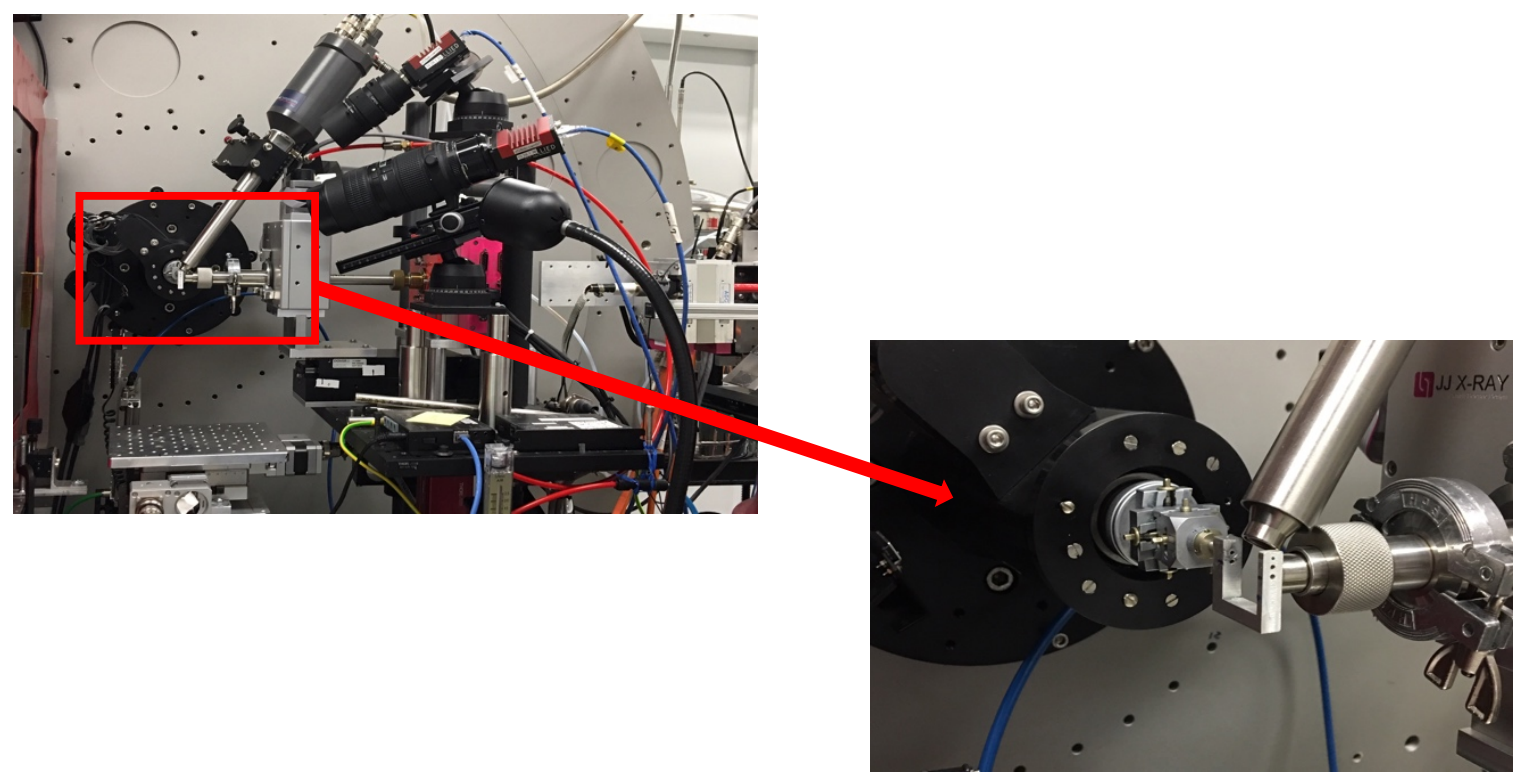

Figure 13 Inside of the hutch and PDF sample holder

The intensities were measured in a total scattering experiment, and $I_{m}(Q)$ is denoted as the following equation

$$
\mathrm{I}_{\mathrm{m}}(\mathrm{Q})=\mathrm{a}(\mathrm{Q}) \mathrm{I}_{\mathrm{c}}(\mathrm{Q})+\mathrm{b}(\mathrm{Q})
$$

where $\mathrm{I}_{c}(\mathrm{Q})$ is the coherent scattering intensity, which contains all the atoms arrangement information within the sample. Here, $a(Q)$ and $b(Q)$ are multiplicative and additive corrections respectively, which are used to the measured intensity. But they do not have any structurally related information.

$\mathrm{S}(\mathrm{Q})$ is defined according to the following equation

$$
S(Q)=\frac{I_{C}(Q)-\left\langle f(Q)^{2}\right\rangle+\langle f(Q)\rangle^{2}}{\langle f(Q)\rangle^{2}}
$$


where $f(Q)$ is the atomic scattering factor. The angle brackets show the average of all the atom types in the sample.

The PDF, $G(r)$, is achieved by the Fourier Transform of the total diffraction pattern as below,

$$
\begin{aligned}
G(r) & =4 \pi r\left[\rho(r)-\rho_{0}\right] \\
& =\frac{2}{\pi} \int_{0}^{\infty} Q[S(Q)-1] \sin (Q r) d Q
\end{aligned}
$$

Where $\rho(r)$ is the microscopic pair density, $\rho_{0}$ is the average number density and Q is the momentum transfer,

$$
Q=4 \pi \sin \theta / \lambda
$$

Where, $\theta$ is the direction angle and $\lambda$ is the wavelength of X-ray. $S(Q)$ is the normalized structure function determined from the experimental diffraction intensity. For the calculation of $\mathrm{S}(\mathrm{Q})$ and $\mathrm{G}(\mathrm{r})$, academic software such as PDFgetX3 would be used.

The PDF was used to the study of materials which do not show a long-range order. So, it is very suitable for metallic glass research. The PDF is calculated from the diffraction scattering intensities. Thus, a PDF can classify the short-range order and random displacements of the atoms. Figure 14 shows Schematic illustration of $g(r)$ dependence on different distance. $G(r)$ is the number of atoms in an annulus of distance $r$ from another atom. 


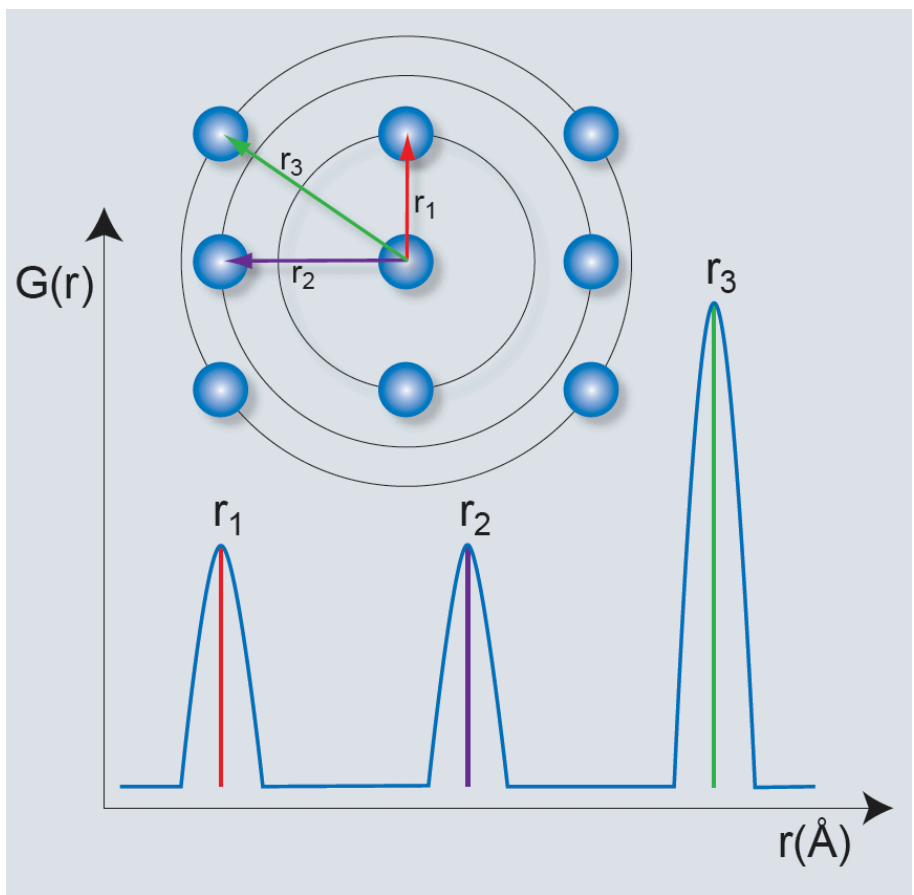

Figure 14 Schematic illustration of $\mathrm{g}(\mathrm{r})$ dependence on radius [88]

\subsubsection{Synchrotron XRD}

Our X-ray diffraction (XRD) experiments were mainly conducted at the Advanced Photon Source (APS) Beamline 13-ID-D at Argonne National Lab (ANL) Chicago and the center of the study of matter at extreme condition (CeSMEC) FIU.

Beamline 13-ID-D is available for both X-ray diffraction and high pressure/high temperature diamond anvil cell experiments. Higher flux monochromatic beam with beam size of $2 \mathrm{um} \times 2 \mathrm{um}$ is available by using a 3.0 undulator-bent, double Si 111 crystal Laue mode monochromator. With an ultra-high brilliance and small sized focused white/monochromatic beam (resolution $1 * 10^{-4}$, flux $1 * 10^{13}$ at $10 \mathrm{kev}$ ), Beamline 13 -ID-D is able to run experiments for regular diffractions as well as in-situ diffraction at extreme conditions for different types of samples, such as powders, single crystals, and nanocrystals. In addition, at Beamline 13-ID-D, higher energy range of monochromatic beam is available 
at $45 \mathrm{keV}$ for a very high $\mathrm{Q}$ range to get data for total scattering geometry on Angle Dispersive Diffraction.

\subsubsection{Laboratory X-ray Diffraction (XRD)}

Before and after annealing, all the MG samples are examined using the X-ray facility in Center for the Study of Matter at Extreme Conditions (CeSMEC), FIU, as shown in Figure 15. This facility includes Bruker GADD/D8 X-ray system equipped with an Apex Smart CCD detector, The X-ray diffraction studies were carried out using Bruker GADDS/D8 Xray facility with molybdenum MacSci rotating anode, $\lambda$ is $0.709319 \AA$ and Apex Smart CCD at CeSMEC. The XRD patterns were collected for five minutes for each sample and the diffraction angle 2-thera range was set to 35 degrees. The 2-dimensional diffraction patterns were integrated by using Fit2D, and the crystalline structure was analyzed by Match. 


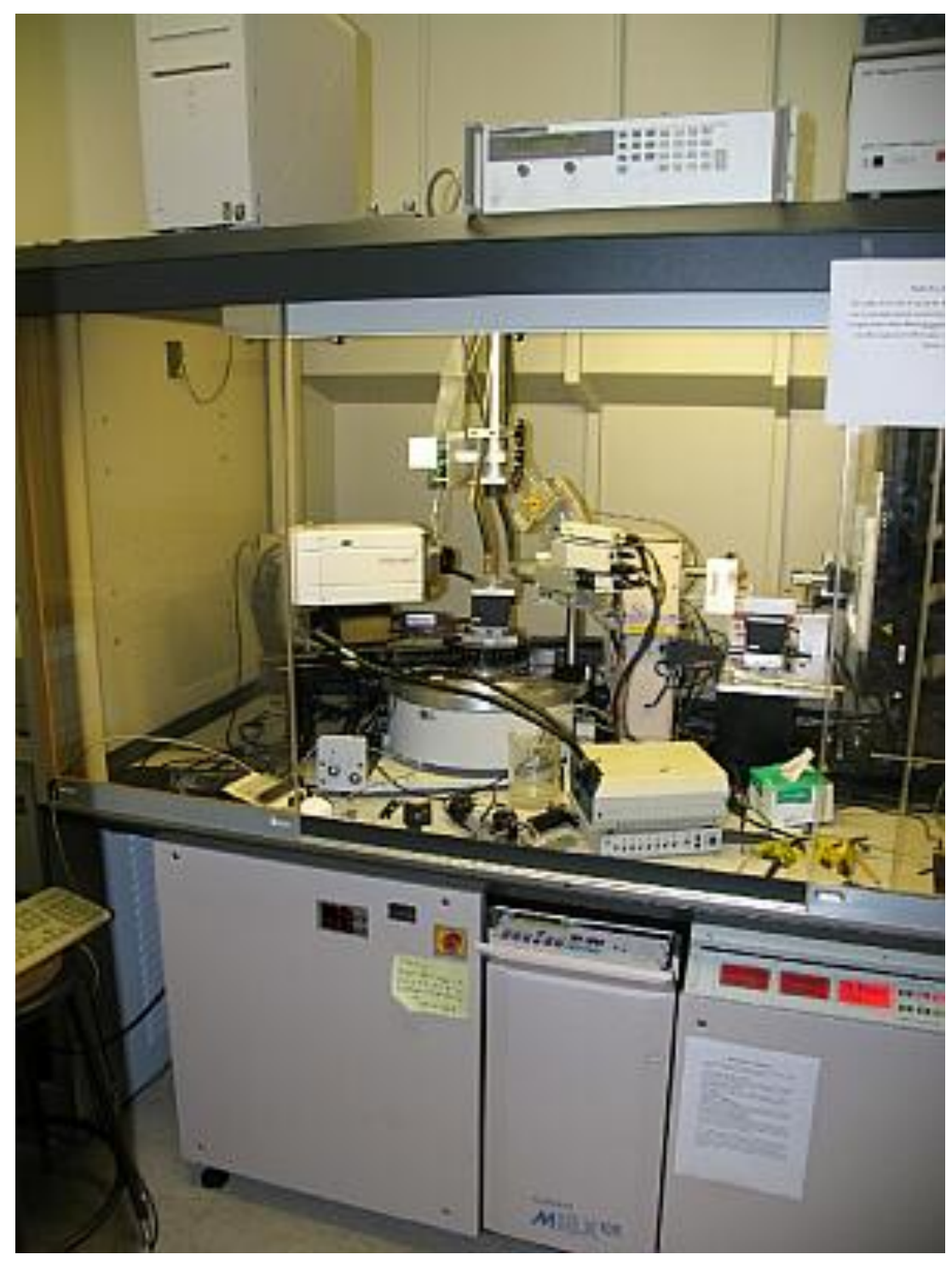

Figure $15 \mathrm{X}$-ray diffractometer (XRD) at CeSMEC

\subsection{Hardness Measurement}

The hardness of the samples was measured using the LECO's LM Microindentation Hardness Testing System (shown in Figure 16). The microindentation tests were carried out at $25 \mathrm{~g}$ loads and a $10 \mathrm{~s}$ dwelling time on all samples. Nine Vickers indentations were placed on each sample with a three by three array and sufficient space was kept between 
indents to avoid the potential plastic deformation zone overlapping. The averaged hardness values and the deviations of the samples were calculated.

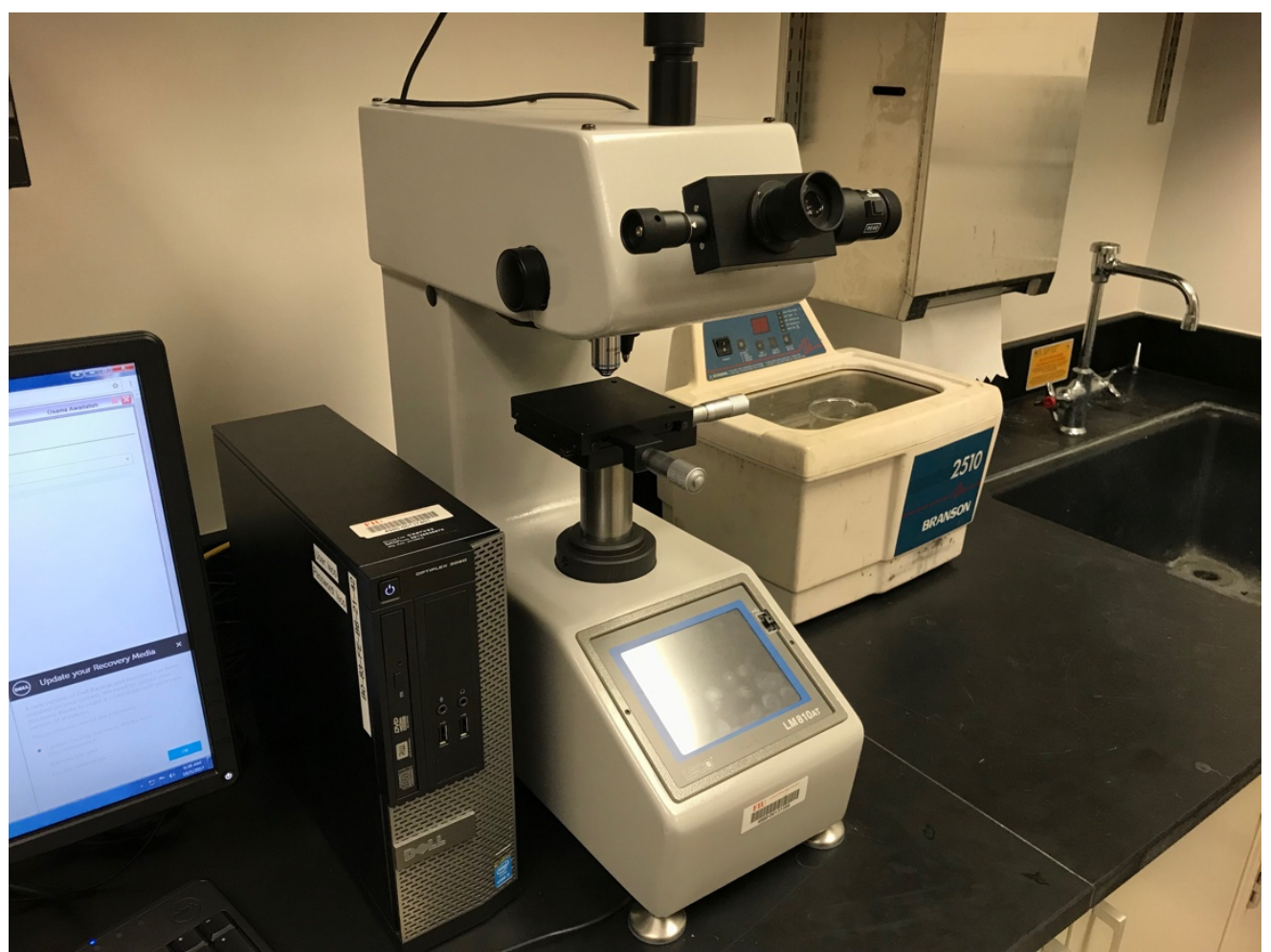

Figure 16 Hardness test equipment at Advanced Materials Engineering Research Institute (AMERI)

\subsection{Transmission Electron Microscopy (TEM)}

The TEM result was finished by using JEM-ARM300F spherical aberration corrected Transmission Electron Microscope at Shanghai Institute of Microsystem and Information Technology. 


\section{CHAPTER 4. EFFECT OF PRECIPITATION ON THE HARDNESS OF TERNARY METALLIC GLASS}

\subsection{Introduction}

Metallic glasses (MGs) attract tremendous interests regarding their special mechanical, acoustic, elastic, and magnetic properties [89-93]. Among these properties, the superior mechanical properties of MGs or bulk metallic glasses (BMGs) are the most promising for engineering applications considering the lack of dislocation mechanism for plastic deformation [94-96]. Also, MGs are used in high efficiency transformers regarding their soft-magnetic properties due to the absence of a magneto-crystalline anisotropy. Besides the aforementioned properties, high resistance to corrosion is another impressive property of MGs [97]. Thus, BGMS or coated MGs can be used in very aggressive environments with the combined strong wear resistance ability and corrosion resistance ability. In previous studies, various preparation methods have been developed to produce MGs. One of the general guiding principles of designing MGs is selecting elements with large differences in size, a choice that leads to a complex structure that crystallizes less easily. [98]. The Ce-based rare earth bulk metallic glass with a lower glass transition temperature and special mechanical properties such as lower elastic modulus was reported in one previous study [99].

Cerium is the most abundant of all the lanthanide among the earth crust, and it occurs in various minerals [100]. Ce can replace $\mathrm{Zr}$ as the based constituent material during BMG

preparing since they have a similar atom structure. Ce-based MGs (i.e., $\mathrm{Ce}_{55} \mathrm{Al}_{45}$ and $\mathrm{Ce}_{75} \mathrm{Al}_{25}$ ) have been successfully prepared, and their unique properties (i.e., pressure 
induced polyamorphism) have been reported in these kinds of MGs [101-104]. One possible mechanism was that the $4 \mathrm{f}$ electron delocalization in Ce under high pressure causes bond shortening. This electronic polyamorphism is very different from the structural polyamorphism compared with other amorphous materials. Moreover, the electronic structure of $\mathrm{Ce}$ in Ce-bearing materials can not only be changed by pressure but also through alloying with other elements. Zeng et al. reported that the minor alloying effect (i.e., Si doping in the $\mathrm{Ce}_{75} \mathrm{Al}_{25} \mathrm{MG}$ system) can noticeably change the transition pressure, even properties of both high-density amorphous (HDA) and low-density amorphous (LDA) of $\mathrm{Ce}_{75} \mathrm{Al}_{23} \mathrm{Si}_{2}$ metallic glass $[101,104]$.

To characterize the mechanical performances of bulk metallic glasses, both standard or customized tensile tests and indentation tests have been conducted. However, the tensile tests would require special care for sample preparation, especially for MGs that are mostly prepared in foil or powder rather than large bulks (i.e., $25.4 \mathrm{~mm}$ length and $6.35 \mathrm{~mm}$ width). Thus, the multi-scaling indentation is more favored for studying MGs to examine both the macro/micro mechanical response via hardness and the deformation zones around/underneath the indent $[103,104]$. However, in many other experiments, roughly semicircular shear bands were observed, a result that is not predicted by the slip-line theory. These shear bands and their associated hemispherical plastic zone beneath the indent were explained using the expanding cavity model. Also, previous studies have demonstrated that annealing-induced hardening might be possible in bulk metallic glasses (BMG) [98, 105]. Multi-scaling indentation as well as different inverse methods can be utilized to access the elastic properties [106] and plastic properties of individual grains $[107,108]$ and individual phases [109]. Also, the application of multi-direction indentation will be helpful for 
understanding the possible anisotropy of REMGs foils [110]. However, some studies reported the annealing effects on the mechanical properties of REMGs.

Our aim is to examine the influence of annealing on the mechanic properties of melt-spun glassy $\mathrm{Ce}_{75} \mathrm{Al}_{23} \mathrm{Si}_{2}$ ribbons. In this project, I applied the microindentation in REMGs to correlate the mechanical performances and annealing temperatures. The XRD and SEM are followed to illustrate the evolution of the structure and the element distributions. The understanding of annealing effects on the mechanical behaviors of these alloys will shed light on future research. Figure 17 shows the whole procedure of the experiment.

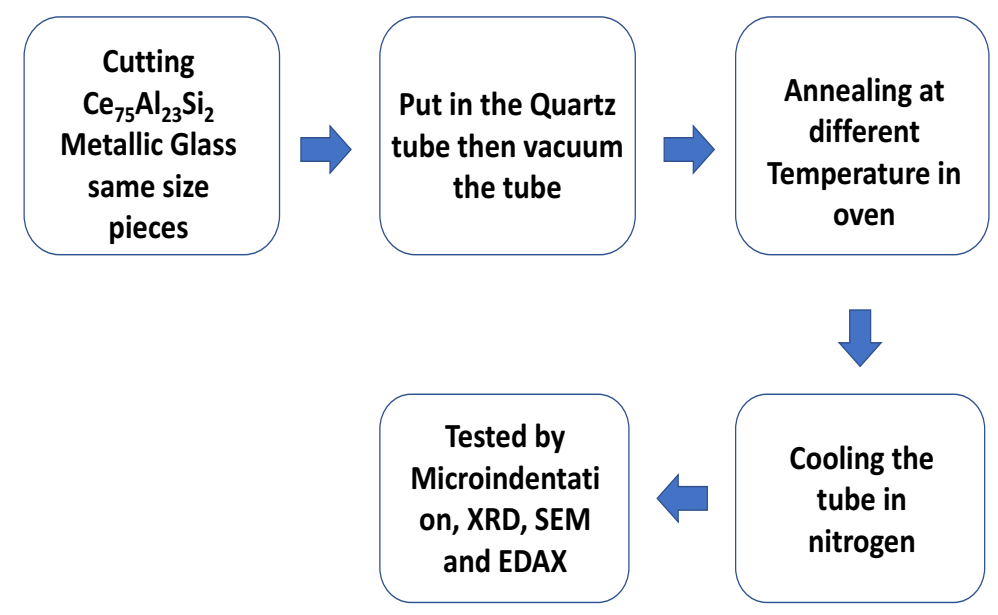

Figure 17 Processing of $\mathrm{Ce}_{75} \mathrm{Al}_{23} \mathrm{Si}_{2}$ metallic glass mechanical properties and structure measurement 


\subsection{Experiment}

\subsubsection{Sample Preparation}

All master ingots were prepared by arc-melting a mixture of pure Ce (99.5 at. \%), $\mathrm{Al}(99.95$ at. \%), Si (99.99 at. \%) in a Zirconium-gettered argon atmosphere. Each ingot was melted five times to ensure homogeneity in composition. Using these master ingots, thin ribbon $\mathrm{Ce}_{75} \mathrm{Al}_{23} \mathrm{Si}_{2}$ (the numbers present atomic percentage) metallic glass with a thickness of about $\sim 35 \mu \mathrm{m}$ and a width of $\sim 3 \mathrm{~mm}$ was further prepared via single-roller melt-spinning with a $\mathrm{Cu}$ wheel surface rotating speed of $40 \mathrm{~m} / \mathrm{s}$ (more details can be found in chapter 3 ). Then, the ribbon was divided into six pieces, with each piece was $5 \mathrm{~mm} * 2 \mathrm{~mm} * 35 \mu \mathrm{m}$. Each $\mathrm{Ce}_{75} \mathrm{Al}_{23} \mathrm{Si}_{2}$ metallic glass sample was loaded in quartz capillary and kept under vacuum at $4 * 10^{-4}$ Torr to reduce the possibility of oxidation in annealing heat treatment. A Fisher Scientific oven was used to heat the sample at $373 \mathrm{~K}, 473 \mathrm{~K}, 523 \mathrm{~K}, 543 \mathrm{~K}$ and $563 \mathrm{~K}$ for $30 \mathrm{~min}$, respectively.

\subsubsection{Materials Characterization}

The X-ray diffraction studies were carried out using Bruker GADDS/D8 X-ray facility with molybdenum MacSci rotating anode, $\lambda$ is $0.709319 \AA$ and Apex Smart CCD at Center for the Study of Matter at Extreme Conditions (CeSMEC), FIU. The XRD patterns were collected for five minutes for each sample and the diffraction angle 2-thera range was set to 35 degrees. The SEM studies were carried out by using JEOL 6330 equipped with a Noran System Six EDS analyzer. The hardness of the samples was measured using the LECO's LM Microindentation Hardness Testing System. The surface of the MGs was polished using a standard processing to reduce the surface roughness. The microindentation tests were carried out at $25 \mathrm{~g}$ loads and a $10 \mathrm{~s}$ dwelling time on all samples. Nine Vickers 
indentations were placed on each sample with a three by three array and sufficient space was kept between indents to avoid the potential plastic deformation zone overlapping. The averaged hardness values and the deviations of the six samples were calculated. Microindentation was performed at the Advanced Materials Engineering Research Institute (AMERI). The TEM result was finished by using JEM-ARM300F spherical aberration corrected Transmission Electron Microscope at Shanghai Institute of Microsystem and Information Technology.

\subsection{Results and Discussion}

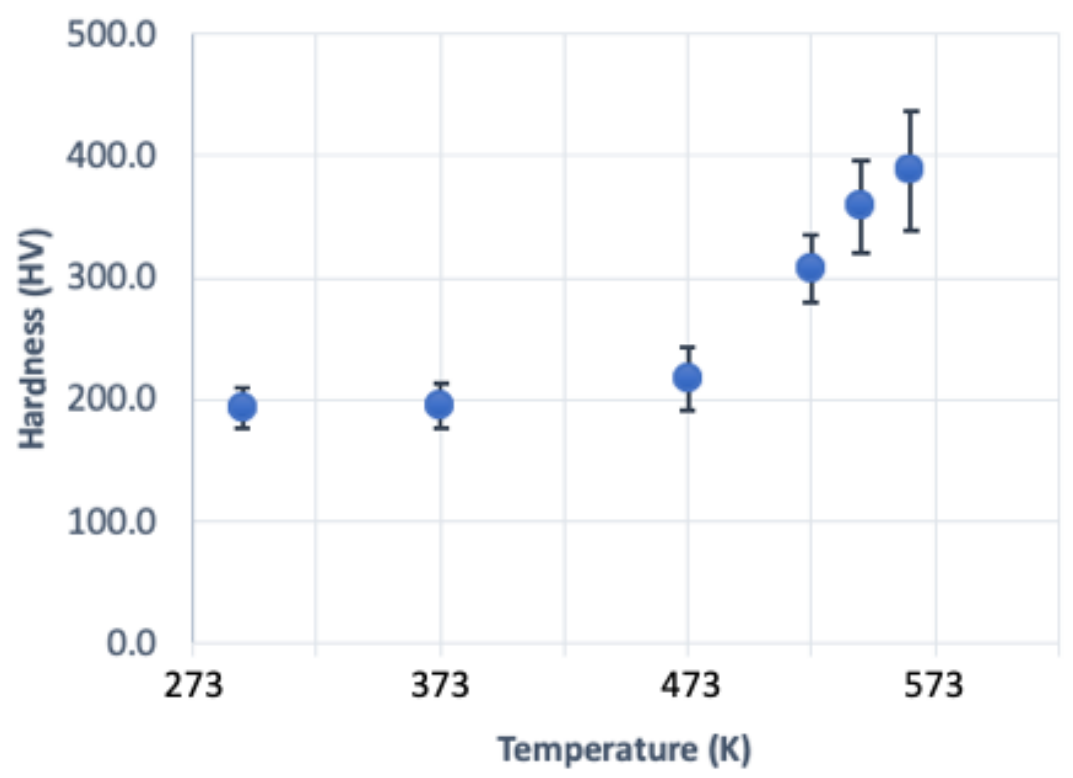

Figure 18 The average hardness values (Hv) of each sample with different annealing temperatures (The points from left to right were the as received sample and samples annealing at $373 \mathrm{~K}, 473 \mathrm{~K}, 523 \mathrm{~K}, 543 \mathrm{~K}$ and $563 \mathrm{~K})$. Bars attached to the symbols represent the experimental uncertainty.

Figure 18 shows the result of hardness measurement for the six samples of different annealing conditions. The initial hardness for the sample as received was around $200 \mathrm{HV}$, 
and this value remained nearly unchanged for the sample annealed at $373 \mathrm{~K}$. When the annealing temperature was increased to $473 \mathrm{~K}$, the hardness increased by $\sim 10 \%$ to $220 \mathrm{HV}$. However, the hardness increased to $310 \mathrm{HV}$, which is $~ 50 \%$ higher compared to the asreceived samples when the annealing temperature was raised to $523 \mathrm{~K}$. Finally, the average hardness of the annealed sample reached $\sim 400 \mathrm{HV}$ after being treated at $563 \mathrm{~K}$.

Figure 3 shows X-ray diffraction patterns of the specimens before and after the annealing at diffraction conditions. No sharp peaks were observed for the as-received sample and the pattern is identical to that of the REMG with the same composition [100] and similar to that of $\mathrm{Ce}_{75} \mathrm{Al}_{25}$ [104]. Singh et al [99] studied $\mathrm{Ce}_{75} \mathrm{Al}_{25-\mathrm{x}} \mathrm{Ga}_{\mathrm{x}}$ metallic glasses and found that incorporation of small amount of $\mathrm{Ga}(\mathrm{x}=2)$ may introduce a new major diffraction peak at a higher angle, but appearance of such a new peak was not observed in the case of $\mathrm{Si}$ incorporation with the same amount $(x=2)$. The diffraction pattern of the sample annealed at $373 \mathrm{~K}$ did not show any significant change compared to that of the as-received sample, indicating no crystallization at this annealing temperature. Upon annealing at higher temperatures, sharp crystalline diffraction peaks were observed. All the observed peaks were identified as belonging to the hexagonal $\alpha$-AlCe3 phase.

The average crystallite sizes of the annealed samples were estimated based on the diffraction data using Debye-Scherrer equation [111] as shown below

$$
\beta=\frac{K \lambda}{d \cos \theta}
$$

where $\beta$ is full width at half maximum (FWHM) of the diffraction peak, $\mathrm{K}$ is a dimensionless shape factor with a value close to unity but may vary from 0.9 to 1.1 depending on the actual shape of the crystallite $(K=1$ is used here), $\lambda$ represents the 
wavelength of X-ray source ( $0.7093 \AA$ used in this experiment), $\mathrm{d}$ is the average grain size, and $\theta$ is the Bragg angle of the diffraction peak. The FWHM of each diffraction pattern was obtained through curve fitting using Fityk [112], and the average crystallite sizes were derived to be $28,31,33$, and $42 \mathrm{~nm}$ for the samples annealed at $473 \mathrm{~K}, 523 \mathrm{~K}, 543 \mathrm{~K}$ and $563 \mathrm{~K}$ respectively.

Although the crystalline alloy is in general softer than the metallic glass of the same composition, grain boundaries and the statistically stored dislocations (SSDs) in the crystalline grains near the interfaces between amorphous alloy and the new generated nanocrystal serve as barriers to the plastic deformation and hence increase the hardness of the bulk with nano-size precipitations. As more $\mathrm{AlCe}_{3}$ phase precipitates at a higher annealing temperature, Si bearing phase becomes visible in the diffraction patterns. The weak diffraction peaks in the pattern of $563 \mathrm{~K}$ annealed sample in Figure 19 were identified as $\mathrm{Ce}, \mathrm{AlCe}_{3}$ and Cerium Aluminum Silicate Hydroxide $\left[\mathrm{Ce}_{2} \mathrm{Al}\left(\mathrm{SiO}_{4}\right) 2(\mathrm{OH})\right]$. This finding is consistent with the increase in $\mathrm{AlCe}_{3}$ phase as the annealing temperature rises. Nevertheless, a decrease of the hardness is expected if the crystallization is complete and the bulk sample dominated by $\mathrm{AlCe} 3$ crystalline phase of larger crystallite sizes reaches a high enough annealing temperature or obtains a long enough annealing time. 


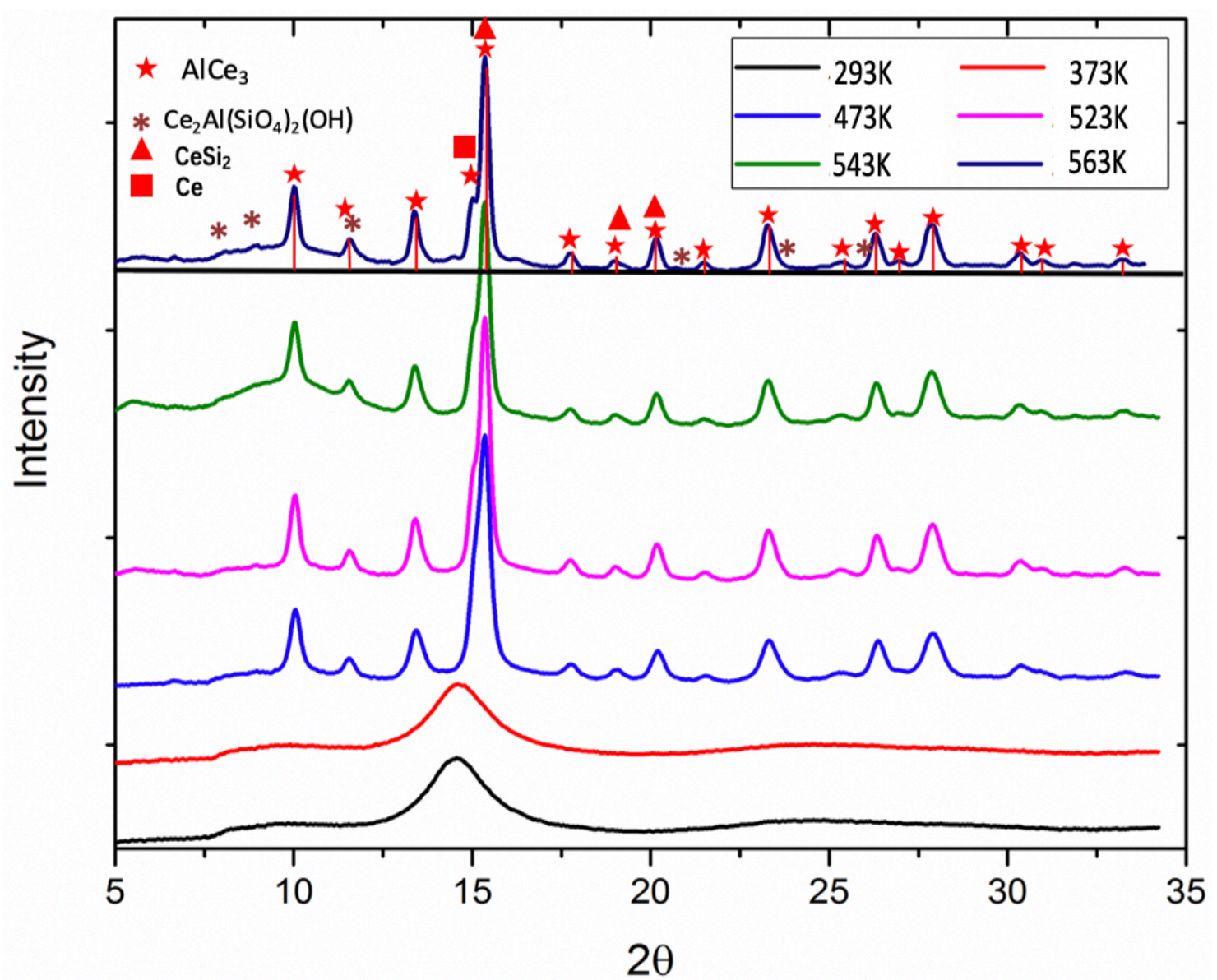

Figure 19 The XRD patterns of each samples: (a) as received (AR) sample, (b) sample annealed at $373 \mathrm{~K}$, (c) sample annealed at $473 \mathrm{~K}$, (d) sample annealed at $523 \mathrm{~K}$, (e) sample annealed at $543 \mathrm{~K}$, and (f) sample annealed at $563 \mathrm{~K}$ (Wavelength $\lambda$ is $0.7093 \AA$, exposure time is $300 \mathrm{sec}$.)

The TEM micrograph in Figure 20 confirms that the crystallite sizes are $\sim$ nanometer range. According to the Hall-Petch relationship for yielding strength $\left(\sigma_{Y}\right)$ of a crystalline sample, i.e. $\sigma_{Y}=\sigma_{0}+k_{Y} d^{-1 / 2}$, the increase of crystallite sizes (d) may result in a decrease in strength. Regarding the linear relationship, the microhardness values can be converted to the $\sigma_{y}$. Using $\sigma_{0}=255 \mathrm{Hv}$ (the hardness for $\mathrm{Ce}_{75} \mathrm{Al}_{25}$ metallic glass measured with $25 \mathrm{~g}$ load [99] and ky value from 2 to $5 \mathrm{MPa} \mathrm{m} 1 / 2$ for the estimation of Hall-Petch effect [114], the 
hardness is expected to decrease by about $15-17 \%$ when the crystallite sizes increase from 28 to $42 \mathrm{~nm}$. Therefore, the fact that the bulk hardness increases by more than $50 \%$ is dominantly influenced by the increase of the crystalline precipitation, not by the change in the size of such precipitation at a higher annealing temperature.

As seen in the TEM images in Figure 20 (a) and (b), the matrix is dominated by the plain areas which are the amorphous phases. Then, we could find three different features within the microstructures: the regions highlighted in white solid lines are nanocrystalline because of the clear atom arrangement; the regions highlighted in the solid green lines are a mixture of the amorphous phase and the nanocrystalline; the uneven regions marked in the blue lines are the fold area, which is possibly formed due to the concentration of one element during annealing processing. The size of the nanocrystalline could be coarsely determined using the magnified image as the highlighted areas in Figure 5 (b). The averaged radius of nanograin highlighted in Figure 5(b) would be below $20 \mathrm{~nm}$. Then, the annealed temperature reached $543 \mathrm{~K}$, and the initial sample was turned to an almost fully crystallized state. The dominate regions have already turned to crystalline regions or mixture areas. Also, the number of uneven regions was significantly reduced. Clear grain boundaries among different features were almost formed. The radius of grain was also increased from below $20 \mathrm{~nm}$ to $\sim 40 \mathrm{~nm}$. Such observation also confirmed the previous deduction according to the hardness and hall-patch relationship. It was noticed that the uneven regions observed in the TEM images were rarely discussed in the previous study, which might be an intermediate state of the current MG alloy in the annealing process. Further study should be conducted to detect the alloy composition of such regions to illustrate the evaluation of MGs in the annealing process. 


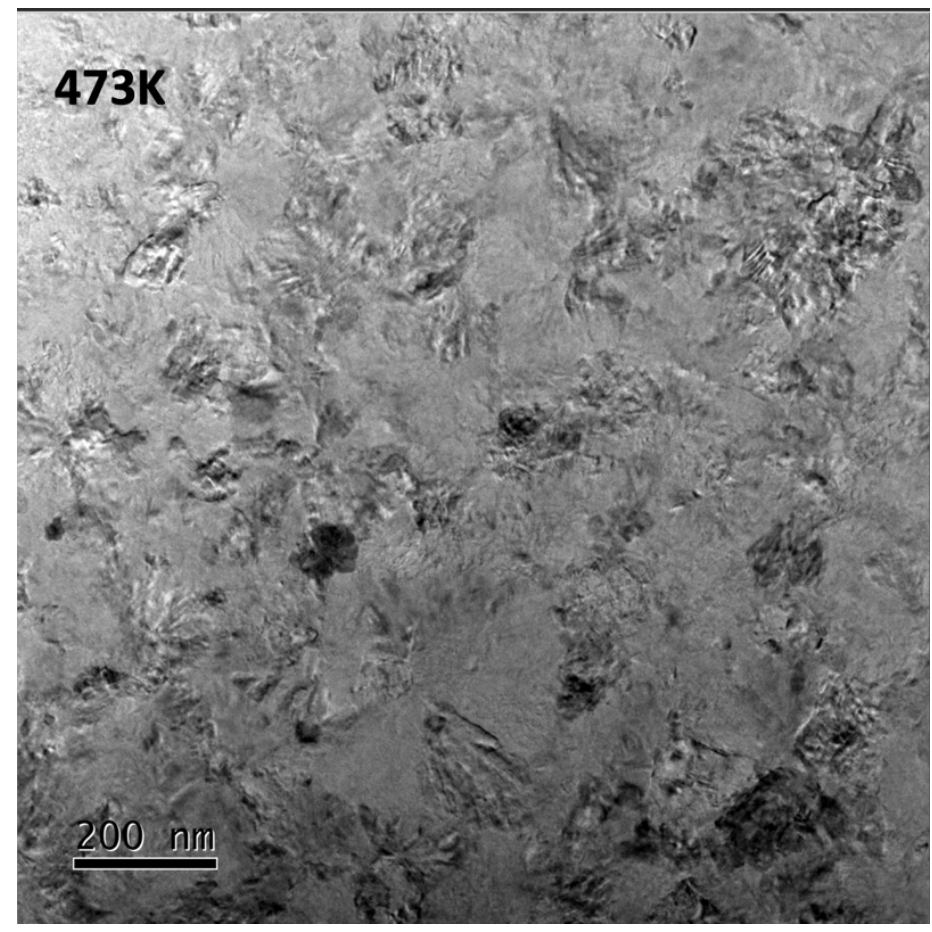

Figure 20 (a) microstructures of $\mathrm{Ce}_{75} \mathrm{Al}_{23} \mathrm{Si}_{2}$ sample annealed at $473 \mathrm{~K}$

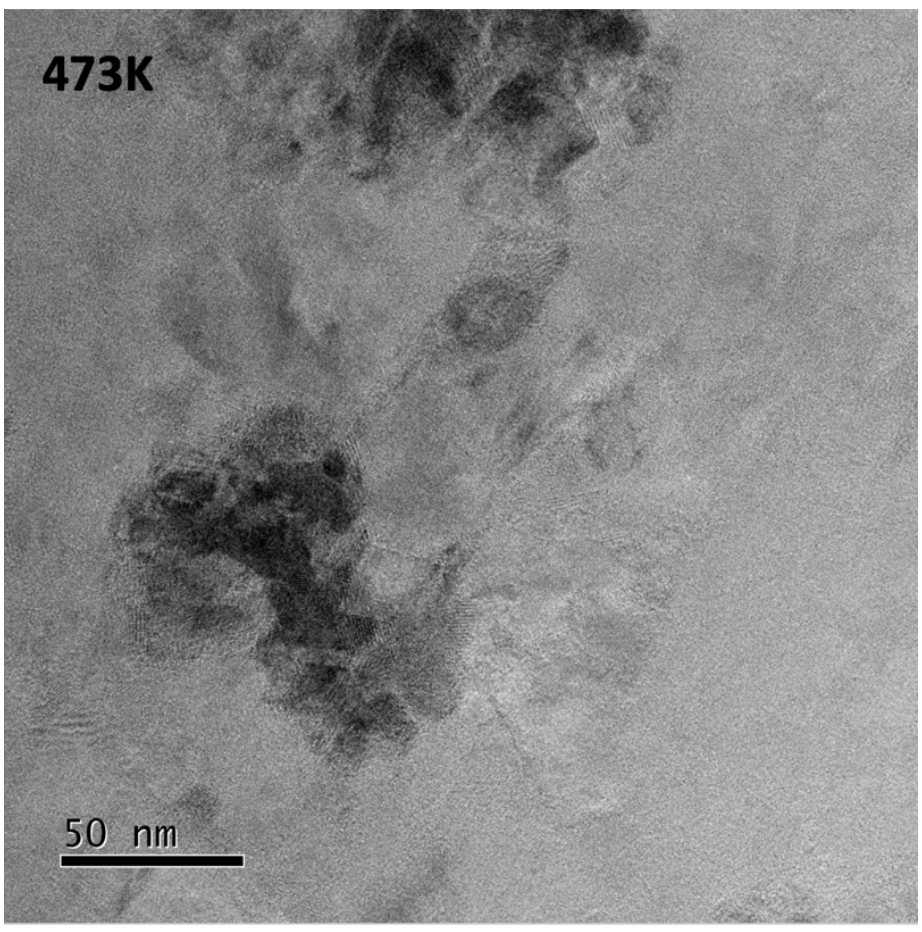

Figure 21 (b) magnified images of $\mathrm{Ce}_{75} \mathrm{Al}_{23} \mathrm{Si}_{2}$ sample annealed at $473 \mathrm{~K}$ 


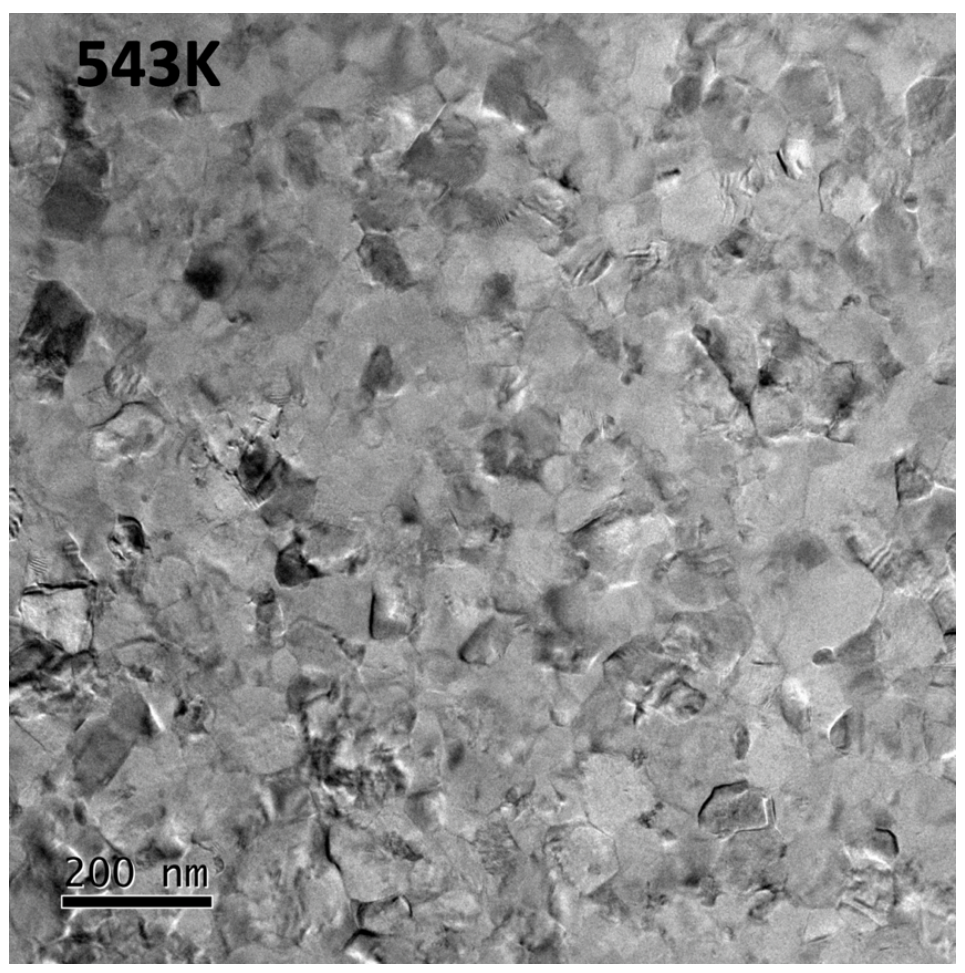

Figure 22 (c) microstructures of $\mathrm{Ce}_{75} \mathrm{Al}_{23} \mathrm{Si}_{2}$ sample annealed at $543 \mathrm{~K}$

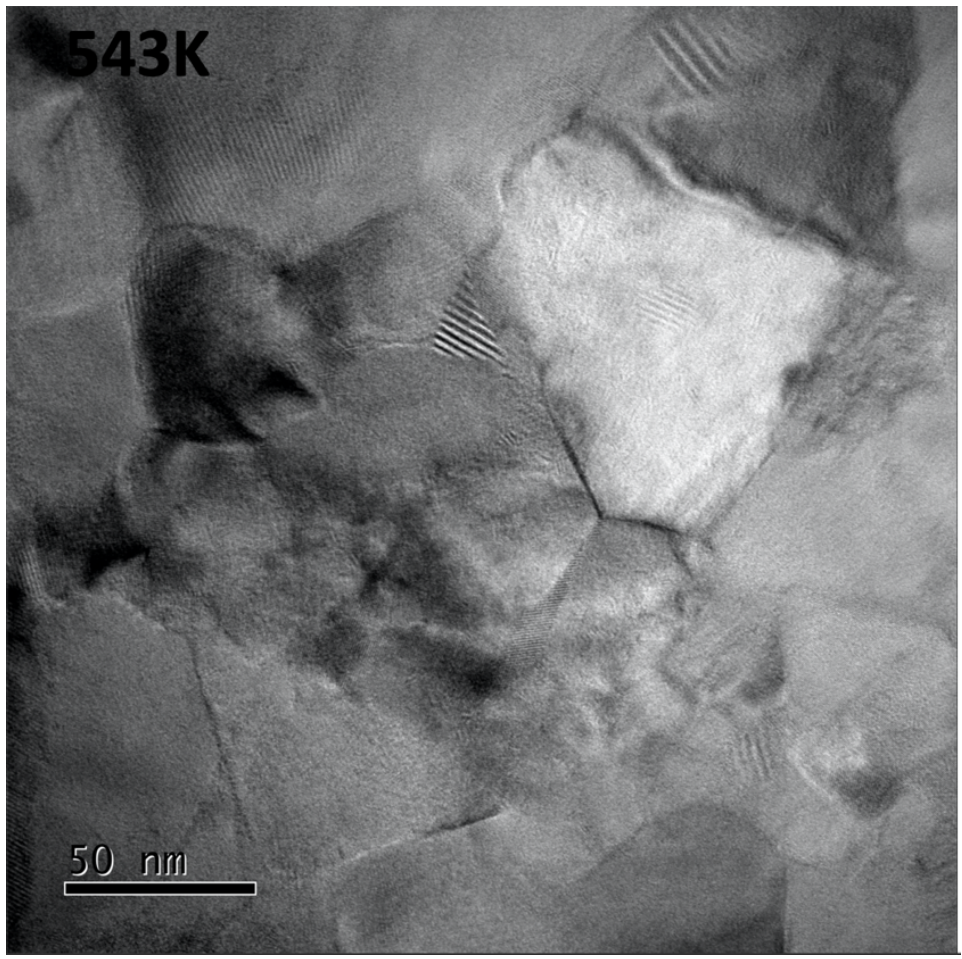

Figure $23(\mathrm{~d})$ magnified images of $\mathrm{Ce}_{75} \mathrm{Al}_{23} \mathrm{Si}_{2}$ sample annealed at $543 \mathrm{~K}$ 


\subsection{Conclusion}

Annealing of the $\mathrm{Ce}_{75} \mathrm{Al}_{23} \mathrm{Si}_{2}$ REMG at a temperature above $473 \mathrm{~K}$ introduces nano $\mathrm{AlCe}_{3}$ crystalline precipitations of about $30-40 \mathrm{~nm}$, and in turn enhances the hardness of the annealed system. The population of such nano precipitations increases with the annealing temperature within the range of $473 \mathrm{~K}-563 \mathrm{~K}$. Consequently, the composites hardness also increases with the annealing temperature. The hardness enhancement, however, is restricted to a limited range of annealing temperature and annealing time. From TEM, we can clearly identify the mixed area of crystalline and non-crystalline structure, the increasing density of grain boundary could help improve the mechanical property of the sample. 


\section{CHAPTER 5. OPTIMIZING COMPOSITION OF AL-NI-CE TERNARY ALLOY FOR IMPROVED GLASS-FORMING ABILITY AND MECHANICAL}

PROPERTIES

\subsection{Introduction}

Aluminum ternary metallic glass with the rare earth element (RE) and transition element (TM) exhibit high strength and corrosion resistance properties [114]. Moreover, because of the high density of nanoparticles within the ternary alloy, its mechanical property can be improved to a new level after annealing it below its crystallization temperature [115]. As a result, Al-TM-RE metallic glasses attract great attention to research institutions and industries.

One unique character of Al ternary MG system is its supercooled, very narrow liquid region. This character indicates that a very high cooling rate is required to produce the Al ternary MG; therefore, most of the Al ternary MG can be only produced as melt-spun ribbons with the thickness no larger than $100 \mu \mathrm{m}$. Meanwhile, the high cooling rate can bring high thermal stresses in the casting, which could lead to fracture. Most of the actual industrial applications, on the other hand, need a larger size and three-dimensional bulk metallic glass (BMG). The main challenge here is how to make this MG bulk at a significantly lower cooling rate when casting. Two possible approaches are used to overcome this problem. The first one is finding a suitable composition with a better glass forming ability (GFA). Supercooled liquid region $\Delta T_{x}=\left(T_{x}-T_{g}\right)$ can be used as a reliable index to represent GFA. The higher $\Delta T_{x}$ means the better glass forming ability, and it is easier to produce such BMG. The other one in use is thermoplastic method with a relatively high manufacture cost. So far it is very challenging to find Al ternary MG with higher 
composition $\Delta T_{x}$ or to reduce the manufacture cost, and most studies are based on a trialand-error scheme.

\subsection{GFA Optimization Method}

GFA is evaluated by the value of the critical cooling rate for glass formation. Critical cooling rate is the smallest cooling rate required to keep the melt amorphous without precipitation of crystals during their solidification. When the required cooling rate for the BMG is small, the GFA of such a system is high. In order to manufacture Al-TM-RE BMG successfully, the composition with higher GFA should be known before we conducted preparation. Practically, it is difficult to precisely measure the critical cooling rate for glass formation. However, there is still a direct gauge to predict and quantify the GFA for MG. The most widely used two parameters to judge the GFA are supercooled liquid region $\left(\Delta T_{x}\right)$ and reduced glass transition temperature $\left(T_{r g}\right)$. Some researchers found that reduced glass transition temperature $\left(T_{r g}\right)$ was not reliable enough to infer GFA in some MG systems such as Pd-Ni-Fe-P[116], My-Cu-M-Y[117]. But a broader temperature range of the supercooled liquid region will lead to a higher GFA. And this correlation has been widely observed and supported by the research results from $\mathrm{Mg}-\mathrm{Cu}-\mathrm{Y}$ system studied by Kim et al. and Fe-(Co, Cr, Mo, Ga, Sb)-P-B-C studied by Shen et al. [118]. As a result, supercooled liquid region $\left(\Delta T_{x}\right)$ was accepted as a stable gauge for the optimization of BMG.

Meanwhile, the glass-forming ability of Al-Ni-RE has a strong relationship with the size

of the RE elements. The atomic radius of $\mathrm{Ce}$ is $0.1825 \mathrm{~nm}$. Although smaller than the radius of $\mathrm{La}(0.1877 \mathrm{~nm})$, Ce has much stronger interactions with other elements (such as $\mathrm{Al}, \mathrm{Ni}$ ) 
in MG because of its higher Pauli electronegativity. As a result, Al-Ni-Ce MG is one of the best Al-TM-RE MGs for GFA optimization.

In the optimization algorithm design procedure for MG, just a small number of new MG candidates need to be synthesized and studied for their physical, mechanical, and corrosion properties to confirm the accuracy of such a procedure. $\Delta T x$ represents the stability of glass,

which denotes the temperatures difference between the crystallization temperature and glass transition point. Therefore, a higher value of $\Delta T x$ leads to greater stability of glass against crystallization [119]. Here, the algorithms are used to optimize the composition of Al-Ni-Ce metallic glass to achieve the best glass-forming ability (the max $\Delta T x$ ). Moreover, it would just need a small number of metallic glass samples to be synthesized and evaluated to check the performance of the MGs. As a result, we can find the best Al-Ni-Ce concentration efficiently and economically.

\subsubsection{Multi-objective Optimization Algorithm}

In previous studies "Trial-and-error" is the commonly used method to find the best GFA in a specific MG system. However, this method is time-consuming and expensive. So far, researcher found a multi-objective optimization algorithm, which is based on self-adapting response surface methodology—an efficient and economical way to find the problem's solution. G S Dulikravich et al. have demonstrated that multi-objective optimization algorithm is an accessible method for optimizing the chemical composition of new MG with superior properties [120]. 
The multi-objective optimization problem generally includes a serious of conflicting objectives and a group of complex objective functions. The details of the multi-objective optimization algorithm have been introduced in Chapter 3 .

To design the most efficient optimization plan, we need to conduct initial research and collect experimental data. As more data are collected, more precise response surface model results should be achieved. For this project, the datasets include the composition of different MGs, the percentage of each elements, their crystalline temperature $T x$ and glass transfer temperature $\mathrm{Tg}$ need to be collected and organized. The strategy for this project is maximizing both the width of the super-cooled liquid region $\Delta T x=T x-T g$ and the crystallization of temperature $T x$.

\subsubsection{Optimization Work}

The multi-objective method was implemented by using a commercial software IOSO developed by Sigma Technology [140]. The IOSO algorithm is used because of its two main merits : (1) It does not require a large database for optimizing the target feature; (2) it calculates faster than the Neural Network algorithm [141]. In our study, we started the initial experimental dataset by searching and organizing the data from all the publications. It should be noted that a large experimental dataset for Al-Ni-Ce metallic glasses manufactured in a consistent manner is unavailable. The sample compositions found in the literatures are listed in Table 5. It should be mentioned that more Al-based amorphous alloys were reported to exist. However, the experimental information of some reported metallic glasses in this system were incomplete, and therefore they were not taken into consideration. The final input MGs had 24 datasets. The algorism requires that 
concentrations of all three alloying ingredients should be used simultaneously as design variables.

Table 5 Metallic glass experimental data collection

\begin{tabular}{cccccccc}
\hline Sample\# & $\mathrm{Al}(\%)$ & $\mathrm{Ni}(\%)$ & $\mathrm{Ce}(\%)$ & $\mathrm{T}_{\mathrm{x}}(\mathrm{K})$ & $\mathrm{T}_{\mathrm{g}}(\mathrm{K})$ & $\Delta \mathrm{Tx}=\left(\mathrm{T}_{\mathrm{x}}-\mathrm{T}_{\mathrm{g}}\right)$ & Reference \\
\hline 1 & 2 & 33 & 65 & 455 & 429.7 & 25.3 & {$[121]$} \\
2 & 2 & 28 & 70 & 420.4 & 411.8 & 8.6 & {$[121]$} \\
3 & 5 & 30 & 65 & 446.8 & 429.8 & 17 & {$[121]$} \\
4 & 5 & 25 & 70 & 420.8 & 390.4 & 30.4 & {$[121]$} \\
5 & 10 & 25 & 65 & 449.4 & 436.1 & 13.3 & {$[121]$} \\
6 & 10 & 20 & 70 & 430.1 & 410 & 20.1 & {$[121]$} \\
7 & 15 & 15 & 70 & 455.8 & 422.6 & 33.2 & {$[121]$} \\
8 & 17 & 18 & 65 & 492 & 448.7 & 43.3 & {$[121]$} \\
9 & 20 & 15 & 65 & 493.9 & 473.4 & 20.5 & {$[122]$} \\
10 & 20 & 10 & 70 & 515.8 & 466.2 & 49.6 & {$[122]$} \\
11 & 85 & 10 & 5 & 540.6 & 523.1 & 17.5 & {$[122]$} \\
12 & 85 & 9 & 6 & 552.8 & 533.1 & 19.7 & {$[122]$} \\
13 & 85 & 8 & 7 & 557.8 & 537.8 & 20 & {$[122]$} \\
14 & 85 & 11 & 4 & 526.2 & 517.3 & 8.9 & {$[122]$} \\
15 & 85 & 10 & 5 & 535.6 & 525.2 & 10.4 & {$[123]$} \\
16 & 85 & 9 & 6 & 541.3 & 528.5 & 12.8 & {$[123]$} \\
17 & 85 & 8 & 7 & 556.5 & 536.6 & 19.9 & {$[123]$} \\
18 & 85.5 & 9.5 & 5 & 537.5 & 518.6 & 18.9 & {$[123]$} \\
19 & 85.5 & 9 & 5.5 & 541.9 & 522.6 & 19.3 & {$[123]$} \\
20 & 86 & 9 & 5 & 517.8 & 503.9 & 13.9 & {$[123]$} \\
21 & 86 & 9.5 & 4.5 & 516.7 & 502.5 & 14.2 & {$[124]$} \\
22 & 86 & 8.5 & 5.5 & 527.4 & 512.2 & 15.2 & {$[124]$} \\
23 & 86 & 8 & 6 & 535.1 & 518.6 & 16.5 & {$[124]$} \\
24 & 87 & 8 & 5 & 512.8 & 500.3 & 12.5 & {$[124]$} \\
\hline
\end{tabular}


Table 6 IOSO partial optimization results

\begin{tabular}{cccc}
\hline $\mathrm{Al}(\%)$ & $\mathrm{Ni}(\%)$ & $\mathrm{Ce}(\%)$ & $\Delta T x(\mathrm{~K})$ \\
\hline 16.5 & 8 & 75.5 & 50.6 \\
16.6 & 8 & 75.4 & 50.6 \\
16.7 & 8 & 75.3 & 50.6 \\
16.7 & 8 & 75.2 & 50.6 \\
16.8 & 8 & 75.2 & 50.6 \\
16.8 & 8.1 & 75.1 & 50.6 \\
16.9 & 8 & 75.1 & 50.6 \\
16.9 & 8.1 & 75 & 50.6 \\
17.4 & 8.4 & 74.2 & 50.5 \\
17.6 & 8.4 & 74 & 50.5 \\
17.6 & 8.2 & 74.1 & 50.5 \\
17.6 & 8.4 & 73.9 & 50.5 \\
17.7 & 8.4 & 73.8 & 50.5 \\
17.8 & 8.2 & 74 & 50.5 \\
17.9 & 8.2 & 73.9 & 50.5 \\
18 & 8 & 74 & 50.5 \\
18 & 8 & 73.9 & 50.5 \\
18.1 & 8.1 & 73.9 & 50.5 \\
18.1 & 8 & 73.9 & 50.5 \\
18.2 & 8.1 & 73.7 & 50.5 \\
18.2 & 8 & 73.8 & 50.5 \\
18.2 & 8 & 73.8 & 50.4 \\
18.3 & 8.5 & 73.2 & 50.5 \\
18.3 & 8 & 73.7 & 50.4 \\
18.3 & 8.2 & 73.5 & 50.5 \\
18.3 & 8.5 & 73.1 & 50.5 \\
18.3 & 8.1 & 73.6 & 50.4 \\
18.6 & 8 & 73.4 & 50.4 \\
18.7 & 8 & 73.3 & 50.4 \\
18.8 & 8.1 & 73.1 & 50.4 \\
\hline & & &
\end{tabular}


In the datasets, there are three design variables - concentrations of $\mathrm{Al}, \mathrm{Ni}$, and $\mathrm{Ce}$ - and two simultaneous objectives maximizing parameter P1, i.e. $\Delta T x=T x-T g$, and minimizing parameter P2, i.e. $\mathrm{Tg}$. The new optimal MGs were created by using the Indirect Optimization on the basis of Self-Organization (IOSO) [135]. IOSO is used to design new materials based on nonlinear, multi-objective optimization methods. In this project, IOSO was used to find the maximum values of P1 and minimum values of P2. The collected data from Table 5 were used as an input value for IOSO. Partial optimization results after IOSO are shown in Table 6.

\subsection{Optimization Results and Experimental Evaluation}

Results of Table 6. represent the composition of the Al-Ni-Ce alloying and the simultaneously optimized values of $\Delta T x$ for optimal metallic glasses. Since the dataset is limited, the optimized design has a wider range. Table 6 provides the partial results. The best candidates that planned to be synthesized and experimentally evaluated should be selected based on additional criteria, such as an element density.

\subsubsection{Sample Selection and Preparation}

After optimization using IOSO (multi-objective, maximized $\Delta T x$, minimized $T g$ ) and Inoue Criteria results, we selected six candidates to evaluate their performance. Liao et al studied and compared the critical cooling rate and free energy of mixing $\Delta G$ of Al-based Ternary and quaternary alloys systems. They assumed that $\mathrm{Al}_{85.5} \mathrm{Ni}_{9.5} \mathrm{Ce}_{5}$ might have the better GFA than other compositions of the Al-based MG [77]. Triveno Rios studied the composition triangle of $\mathrm{Al}-\mathrm{Ni}-\mathrm{Ce}$ system and pointed that the $\mathrm{Al}_{85} \mathrm{Ni}_{8} \mathrm{Ce}_{7} \mathrm{MG}$ would have the best GFA [122]. 
Also, based on the Inoue Criteria, the bond distance of Al-Ce is 3.25, the coordination number is 17 , and the bond distance of $\mathrm{Al}-\mathrm{Ni}$ is 2.44 . If the composition of $\mathrm{Al}$ element and Ce element were similar, its inter-cluster packing would be drastically different from when the composition difference of $\mathrm{Al}, \mathrm{Ce}$ is large. We also knew that local atom disorder would highly influence the glass forming ability. As a result, we chose $\mathrm{Al}_{46} \mathrm{Ni}_{10} \mathrm{Ce}_{44}$ as a candidate to investigate its supercooled liquid region $\Delta T_{x}$.

For sample synthetization, all master ingots were prepared by arc-melting a mixture of pure $\mathrm{Ce}(99.5$ at. \%), $\mathrm{Al}(99.95$ at. \%), $\mathrm{Ni}(99.99$ at. \%) in an argon atmosphere. And each ingot was melted five times to ensure homogeneity. Using these master ingots, metallic ribbon glass with a $\sim 35 \mu \mathrm{m}$ thickness and a $\sim 3 \mathrm{~mm}$ width was prepared using a single-roller meltspinning with a copper wheel. Then, each sample was divided into the same size $5 \mathrm{~mm}$ (Length) $* 2 \mathrm{~mm}$ (Width) *35 $\mu \mathrm{m}$ (Height). The composition of six samples are $\mathrm{Al}_{20} \mathrm{Ni}_{10} \mathrm{Ce}_{70}, \quad \mathrm{Al}_{85.5} \quad \mathrm{Ni}_{9.5} \mathrm{Ce}_{5}, \quad \mathrm{Al}_{85.8} \mathrm{Ni}_{9.1} \mathrm{Ce}_{5.1}, \quad \mathrm{Al}_{46} \mathrm{Ni}_{10} \mathrm{Ce}_{44}, \quad \mathrm{Al}_{85.8} \mathrm{Ni}_{9.1} \mathrm{Ce}_{5.1}$, and $\mathrm{Al}_{46} \mathrm{Ni}_{10} \mathrm{Ce}_{44}$, respectively. In the following section, sample-X (X will be 1 to 6 ) will be used to denote each sample.

\subsubsection{Sample Initial Evaluation and Annealing}

After sample preparation, sample tests including DSC and microindentation was conducted to obtain the original values of each sample. As shown in Table 7, sample-4 had the highest hardness, which was $389(\mathrm{Hv})$. Also, its super-cooled liquid region $\Delta T_{x}$ was the highest, which was 40 K. Sample-1 shows the second highest super-cooled liquid region, which was $34 \mathrm{~K}$. Although its super-cooled liquid region was quite high, its hardness was not as high as expected. Other samples, such as sample-2 from the reference paper also have 
Table 7 Synthesized samples and their initial properties.

\begin{tabular}{cccccc}
\hline Sample \# & Composition & $\mathrm{Tg}(\mathrm{K})$ & $\mathrm{Tx}(\mathrm{K})$ & $\mathrm{Tx}-\mathrm{Tg}(\mathrm{K})$ & Hardness (Hv) \\
\hline 1 & $\mathrm{Al}_{20} \mathrm{Ni}_{10} \mathrm{Ce}_{70}$ & 415 & 449 & 34 & 211 \\
2 & $\mathrm{Al}_{85.5} \mathrm{Ni}_{9.5} \mathrm{Ce}_{5}$ & 520 & 538 & 18 & 380 \\
3 & $\mathrm{Al}_{85.8} \mathrm{Ni}_{9.1} \mathrm{Ce}_{5.1}$ & 494 & 516 & 22 & 353 \\
4 & $\mathrm{Al}_{46} \mathrm{Ni}_{10} \mathrm{Ce}_{44}$ & 530 & 570 & 40 & 389 \\
5 & $\mathrm{Al}_{16.5} \mathrm{Ni}_{8} \mathrm{Ce}_{75.5}$ & 381 & 410 & 29 & 158 \\
6 & $\mathrm{Al}_{85} \mathrm{Ni}_{8} \mathrm{Ce}_{7}$ & 546 & 564 & 18 & 252 \\
\hline
\end{tabular}

quite high hardness value. Although its super-cooled liquid region was not high enough when compared to sample-1 and sample-4, we could still check whether it could obtain an improved hardness after annealing. As a result, we selected sample-1, sample-2, sample-3, and sample-4 for the following annealing treatment to improve their hardness.

Table 8 Annealing temperatures of the selected samples

\begin{tabular}{ccccc}
\hline Samples\# & $\mathrm{Al}_{20} \mathrm{Ni}_{10} \mathrm{Ce}_{70}$ & $\mathrm{Al}_{85.5 \mathrm{Ni}_{9.5} \mathrm{Ce}_{5}}$ & $\mathrm{Al}_{85.8} \mathrm{Ni}_{9.1} \mathrm{Ce}_{5.1}$ & $\mathrm{Al}_{46} \mathrm{Ni}_{10} \mathrm{Ce}_{44}$ \\
\hline 1 & $293 \mathrm{~K}$ & $293 \mathrm{~K}$ & $293 \mathrm{~K}$ & $293 \mathrm{~K}$ \\
2 & $363 \mathrm{~K}$ & $372 \mathrm{~K}$ & $373 \mathrm{~K}$ & $373 \mathrm{~K}$ \\
3 & $393 \mathrm{~K}$ & $473 \mathrm{~K}$ & $423 \mathrm{~K}$ & $473 \mathrm{~K}$ \\
4 & $423 \mathrm{~K}$ & $513 \mathrm{~K}$ & $483 \mathrm{~K}$ & $543 \mathrm{~K}$ \\
5 & $453 \mathrm{~K}$ & $543 \mathrm{~K}$ & $523 \mathrm{~K}$ & $573 \mathrm{~K}$ \\
6 & $483 \mathrm{~K}$ & $593 \mathrm{~K}$ & $553 \mathrm{~K}$ & $603 \mathrm{~K}$ \\
\hline
\end{tabular}

In the annealing processing, the details have been introduced in Chapter 2. In this experiment, each metallic glass sample was loaded in a quartz capillary and kept under 
vacuum at lower $10^{-5}$ Torr to reduce the possibility of oxidation during the annealing heat treatment. A Fisher Scientific oven was used to heat the sample at a designated temperature for 30 mins. The annealing temperature was decided by the initial crystalline temperature Tx of each sample tested by DSC. The first five annealing temperatures were below the $T x$ and the last one was above the Tx. Table 8 shows the details of the annealing temperature for each candidate. All the annealing procedures were performed at the Center for the Study of Matter at Extreme Conditions (CeSMEC), FIU.

\subsection{Materials Characterization}

The X-ray diffraction studies were carried out at the Advanced Photon Source (APS) beamline 13-ID-D, Argonne National Laboratory (ANL). The XRD patterns were collected for 10 seconds for each sample. The wavelength $\lambda$ of X-ray was $0.3344 \AA$ and the exposure time for each frame was $10 \mathrm{sec}$. The hardness of the samples was measured using the LECO’s LM Microindentation Hardness Testing System. The microindentation tests were carried out at $25 \mathrm{~g}$ loads and a $10 \mathrm{~s}$ dwelling time on all samples. Nine Vickers indentations were placed on each sample with a three by three array, and sufficient space was kept between indents to avoid the potential plastic deformation zone overlapping. The averaged hardness values and the deviations of the six samples were calculated. The microindentation tests were performed at the Advanced Materials Engineering Research Institute (AMERI), FIU.

\subsection{Results and Discussion}

The left part of Figure 21-24 shows the XRD patterns of samples at different annealing temperatures of $\mathrm{Al}_{20} \mathrm{Ni}_{10} \mathrm{Ce}_{70}, \mathrm{Al}_{85.5} \mathrm{Ni}_{9.5} \mathrm{Ce}_{5}, \mathrm{Al}_{85.8} \mathrm{Ni}_{9.1} \mathrm{Ce}_{5}$ and $\mathrm{Al}_{46} \mathrm{Ni}_{10} \mathrm{Ce}_{44}$. From each figure, we observed that all the samples had no sharp peak at the beginning. When the 
annealing temperature was raised to their crystallization temperature, sharp peaks were observed. When the temperature was higher than the crystallization temperature, all the amorphous metallic glass was transferred to the crystallization structure. From the position of the peak, which were identified as $\mathrm{Al}_{5} \mathrm{CeNi}_{2}$ for sample $\mathrm{Al}_{20} \mathrm{Ni}_{10} \mathrm{Ce}_{70}, \mathrm{AlCeNi}+\mathrm{Al}_{3} \mathrm{CeNi}_{2}$ for sample $\mathrm{Al}_{85.5} \mathrm{Ni}_{9.5} \mathrm{Ce}_{5}, \mathrm{AlCeNi}$ for sample $\mathrm{Al}_{85.8} \mathrm{Ni}_{9.1} \mathrm{Ce}_{5}$, and $\mathrm{AlCeNi}+\mathrm{AlCe}_{3}$ for sample $\mathrm{Al}_{46} \mathrm{Ni}_{10} \mathrm{Ce}_{44}$. The initial hardness for $\mathrm{Al}_{20} \mathrm{Ni}_{10} \mathrm{Ce}_{70}, \mathrm{Al}_{85.5} \mathrm{Ni}_{9.5} \mathrm{Ce}_{5}, \mathrm{Al}_{85.8} \mathrm{Ni}_{9.1} \mathrm{Ce}_{5}$ and $\mathrm{Al}_{46} \mathrm{Ni}_{10} \mathrm{Ce}_{44}$ were $211 \mathrm{Hv}, 380 \mathrm{Hv}, 353.2 \mathrm{Hv}$, and $389 \mathrm{Hv}$, respectively. In the lowtemperature range, the hardness values were almost unchanged for the sample annealed below $373 \mathrm{~K}$. The hardness increased slowly by $5-15 \%$ when the annealing temperature increased. When the annealing temperature was close to their crystallization temperature, the hardness values of all the samples reached the highest values. The hardness values were $\sim 85 \%$ higher compared to the as-received samples. Then, the hardness of the annealed sample was going down when the annealing temperature was raised to a temperature over their crystallization temperature. 

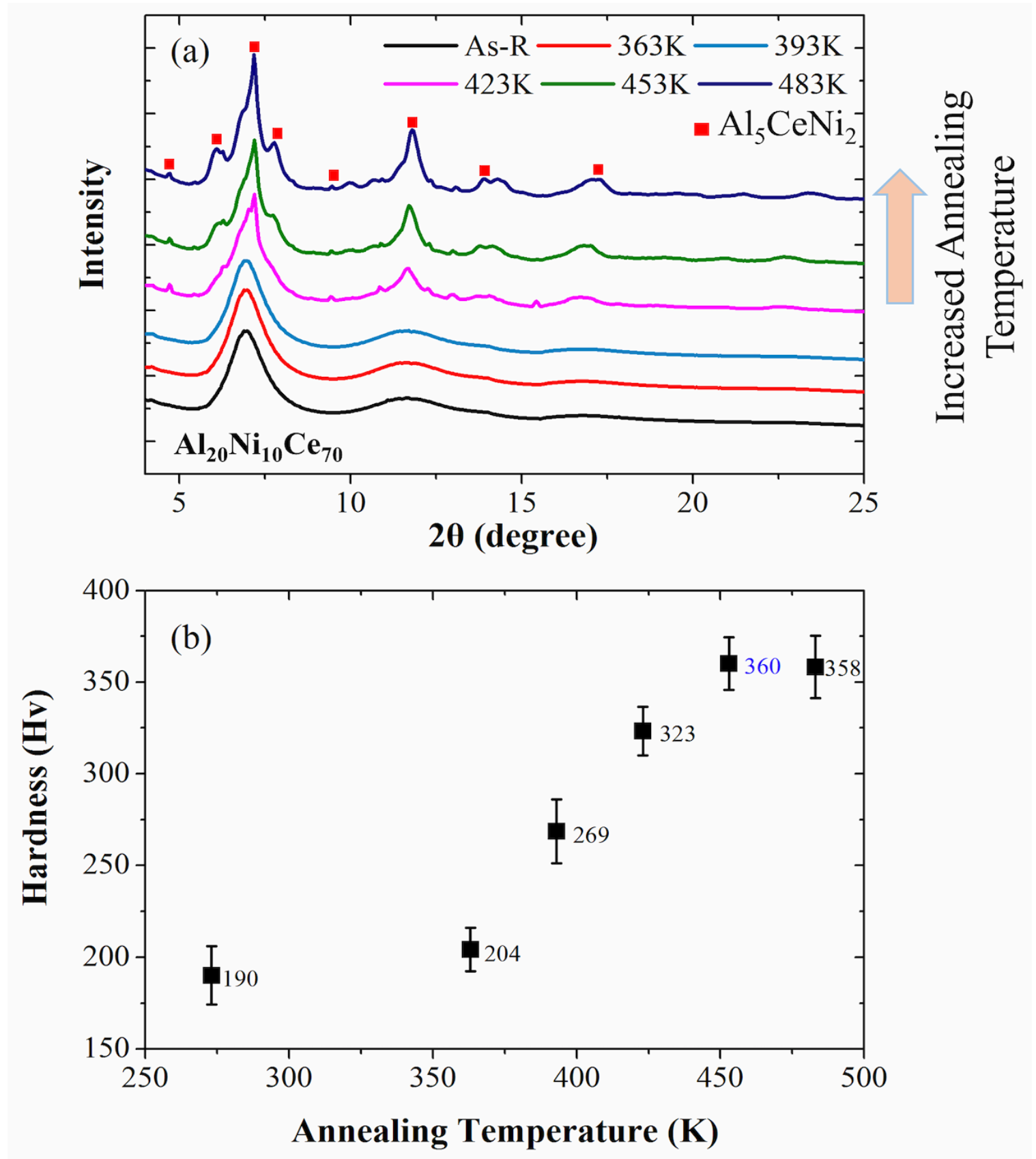

Figure 24 (a) the XRD patterns of $\mathrm{Al}_{20} \mathrm{Ni}_{10} \mathrm{Ce}_{70}$ (Wavelength $\lambda$ is $0.3344 \AA$ and exposure time is $10 \mathrm{sec}$ ), and (b) the average hardness values (Hv) of the $\mathrm{Al}_{20} \mathrm{Ni}_{10} \mathrm{Ce}_{70}$ sample with annealing temperatures at $363 \mathrm{~K}, 393 \mathrm{~K}, 423 \mathrm{~K}, 453 \mathrm{~K}, 483 \mathrm{~K}$, respectively. 

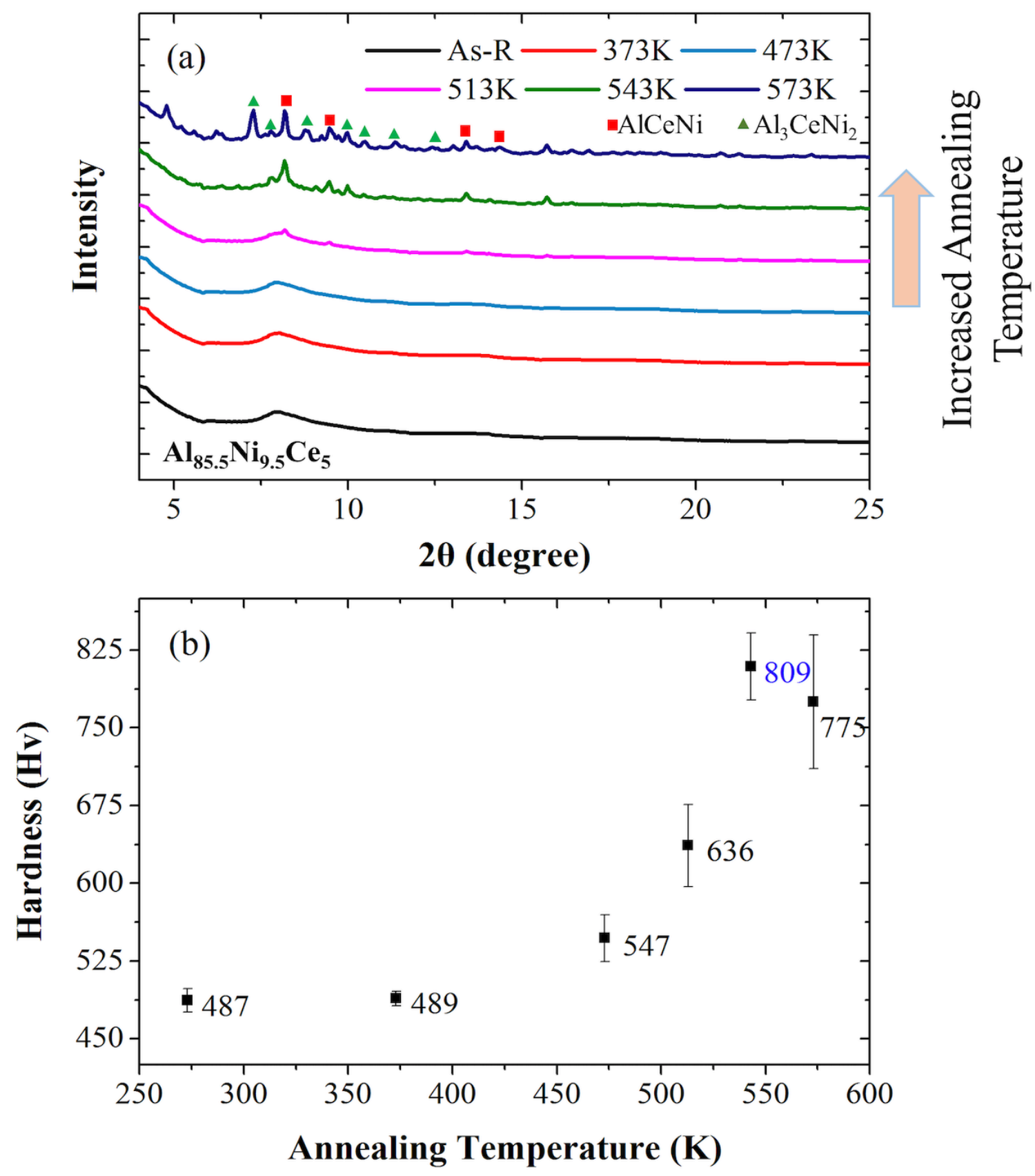

Figure 25 (a) the XRD patterns of $\mathrm{Al}_{85.5} \mathrm{Ni}_{9.5} \mathrm{Ce}_{5}$ (Wavelength $\lambda$ is $0.3344 \AA$, exposure time is $10 \mathrm{sec})$ and (b)the average hardness values $(\mathrm{Hv})$ of the $\mathrm{Al}_{20} \mathrm{Ni}_{10} \mathrm{Ce}_{70}$ sample with annealing temperatures at $373 \mathrm{~K}, 473 \mathrm{~K}, 513 \mathrm{~K}, 543 \mathrm{~K}, 573 \mathrm{~K}$, respectively. 

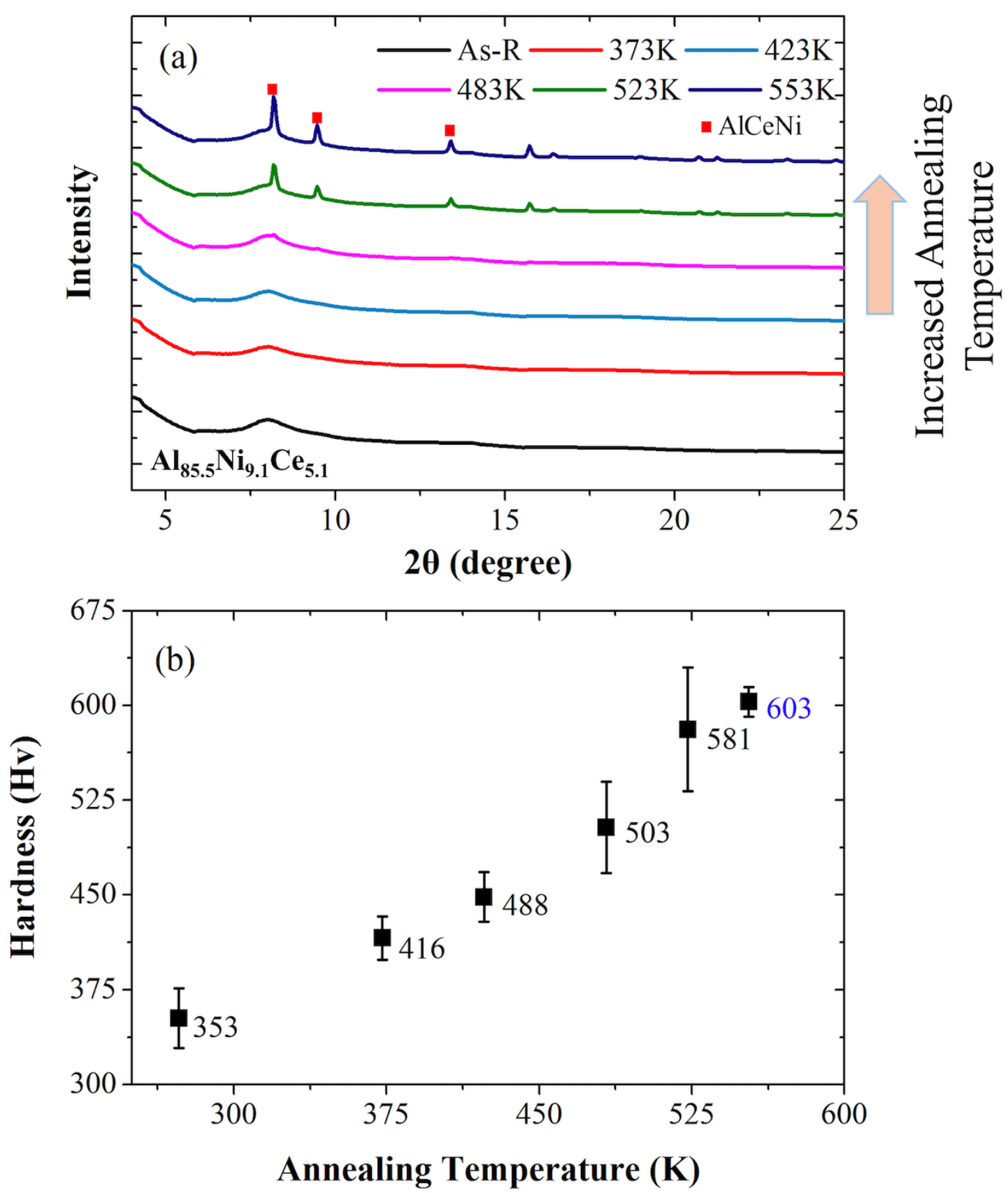

Figure 26 Top is the XRD patterns of $\mathrm{Al}_{85.8} \mathrm{Ni}_{9.1} \mathrm{Ce}_{5.1}$ (Wavelength $\lambda$ is $0.3344 \AA$, exposure time is $10 \mathrm{sec}$ ); Bottom are the average hardness values (HV) of the $\mathrm{Al}_{20} \mathrm{Ni}_{10} \mathrm{Ce}_{70}$ sample with annealing temperatures at $373 \mathrm{~K}, 423 \mathrm{~K}, 483 \mathrm{~K}, 523 \mathrm{~K}, 553 \mathrm{~K}$, respectively. 

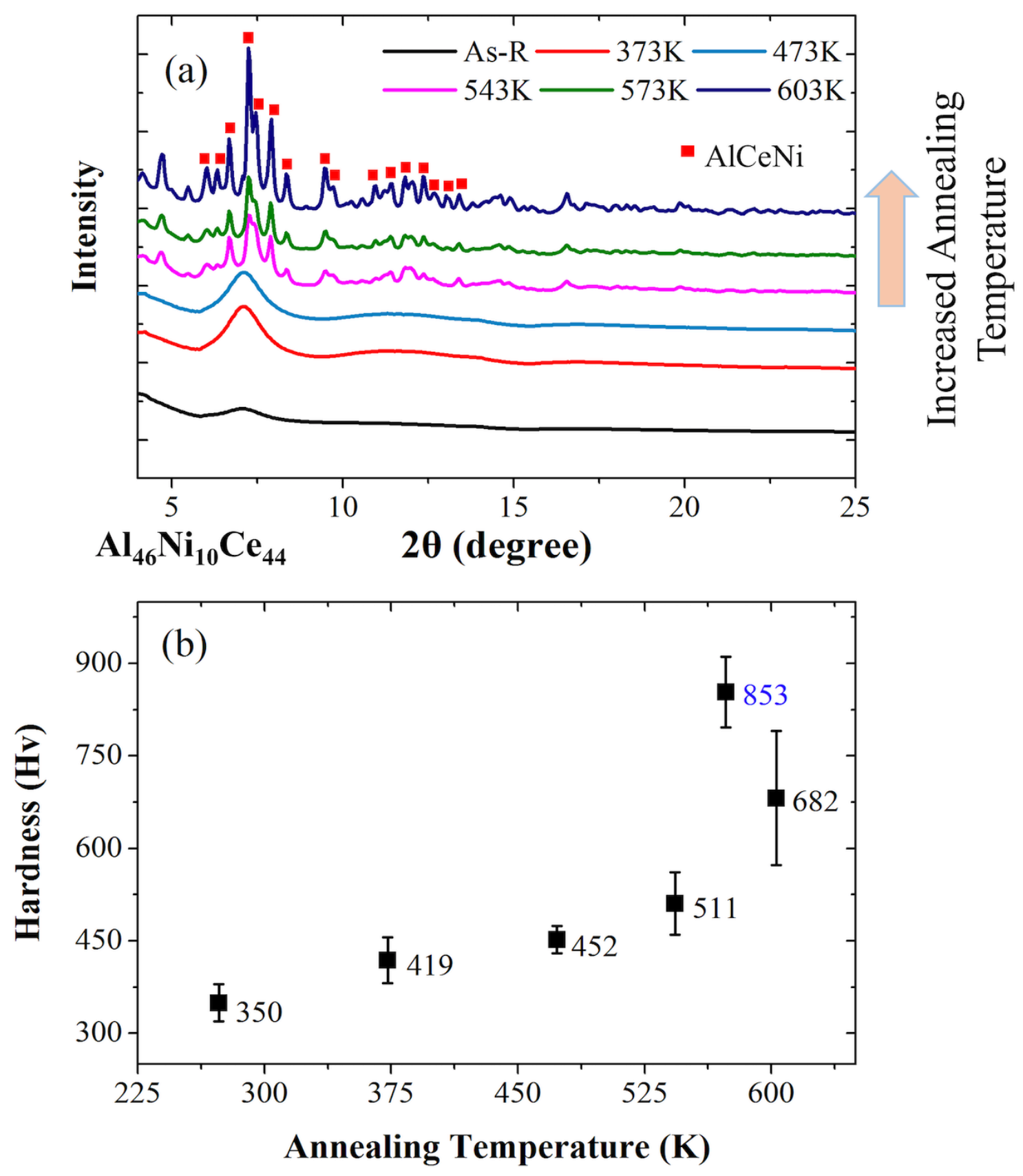

Figure 27 Top is the XRD patterns of $\mathrm{Al}_{46} \mathrm{Ni}_{10} \mathrm{Ce}_{44}$ (Wavelength $\lambda$ is $0.3344 \AA$, exposure time is $10 \mathrm{sec}$ ); Bottom are the average hardness values (HV) of the $\mathrm{Al}_{20} \mathrm{Ni}_{10} \mathrm{Ce}_{70}$ sample with annealing temperatures at $373 \mathrm{~K}, 473 \mathrm{~K}, 523 \mathrm{~K}, 573 \mathrm{~K}, 603 \mathrm{~K}$, respectively. 
From Figure 25, we found that compared to other Al-Ni-Ce samples, sample $\mathrm{Al}_{46} \mathrm{Ni}_{10} \mathrm{Ce}_{44}$ had a very outstanding supercooled liquid region value. At the same time, most publications just focused on the Al-based MG (at. \% of $\mathrm{Al}>80 \%$ ) or Ce-based MG (at. \% of $\mathrm{Ce} \%>70$ ). In the figure, the black color dots are data from publication, the green color dot is multi-objective optimization result and the red color dot is Inoue Criteria predication result.

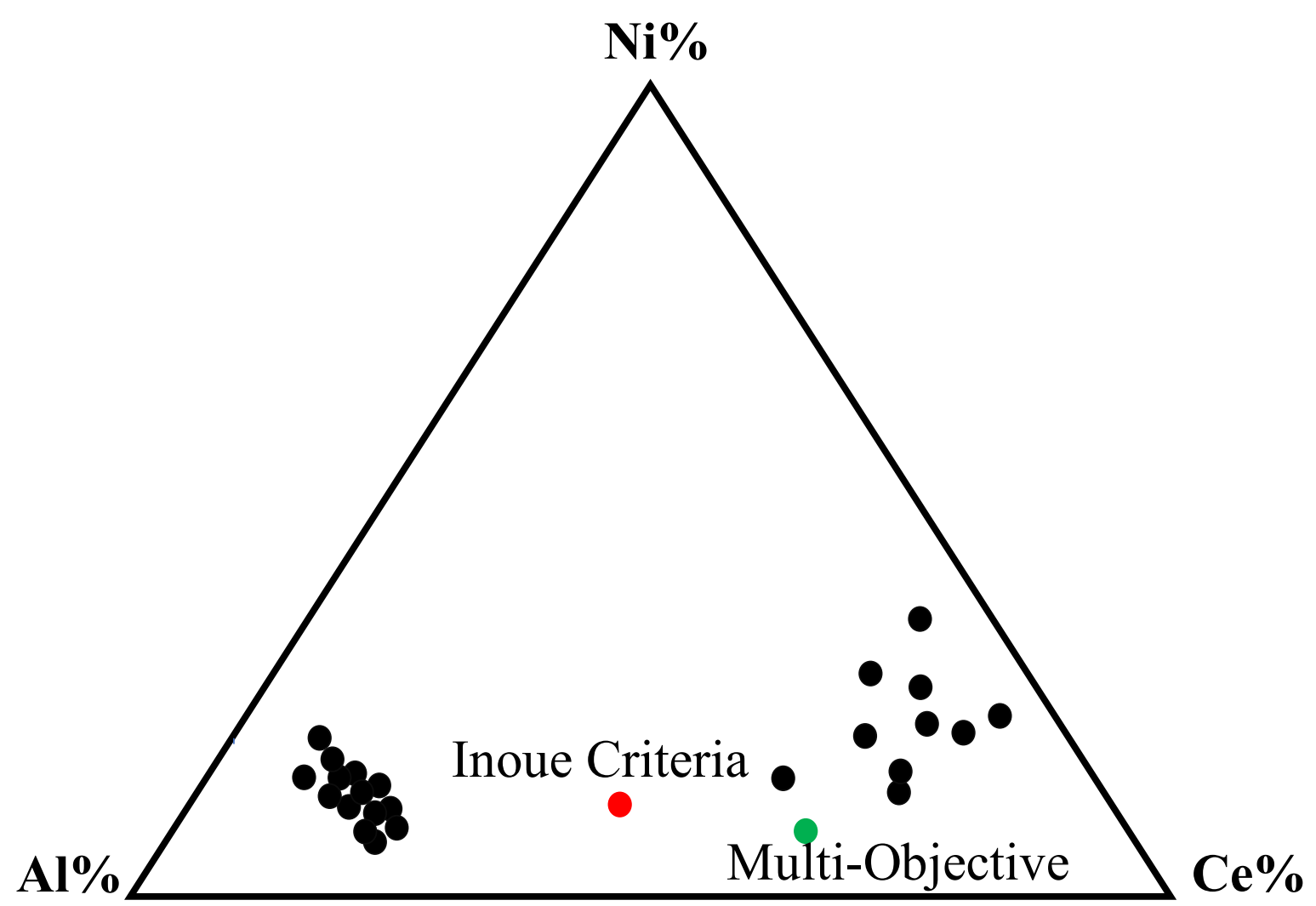

Figure 28 The composition map for Al-based MG alloys areas. 
Inoue Criteria indicated when the composition percentage (atom ratio) of $\mathrm{Al}$ and $\mathrm{Ce}$ is similar, size difference in the volume would be reach the max. From topological aspect, this would help improve the glass forming ability. $\mathrm{Al}_{46} \mathrm{Ni}_{10} \mathrm{Ce}_{44}$ is chosen as a candidate. Since the dataset for multi-objective method is limited, the limited dataset would result in the local optimum. This is the reason multi-objective result is not the best. But Inoue Criteria gave the global optimum result.

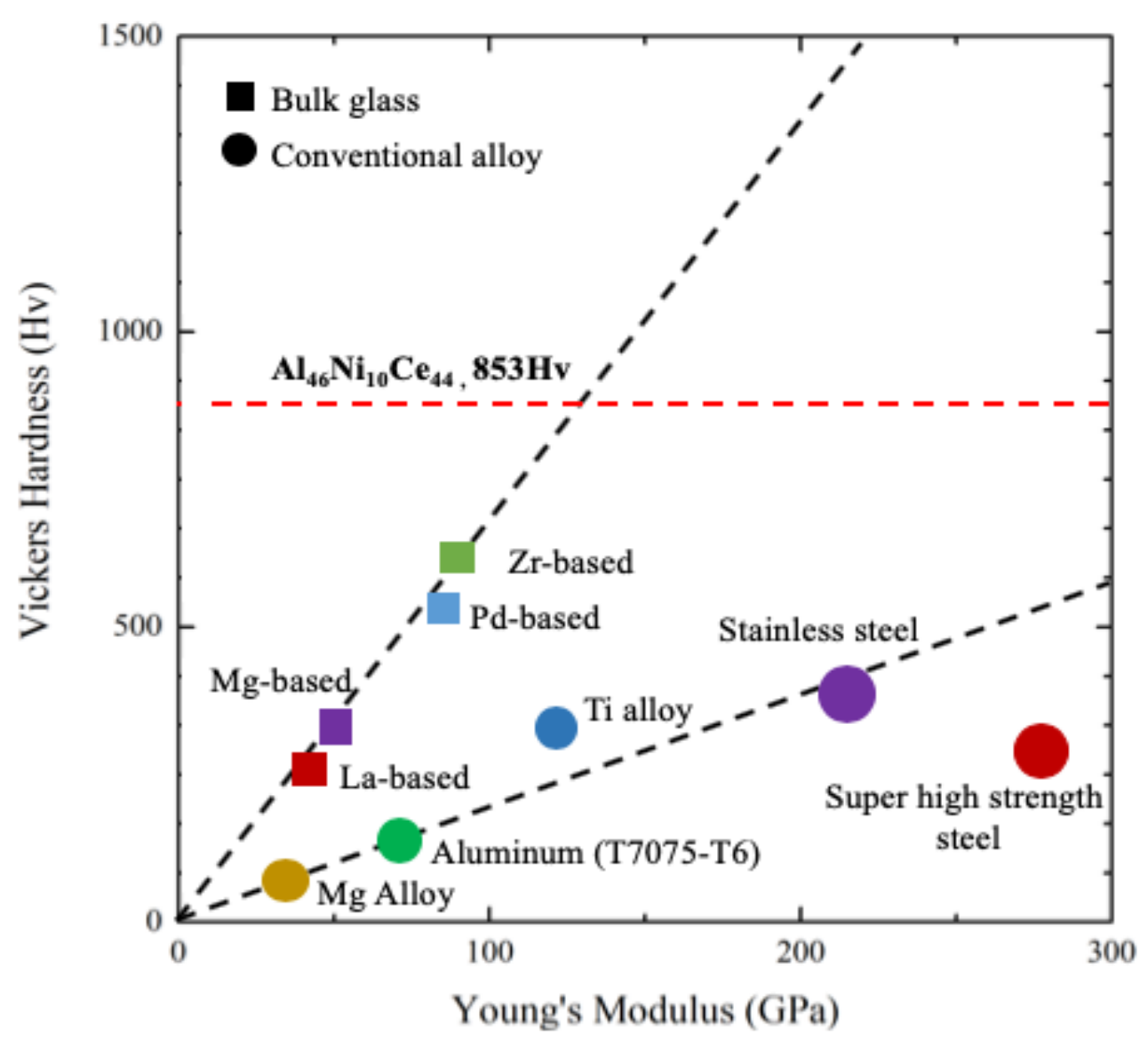

Figure 29 The hardness of the metallic glass $\mathrm{Al}_{46} \mathrm{Ni}_{10} \mathrm{Ce}_{44}$ after annealing shows the excellent mechanical property compared to other MG system or other crystalline alloys [126]. 
Figure 26 shows the data of Young's modulus versus Vickers hardness of different element MG systems as well as some widely used crystalline alloys. From this figure, we found that after the annealing procedure, sample $\mathrm{Al}_{46} \mathrm{Ni}_{10} \mathrm{Ce}_{44}$ alloy had the highest hardness. That means the annealing can introduce high density of grain boundary and it would improve the mechanical property significantly.

\subsection{Conclusion}

Inoue Criteria successfully predicted the Al-Ni-Ce ternary MG composition with the optimized $\Delta T x$, which represents the greater stability of glass against crystallization. The sample preparation and the experimental results have confirmed the accuracy of the prediction. In addition, the composition Al-Ni-Ce metallic glass with the highest initial hardness was also located. The evolution of the crystalline structure of Al-Ni-Ce samples after annealing at different temperatures has been investigated by high energy X-ray diffraction. The hardness of each sample was significantly improved by the annealing treatment. Obtained X-ray diffraction results and microindentation values show that when the annealing temperature is close to $T x$, the hardness of the sample reaches the highest value.

The highest hardness value, $853(\mathrm{Hv})$, was achieved when annealed $\mathrm{Al}_{46} \mathrm{Ni}_{10} \mathrm{Ce}_{44}$ at $573 \mathrm{~K}$ for 30 mins. This value is significantly high compared to the published hardness of bulk MG systems, such as Zr-based, Pd-based and Mg-based metallic glasses, as well as conventional alloys such as stainless steel and super high strength steel. Also, the 
supercooled liquid region of $\mathrm{Al}_{46} \mathrm{Ni}_{10} \mathrm{Ce}_{44}$ could reach $40 \mathrm{~K}$, this is the highest value achieved in the current study. The optimized $\mathrm{Al}_{46} \mathrm{Ni}_{10} \mathrm{Ce}_{44}$ metallic glass and its composite should be one of the best candidates for future mechanical engineering application. 


\section{CHAPTER 6.SHORT-RANGE ORDER RESEARCH IN AL-NI-CE METALLIC GLASSES AND THEIR COMPOSITES}

\subsection{Introduction}

Metallic glass alloy exhibits very unique mechanical, magnetic and corrosion resistance properties because of a unique structure without a long-range crystalline order. The outstanding properties attract great research interests regarding their application possibility in medical parts, sporting goods, automatic components, airspace gear, and so on $[3,9,10,14]$.

The first Au-Si metallic glass was discovered in 1960s [1]. After that, researchers developed the preparation method for producing metallic glass in different geometrical shapes: thin film, ribbon, or even bulk. We also invented several approaches to improve the properties of metallic glasses. Annealing is one of the most effective ways to improve the hardness of MGs. However, the mechanical properties such as strengths, elastic elongations, and bending ductility would be reduced when the metallic glass were annealed.

To investigate the structures of the materials with a long-range order, researchers used Xray diffraction (XRD), which is one of the most common and effective method. However, $\mathrm{XRD}$ is not an effective way for studying materials, such as metallic glass alloys, which do not possess the long-range order. An alternative structural research technique - named "pair distribution function" (PDF) — could be used. The rationale is that PDF is a modeling method in a real space, rather than the reciprocal-space powder diffraction data. The PDF could clearly reflect the short-range order in a material directly $[127,128]$. 
To further understand the mechanism of the annealing process and the effects of alloy compositions on the initial hardness, we chose to study the local atomic structure of ternary Al-Ni-Ce using the PDF analysis. Our research focuses on the effect of annealing temperature on the microstructure evolution of $\mathrm{Al}-\mathrm{Ni}-\mathrm{Ce}$ amorphous alloys with different compositions.

In this research, two parameters related to Al-Ni-Ce metallic glasses were studied. One parameter was the effect of the Ni in the Al-based MG. Since the local order of the MG depended on which transition element was contained in the MG. Moreover, we could study the short-range order or even the medium-range order during different types of temperature annealing processing. The second feature was the influence of the rare earth (RE) element (Ce). Because the significant atom size differences of various elements in the MG could result in the atom order with a higher packing fraction compared to a similar atom size of different elements [158], the size of the Ce atom was much larger than that of other elements. This result would influence both initial hardness and glass forming ability [101].

In addition, a comparative study of the short-range order of Al-Ni-Ce amorphous samples with one nominal composition is discussed. The short-range order of metallic glass samples will help us understand the different origin of local order and the effects of local order to the final mechanical properties of metallic glass samples. [129]. 


\subsection{Experimental process and data analyses}

The Al-Ni-Ce metallic glass was prepared from purity elements (Al with 99.99\%, Ni with $99.95 \%$, and Ce with 99.95\%). The amorphous ribbons were synthesized by the rapid meltspinning method. The size of the ribbons produced was $35 \mu \mathrm{m}$ thick, $2 \mathrm{~mm}$ wide. XRD data were collected at the Advanced Photon Source (APS) Beamline 13-ID-D at Argonne National Lab (ANL). With an ultra-high brilliance and a small sized, focused white/monochromatic beam (resolution $10^{-4}$, flux $10^{13}$ at $10 \mathrm{kev}$ ), diffraction data were collected by using high energy synchrotron X-ray diffraction with a maximum value of $Q=4 \pi^{\sin \theta} / \lambda=37.58 \AA^{-1}(\lambda=0.3344 \AA)$.

For each MG sample, a background image was obtained under the same conditions and then subtracted from XRD images. $I_{m}(Q)$ data were corrected from inelastic scattering and normalized by using Fit2D. PDFgetX3 software was used to obtain the total structure factors and reduced atomic distribution function.

\subsection{Results and discussion}

We chose four Al-Ni-Ce metallic glass with different compositions to conduct PDF analysis. The details of the sample were shown in Table 9. 
Table 9 The properties of four samples $\left(\mathrm{Al}_{20} \mathrm{Ni}_{10} \mathrm{Ce}_{70}, \mathrm{Al}_{46} \mathrm{Ni}_{10} \mathrm{Ce}_{44}, \mathrm{Al}_{86.5} \mathrm{Ni}_{9.5} \mathrm{Ce}_{5}\right.$ and $\mathrm{Al}_{85.8} \mathrm{Ni}_{9.1} \mathrm{Ce}_{5.1}$ ): experimental measured super-cooled liquid region ( $\mathrm{Tx}-\mathrm{Tg}$ ), initial hardness and hardness after annealing.

\begin{tabular}{lccc} 
Composition & Tx-Tg(K) & Initial Hardness (Hv) & $\begin{array}{c}\text { Hardness after } \\
\text { Annealing (Hv) }\end{array}$ \\
\hline $\mathrm{Al}_{20} \mathrm{Ni}_{10} \mathrm{Ce}_{70}$ & 34 & 211 & 360 \\
$\mathrm{Al}_{86.5} \mathrm{Ni}_{9.5} \mathrm{Ce}_{5}$ & 18 & 380 & 809 \\
$\mathrm{Al}_{85.8} \mathrm{Ni}_{9.1} \mathrm{Ce}_{5.1}$ & 22 & 353 & 580 \\
$\mathrm{Al}_{46} \mathrm{Ni}_{10} \mathrm{Ce}_{44}$ & 40 & 389 & 853 \\
\hline
\end{tabular}

From Table 9, sample $\mathrm{Al}_{46} \mathrm{Ni}_{10} \mathrm{Ce}_{44}$ has the highest initial hardness, and its hardness after annealing is the highest among these four samples. Meanwhile, its supercooled liquid region $T_{x}-T_{g}\left(\Delta T_{x}\right)$ is also the highest, which is $40.04 \mathrm{~K}$. Higher value of the supercooled liquid region indicates a better glass forming ability (GFA). GFA is one of the most important features influencing the size of the metallic glass when manufacturing the metallic glass. The second sample with a larger super-cooled liquid region is $\mathrm{Al}_{20} \mathrm{Ni}_{10} \mathrm{Ce}_{70}$, which is $34.4 \mathrm{~K}$. The composition of this sample is optimized from reference has mentioned in chapter 5. Although its super-cooled liquid region is lower than $\mathrm{Al}_{46} \mathrm{Ni}_{10} \mathrm{Ce}_{44}$, it is still higher than the recently reported results [130]. Other two sample, $\mathrm{Al}_{86.5} \mathrm{Ni}_{9.5} \mathrm{Ce}_{5}$ and $\mathrm{Al}_{85.8} \mathrm{Ni}_{9.1} \mathrm{Ce}_{5.1}$ from the reference paper also have very high hardness values.

Also, we investigated the total structure factors as well as the short-range order in each of the Al-Ni-Ce metallic glasses. By using X-ray diffraction (XRD) and indentation 
measurement, we attempted to illustrate the relationship between the element concentration, super-cooled liquid region, and initial hardness. The correlation will guide us in further optimizing metallic glass properties.

Then, the short-range order analysis of $\mathrm{Al}_{46} \mathrm{Ni}_{10} \mathrm{Ce} 44$ with different annealing temperatures was studied. The samples were annealed at $373 \mathrm{~K}, 473 \mathrm{~K}, 543 \mathrm{~K}, 643 \mathrm{~K}$, and $673 \mathrm{~K}$, respectively. The purpose of this part of the study is to help us figure out the mechanism of annealing treatment in improving the hardness of the metallic sample.

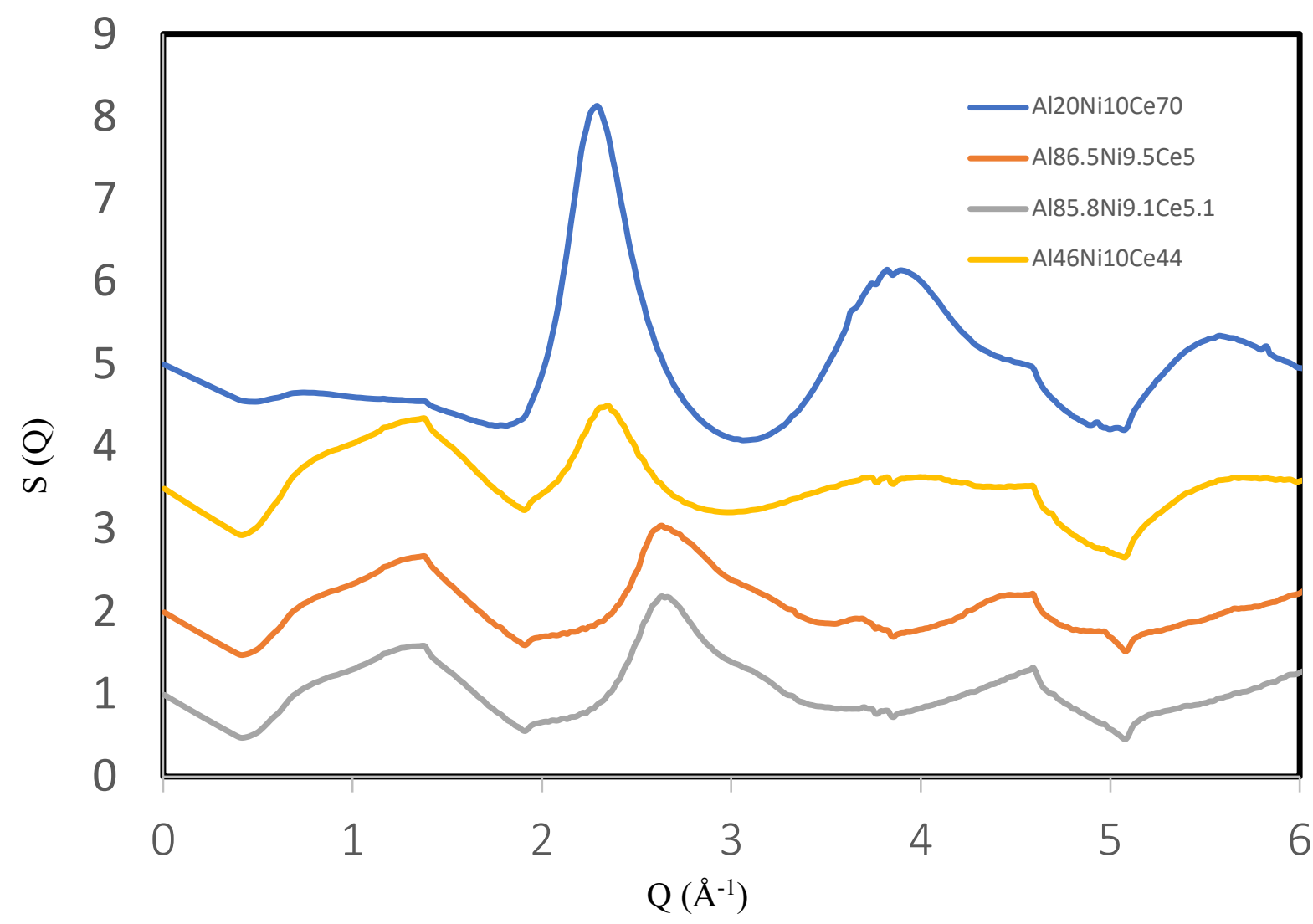

Figure 30 Total structure factors $\mathrm{S}(\mathrm{Q})$ obtained from X-ray diffraction for amorphous $\mathrm{Al}_{20} \mathrm{Ni}_{10} \mathrm{Ce}_{70}, \mathrm{Al}_{46} \mathrm{Ni}_{10} \mathrm{Ce}_{44}, \mathrm{Al}_{86.5} \mathrm{Ni}_{9.5} \mathrm{Ce}_{5}$ and $\mathrm{Al}_{85.8} \mathrm{Ni}_{9.1} \mathrm{Ce}_{5.1}$. 
Normally, there should be a prepeak on the left part of the main first peak [128]. As shown in Figure 27, samples $\mathrm{Al}_{46} \mathrm{Ni}_{10} \mathrm{Ce}_{44}, \mathrm{Al}_{86.5} \mathrm{Ni}_{9.5} \mathrm{Ce}_{5}$, and $\mathrm{Al}_{85.8} \mathrm{Ni}_{9.1} \mathrm{Ce}_{5.1}$ have the general similar features and all of these three samples have a prepeak at around 1.6 to $1.7 \AA^{-1}$. The prepeak for sample $\mathrm{Al}_{20} \mathrm{Ni}_{10} \mathrm{Ce}_{70}$ is not obvious. Then, a subsequent second peak followed the first main peak, and the following one is the third peak. The intensity and the number of the peaks highly depend on the structure of the sample.

Figure 27 shows the total structure factors $\mathrm{S}(\mathrm{Q})$ obtained from XRD and processed by Fit2D. First, the different composition for each sample would strongly affect the total structure factors, especially when the concentration of Ce is high. Also, samples with similar compositions would have very different peak positions. When the concentration of Ce is relatively high, left shift on the first main peak was observed. Since the atomic radius of Ce is larger than other two elements, a higher concentration of Ce will lead to an increase of the average interatomic distance. Second, the prepeak of $\mathrm{Al}_{20} \mathrm{Ni}_{10} \mathrm{Ce}_{70}$ has the least intensity than the prepeak of other samples. Since the prepeak is highly related to those clusters, which are formed with the strong interaction between atoms, a higher concentration of Ce in alloy renders a more homogenous local structure than the alloy with a high concentration of $\mathrm{Al}$. Moreover, the prepeaks of samples $\mathrm{Al}_{20} \mathrm{Ni}_{10} \mathrm{Ce}{ }_{70}, \mathrm{Al}_{46} \mathrm{Ni}_{10} \mathrm{Ce}_{44}$, $\mathrm{Al}_{86.5} \mathrm{Ni}_{9.5} \mathrm{Ce}_{5}$, and $\mathrm{Al}_{85.8} \mathrm{Ni}_{9.1} \mathrm{Ce}_{5.1}$ are located at $1.36-1.38 \AA^{-1}$; this value is very close to the similar prepeak obtained by previous study $-1.34-1.36 \AA^{-1}[131]$.

There are two theoretical explanations for the mechanisms of Al-TM and Al-Re interactions. The first theory was proposed by Zhang et. al [140]. They used $\mathrm{Al}_{80} \mathrm{Ni}_{20}$ metallic glass to analyze the mechanism of Al-Tm interaction and concluded that in the 
total structure factor, the contribution to the prepeak resulted from the heteroatomic interaction between $\mathrm{Al}$ and $\mathrm{TM}$. There was minimal size effect bought by $\mathrm{Al}$ and $\mathrm{TM}$. Another theory was proposed by Hsieh et al. [132]. They collected experimental X-ray diffraction data from amorphous Al-Fe-Ce metallic glass. Their results indicated that perpeak was only influenced by Al-Re.

In our study, it was shown that the position of the prepeak was different with the concentration of four different metallic glasses. These observations are well explained by the theory that the size effects are mainly caused by the Ce containing amorphous alloys.

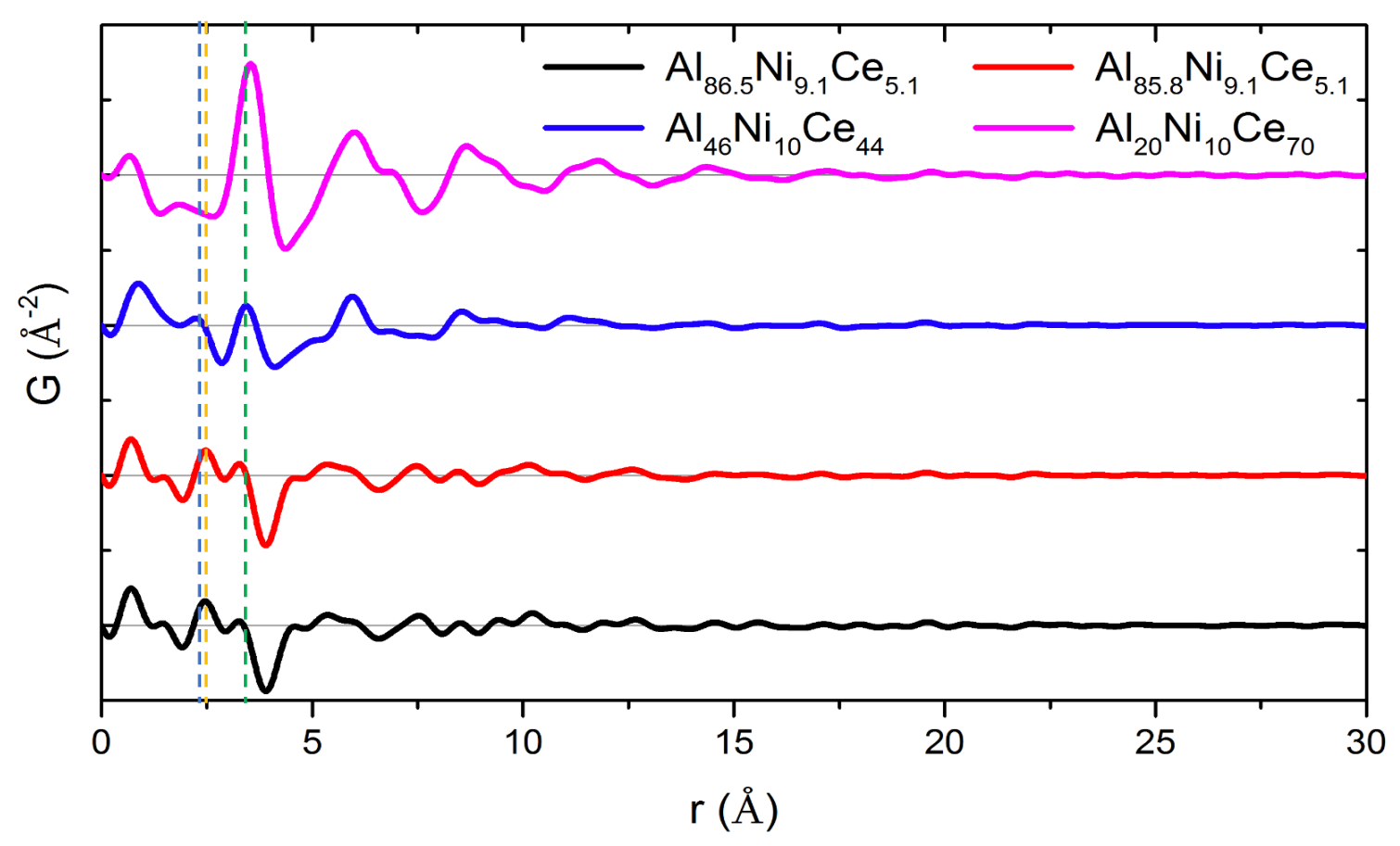

Figure 31 Reduced atomic distribution function, G(r), for four amorphous alloys. The vertical blue dash line is used to mark the position of Al-Ni pair, yellow dash line is marked the position of Al-Al pair and green dash line is for Al-Ce pair. The intensity of $\mathrm{Al}-\mathrm{Ni}$ and $\mathrm{Al}-\mathrm{Ce}$ are shifted with different composition. 
The reduced atomic distribution function, G(r), of four alloys was shown in Figure 28 . Table 10 shows the positions of the maxima of the reduced atomic distribution function. The first peak in the figure is the count of those contributions from the closest atoms. The peak positions were determined using Gaussian peak profile fitting.

There are three contributions [58]:

- Al-Ni pair ideally should be at $2.68 \AA ̊$;

- $\quad$ Al-Al pair ideally should be at $2.86 \AA$ A;

- Al-Ce pair ideally should be at $3.24 \AA$.

Table 10 Peak positions of the pair distribution function, G(r), for the Al-based MGs

Peak Position $(\AA ̊)$

\begin{tabular}{|c|c|c|c|c|c|c|}
\hline & 1 & 2 & 3 & 4 & 5 & 6 \\
\hline $\mathrm{Al}_{20} \mathrm{Ni}_{10} \mathrm{Ce}_{70}$ & & $3.46 \pm 0.04$ & & $6.1 \pm 0.04$ & $6.908 \pm 0.08$ & $8.87 \pm 0.08$ \\
\hline $\mathrm{Al}_{86.5} \mathrm{Ni}_{9.5} \mathrm{Ce}_{5}$ & $2.57 \pm 0.02$ & $3.38 \pm 0.04$ & $4.68 \pm 0.04$ & $5.52 \pm 0.04$ & $7.58 \pm 0.08$ & $8.54 \pm 0.08$ \\
\hline $\mathrm{Al}_{85.8} \mathrm{Ni}_{9.1} \mathrm{Ce}_{5.1}$ & $2.58 \pm 0.02$ & $3.39 \pm 0.04$ & $4.72 \pm 0.04$ & $5.51 \pm 0.04$ & $7.63 \pm 0.08$ & $8.6 \pm 0.08$ \\
\hline $\mathrm{Al}_{46} \mathrm{Ni}_{10} \mathrm{Ce}_{44}$ & $2.41 \pm 0.02$ & $3.5 \pm 0.04$ & $4.97 \pm 0.04$ & $6.05 \pm 0.04$ & $6.99 \pm 0.08$ & $7.78 \pm 0.08$ \\
\hline
\end{tabular}

For samples $\mathrm{Al}_{46} \mathrm{Ni}_{10} \mathrm{Ce}_{44}$ and $\mathrm{Al}_{86.5} \mathrm{Ni}_{9.5} \mathrm{Ce}_{5}$, the fit of the first peak in Figure 28 provides contributions with a clear split because the large value of Ce radius lead to long Al-Ce bond. For samples $\mathrm{Al}_{20} \mathrm{Ni}_{10} \mathrm{Ce}_{70}$ and $\mathrm{Al}_{46} \mathrm{Ni}_{10} \mathrm{Ce}_{44}$, their first peak did not split—meaning 
their short-range pairs were dominated by a short $\mathrm{Al}-\mathrm{Ni}$ or $\mathrm{Al}-\mathrm{Al}$ bond. This would be the reason why both of them have a better initial super-cooled liquid region $\left(\Delta T_{x}\right)$ than $\mathrm{Al}_{46} \mathrm{Ni}_{10} \mathrm{Ce}_{44}$ and $\mathrm{Al}_{86.5} \mathrm{Ni}_{9.5} \mathrm{Ce}_{5}$.

A more detailed analyses with three components show the following: Al-Ni distance is 2.41 $\AA$, Al- $\mathrm{Al}$ distance is $2.58 \AA$, Al-Ce distance is $3.5 \AA$, and the Al-Ni-Ce MGs are close to each other.

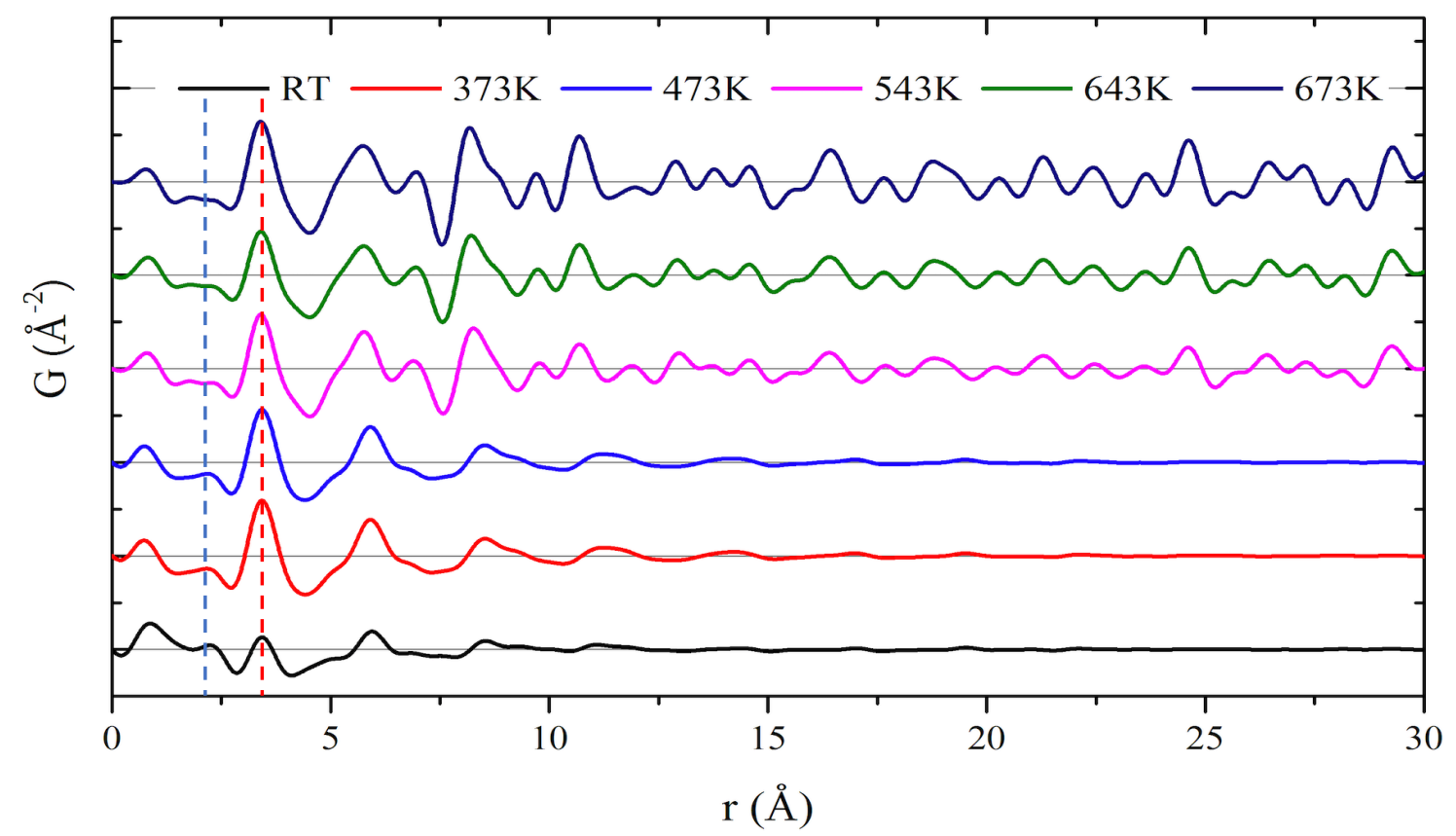

Figure 32 Reduced atomic distribution function, $\mathrm{G}(\mathrm{r})$, for amorphous $\mathrm{Al}_{46} \mathrm{Ni}_{10} \mathrm{Ce}_{44}$ at room temperature (RT) and after annealing at $373 \mathrm{~K}, 473 \mathrm{~K}, 543 \mathrm{~K}, 643 \mathrm{~K}$ and $673 \mathrm{~K}$, respectively. The vertical blue dash line is the position of first main peak, red dash line is the position of the second peak for each sample.

Figure 29 shows the reduced atomic distribution function for $\mathrm{Al}_{46} \mathrm{Ni}_{10} \mathrm{Ce}_{44}$ metallic glass. The samples were annealed at $373 \mathrm{~K}, 473 \mathrm{~K}, 543 \mathrm{~K}, 643 \mathrm{~K}$, and $673 \mathrm{~K}$, respectively. The first peak for each sample was located at around $2.4 \AA$. With the increase of annealing 
temperature, the intensity of the first peak disappeared and the intensity of the second peak increased. The second peak is Al-Ce pair, meaning more Al-Ce pairs were packed at the short order distance. Moreover, the third peak was splitting into two peaks with the increasing annealing temperature. The result occurred because of the long Al-Ce bond and the large value of Ce metallic radius. When the annealing temperature reached $543 \mathrm{~K}$, the structure started to turn to the medium-range order. This phenomenon was demonstrated by the regular peaks detected even at $30 \AA$. For the samples annealed at $543 \mathrm{~K}, 643 \mathrm{~K}$, and $673 \mathrm{~K}$, the intensity of their 5th and 6th peaks were increased. Meanwhile, the hardness of these samples also increased and reached the maximum in the $643 \mathrm{~K}$ sample. When the temperature arrived $673 \mathrm{~K}$, the sample was fully crystalline.

\subsection{Conclusion}

The PDF obtained from XRD experiments of $\mathrm{Al}_{20} \mathrm{Ni}_{10} \mathrm{Ce}_{70}, \mathrm{Al}_{46} \mathrm{Ni}_{10} \mathrm{Ce}_{44}, \mathrm{Al}_{86.5} \mathrm{Ni}_{9.5} \mathrm{Ce}_{5}$, and $\mathrm{Al}_{85.8} \mathrm{Ni}_{9.1} \mathrm{Ce}_{5.1}$ samples can be used to investigate the correlation between the shortrange order, $\mathrm{Al}, \mathrm{Ni}$ and $\mathrm{Ce}$ elements, the initial super-cooled liquid region $\left(\Delta T_{x}\right)$. In addition, PDF can be used to observe the sample crystalline structure at different annealing temperature.

From those results, we can conclude that the sample with different composition shown for better glass forming ability, there is an atom amount balance for $\mathrm{Al}$ atoms' closest $\mathrm{Ni}$ and $\mathrm{Ce}$ atoms. When $\mathrm{Al}-\mathrm{Ni}$ and $\mathrm{Al}-\mathrm{Ce}$ reach the balanced peak intensity, the sample would have larger GFA compare with those have either higher Al-Ni peak or higher Al-Ce peak samples. The pair distribution function result from $\mathrm{Al}_{86.5} \mathrm{Ni}_{9.5} \mathrm{Ce}_{5}$, and $\mathrm{Al}_{85.8} \mathrm{Ni}_{9.1} \mathrm{Ce}_{5.1}$ indicated that a slight difference of concentration will not significantly affect the final 
performance. The increases of $\mathrm{Ce}$ will bring a medium-range order because the larger $\mathrm{Ce}$ size. 


\section{CHAPTER 7.CONCLUSION}

- Inoue Criteria successfully predicted $\mathrm{Al}_{46} \mathrm{Ni}_{10} \mathrm{Ce}{ }_{44}$ has the best glass-forming ability in the current study. Its supercooled liquid region is $40 \mathrm{~K}$. This optimized Al-Ni-Ce metallic glass should be one of the best candidates for future preparing bulk metallic glass. The relationship between the crystalline structure of Al-Ni-Ce samples and the annealing temperatures has been investigated by synchrotron X-ray diffraction. The hardness of each sample was significantly improved by the annealing treatment. Obtained X-ray diffraction results and microindentation values show that when the annealing temperature is close to $T x$, the hardness of the sample will reach the highest value.

- The highest hardness value, 853(Hv), was achieved when annealed $\mathrm{Al}_{46} \mathrm{Ni}_{10} \mathrm{Ce}_{44}$ at $573 \mathrm{~K}$ for 30 mins. This value is significantly high compared to the published hardness of bulk MG systems, such as Zr-based, Pd-based and Mg-based metallic glasses, as well as conventional alloys such as stainless steel and super high strength steel. Annealing procedure for metallic glass can significantly introduced nano size crystalline precipitations, the higher density of grain boundaries of these precipitations would block the dislocation movement and enhances the hardness of the annealed MG system. The optimized $\mathrm{Al}_{46} \mathrm{Ni}_{10} \mathrm{Ce}_{44}$ metallic glass and its composite should be one of the best candidates for future mechanical engineering application.

- Annealing $\mathrm{Ce}_{75} \mathrm{Al}_{23} \mathrm{Si}_{2} \mathrm{MG}$ at a temperature above $473 \mathrm{~K}$ introduced nano- $\mathrm{AlCe}_{3}$ crystalline precipitations of about $30-40 \mathrm{~nm}$, which in turn enhanced the hardness 
of the annealed system. The population of such nano-precipitations increased with the annealing temperature within the range of $473 \mathrm{~K}-563 \mathrm{~K}$. Consequently, the hardness also increased with the annealing temperature. From TEM, we can clearly identify the mixed area of crystalline and non-crystalline structure. This kind of structure could help improve the mechanical property of the sample.

- The PDF obtained from XRD experiments of $\mathrm{Al}_{20} \mathrm{Ni}_{10} \mathrm{Ce}_{70}, \mathrm{Al}_{46} \mathrm{Ni}_{10} \mathrm{Ce}_{44}, \mathrm{Al}_{86.5}$ $\mathrm{Ni}_{9.5} \mathrm{Ce}_{5}$, and $\mathrm{Al}_{85.8} \mathrm{Ni}_{9.1} \mathrm{Ce}_{5.1}$ samples was used to investigate the correlation among the short-range order, $\mathrm{Al}, \mathrm{Ni}$ and Ce elements, the initial supercooled liquid region $\left(\Delta T_{x}\right)$, and hardness. $\mathrm{Al}_{20} \mathrm{Ni}_{10} \mathrm{Ce}_{70}, \mathrm{Al}_{46} \mathrm{Ni}_{10} \mathrm{Ce}_{44}, \mathrm{Al}_{86.5} \mathrm{Ni}_{9.5} \mathrm{Ce}_{5}$, and $\mathrm{Al}_{85.8} \mathrm{Ni}_{9.1} \mathrm{Ce}_{5.1}$ appear to be related to an important size effect. From the experimental results, we concluded that the atom amount of $\mathrm{Al}$ atoms' closest $\mathrm{Ni}$ and $\mathrm{Ce}$ atoms could influence the glass forming ability (GFA). When the nearest $\mathrm{Ni}$ and Ce atoms for Al reached the balanced amount, the Al-Ni-Ce MG could have the best glass forming ability. The pair distribution function resulting from $\mathrm{Al}_{86.5} \mathrm{Ni}_{9.5} \mathrm{Ce}_{5}$ and $\mathrm{Al}_{85.8} \mathrm{Ni}_{9.1} \mathrm{Ce}_{5.1}$ indicates that a slight difference of concentration will not significantly affect the final performance. 


\section{REFERENCES}

1. Duwez, P. (1967). Structure and properties of alloys rapidly quenched from the liquid state. ASM Trans Quart, 60(4), 605-633.

2. Shechtman, D., Blech, I., Gratias, D., \& Cahn, J. W. (1984). Metallic phase with long-range orientational order and no translational symmetry. Physical Review Letters, 53(20), 1951.

3. Krabbes, G., Fuchs, G., Canders, W. R., May, H., \& Palka, R. (2006). High temperature superconductor bulk materials: fundamentals, processing, properties control, application aspects. John Wiley \& Sons.

4. Zallen, R. (2008). The physics of amorphous solids. John Wiley \& Sons.

5. Wang, W. H. (2009). Bulk metallic glasses with functional physical properties. Advanced Materials, 21(45), 4524-4544.

6. http://www.materials.unsw.edu.au/tutorials/online-tutorials/1-atomic-structure.

7. Bar-Yam, Y., \& Joannopoulos, J. D. (1987). Theories of defects in amorphous semiconductors. Journal of Non-Crystalline Solids, 97, 467-474.

8. Turnbull, D. (1981). Metastable structures in metallurgy. Metallurgical Transactions B, 12(2), 217-230.

9. Anantharaman, T.R., ed. (1984). Metallic Glasses: Production, Properties, and Applications. Zürich, Switzerland: Trans Tech Publications.

10. Liebermann, H.H., ed. (1993). Rapidly Solidified Alloys: Processes, Structures, Properties, Applications. New York: Marcel Dekker.

11. Anantharaman, T.R. and C. Suryanarayana (1987). Rapidly Solidified Metals: A Technological Overview. Zürich, Switzerland: Trans Tech Publications.

12. Cahn, R. W., \& Haasen, P. (1991). Processing of Metals and Alloys (Vol. 15). Wiley-VCH.

13. Gleiter, H. (2008). Our thoughts are ours, their ends none of our own: are there ways to synthesize materials beyond the limitations of today?. Acta Materialia, 56(19), 5875-5893. 
14. Krabbes, G., G. Fuchs, W.-R. Canders, H. May, and R. Palka (2006). High Temperature Superconductor Bulk Materials: Fundamentals-ProcessingProperties Control-Application Aspects. Weinheim, Germany: Wiley-VCH.

15. Yum, J. H., Bersuker, G., Oh, J., \& Banerjee, S. K. (2012). Theoretical approach to evaluating beryllium oxide as a gate dielectric considering electromagnetics and thermal stability. Applied Physics Letters, 100(5), 053501.

16. Löffler, J. F. (2003). Bulk metallic glasses. Intermetallics, 11(6), 529-540.

17. Das, S. K., Perepezko, J. H., Wu, R. I., \& Wilde, G. (2001). Undercooling and glass formation in Al-based alloys. Materials Science and Engineering: A, 304, $159-165$.

18. Chen, H. S., Kimerling, L. C., Poate, J. M., \& Brown, W. L. (1978). Diffusion in a Pd-Cu-Si metallic glass. Applied Physics Letters, 32(8), 461-463.

19. Chen, H. S., \& Turnbull, D. (1969). Formation, stability and structure of palladium-silicon based alloy glasses. Acta Metallurgica, 17(8), 1021-1031.

20. Chen, H. S. (1974). Thermodynamic considerations on the formation and stability of metallic glasses. Acta Metallurgica, 22(12), 1505-1511.

21. Inoue, A., Kita, K., Zhang, T., \& Masumoto, T. (1989). An amorphous $\mathrm{La}_{55} \mathrm{Al}_{25} \mathrm{Ni}_{20}$ alloy prepared by water quenching. Materials transactions, JIM, 30(9), 722-725.

22. Turnbull, D. (1981). Metastable structures in metallurgy. Metallurgical Transactions B, 12(2), 217-230.

23. Nishiyama, N., \& Inoue, A. (1996). Glass-forming ability of bulk $\mathrm{Pd}_{40} \mathrm{Ni}_{10} \mathrm{Cu}_{30} \mathrm{P}_{20}$ alloy. Materials Transactions, JIM, 37(10), 1531-1539.

24. Busch, R., Schneider, S., Peker, A., \& Johnson, W. L. (1995). Decomposition and primary crystallization in undercooled $\mathrm{Zr}_{41.2} \mathrm{Ti}_{13.8} \mathrm{Cu}_{12.5} \mathrm{Ni}_{10.0} \mathrm{Be}_{22.5}$ melts. Applied Physics Letters, 67(11), 1544-1546.

25. Inoue, A., \& Nishiyama, N. (1997). Extremely low critical cooling rates of new $\mathrm{Pd}-\mathrm{Cu}-\mathrm{P}$ base amorphous alloys. Materials Science and Engineering: A, 226, 401405.

26. Inoue, A., \& Zhang, T. (1997). Thermal stability and glass-forming ability of amorphous Nd-Al-TM (TM= Fe, Co, $\mathrm{Ni}$ or $\mathrm{Cu})$ alloys. Materials Science and Engineering: A, 226, 393-396. 
27. Inoue, A., Zhang, T., Nishiyama, N., Ohba, K., \& Masumoto, T. (1993). Preparation of $16 \mathrm{~mm}$ diameter rod of amorphous $\mathrm{Zr}_{65} \mathrm{Al}_{7.5} \mathrm{Ni}_{10} \mathrm{Cu}_{17.5}$ alloy. Materials Transactions, JIM, 34(12), 1234-1237.

28. Chen, L.Y., H.T. Hu, G.Q. Zhang, and J.Z. Jiang (2007). Catching the Ni-based ternary metallic glasses with critical diameter up to $3 \mathrm{~mm}$ in $\mathrm{Ni}-\mathrm{Nb}-\mathrm{Zr}$ system. $J$. Alloys Compd. 443: 109-113.

29. Peker, A., \& Johnson, W. L. (1994). U.S. Patent No. 5,368,659. Washington, DC: U.S. Patent and Trademark Office.

30. Lin, X., Peker, A., \& Johnson, W. L. (1997). U.S. Patent No. 5,618,359. Washington, DC: U.S. Patent and Trademark Office.

31. Vaillant, M. L., Keryvin, V., Rouxel, T., \& Kawamura, Y. (2002). Changes in the mechanical properties of a $\mathrm{Zr}_{55} \mathrm{Cu}_{30} \mathrm{Al}_{10} \mathrm{Ni}_{5}$ bulk metallic glass due to heat treatments below $540{ }^{\circ} \mathrm{C}$. Scripta Materialia, 47(1), 19-23.

32. Zhao, Z., Chang, C., Makino, A., Okubo, A., \& Inoue, A. (2009). Preparation of bulk glassy $\mathrm{Fe}_{76} \mathrm{Si}_{9} \mathrm{~B}_{10} \mathrm{P}_{5}$ as a soft magnetic material by spark plasma sintering. Materials Transactions, 50(3), 487-489.

33. Suryanarayana, C., \& Inoue, A. (2013). Iron-based bulk metallic glasses. International Materials Reviews, 58(3), 131-166.

34. Shan, G. B., Li, J. X., Yang, Y. Z., Qiao, L. J., \& Chu, W. Y. (2007). Hydrogenenhanced plastic deformation during indentation for bulk metallic glass of $\mathrm{Zr}_{65} \mathrm{Al}_{7.5} \mathrm{Ni}_{10} \mathrm{Cu}_{17.5}$. Materials Letters, 61(8-9), 1625-1628.

35. Telford, M. (2004). The case for bulk metallic glass. Materials Today, 7(3), 3643.

36. Erhart, H., \& Grabke, H. J. (1981). Equilibrium segregation of phosphorus at grain boundaries of $\mathrm{Fe}-\mathrm{P}, \mathrm{Fe}-\mathrm{C}-\mathrm{P}, \mathrm{Fe}-\mathrm{Cr}-\mathrm{P}$, and $\mathrm{Fe}-\mathrm{Cr}-\mathrm{C}-\mathrm{P}$ alloys. Metal Science, 15(9), 401-408.

37. Xing, L. Q., Eckert, J., Löser, W., Roth, S., \& Schultz, L. (2000). Atomic ordering and magnetic properties in $\mathrm{Nd}_{57} \mathrm{Fe}_{20} \mathrm{~B}_{8} \mathrm{Co}_{5} \mathrm{Al}_{10}$ solids. Journal of Applied Physics, $88(6), 3565-3569$.

38. Kucuk, I., Aykol, M., Uzun, O., Yildirim, M., Kabaer, M., Duman, \& Mekhrabov, A. O. (2011). Effect of (Mo, W) substitution for $\mathrm{Nb}$ on glass forming ability and magnetic properties of $\mathrm{Fe}-\mathrm{Co}$-based bulk amorphous alloys fabricated by centrifugal casting. Journal of Alloys and Compounds, 509(5), 2334-2337. 
39. Lesz, S., Babilas, R., \& Nowosielski, R. (2013). Influence of copper addition on glass forming ability, thermal stability, structure and magnetic properties of FeCo-based BMGs. In Solid State Phenomena (Vol. 203, pp. 296-301). Trans Tech Publications.

40. Gebert, A., Gostin, F., Kühn, U., \& Schultz, L. (2009). Corrosion of a Zr-based bulk metallic glass with different surface finishing states. ECS Transactions, 16(32), 1-7.

41. Guo, S. F., Liu, L., Li, N., \& Li, Y. (2010). Fe-based bulk metallic glass matrix composite with large plasticity. Scripta Materialia, 62(6), 329-332.

42. Ashby, M. F., \& Greer, A. L. (2006). Metallic glasses as structural materials. Scripta Materialia, 54(3), 321-326.

43. Schuh, C. A., Hufnagel, T. C., \& Ramamurty, U. (2007). Mechanical behavior of amorphous alloys. Acta Materialia, 55(12), 4067-4109.

44. Yang, B. J., Yao, J. H., Chao, Y. S., Wang, J. Q., \& Ma, E. (2010). Developing aluminum-based bulk metallic glasses. Philosophical Magazine, 90(23), 32153231 .

45. Jiang, J. Z., Hofmann, D., Jarvis, D. J., \& Fecht, H. J. (2015). Low-Density HighStrength Bulk Metallic Glasses and Their Composites: A Review. Advanced Engineering Materials, 17(6), 761-780.

46. Wu, N. C., Zuo, L., Wang, J. Q., \& Ma, E. (2016). Designing aluminum-rich bulk metallic glasses via electronic-structure-guided microalloying. Acta Materialia, 108, 143-151.

47. Shen, Y., \& Perepezko, J. H. (2017). Al-based amorphous alloys: glass-forming ability, crystallization behavior and effects of minor alloying additions. Journal of Alloys and Compounds, 707, 3-11.

48. Yan, M., Kohara, S., Wang, J. Q., Nogita, K., Schaffer, G. B., \& Qian, M. (2011). The influence of topological structure on bulk glass formation in Al-based metallic glasses. Scripta Materialia, 65(9), 755-758.

49. Jaswal, S. S., \& Hafner, J. (1988). Atomic and electronic structure of crystalline and amorphous alloys. I. Calcium-magnesium compounds. Physical Review B, $38(11), 7311$.

50. Kim, Y. H., Inoue, A., \& Masumoto, T. (1990). Ultrahigh tensile strengths of $\mathrm{Al}_{88} \mathrm{Y}_{2} \mathrm{Ni}_{9} \mathrm{M}_{1}(\mathrm{M}=\mathrm{Mn}$ or $\mathrm{Fe})$ amorphous alloys containing finely dispersed fcc-Al particles. Materials Transactions, JIM, 31(8), 747-749. 
51. YH, K., Hiraga, K., Inoue, A., \& Masumoto, T. (1994). Crystallization and high mechanical strength of Al-based amorphous alloys. Materials Transactions, JIM, 35(5), 293-302.

52. Greer, A. L., Cheng, Y. Q., \& Ma, E. (2013). Shear bands in metallic glasses. Materials Science and Engineering: R, 74(4), 71-132.

53. Zhong, Z. C., Jiang, X. Y., \& Greer, A. L. (1997). Micro structure and hardening of Al-based nanophase composites. Materials Science and Engineering: A, 226, 531-535.

54. Yavari, A. R., \& Negri, D. (1997). Effect of concentration gradients on nanostructure development during primary crystallization of soft-magnetic ironbased amorphous alloys and its modelling. Nanostructured Materials, 8(8), 969986.

55. Johnson, W. L. (2002). Bulk amorphous metal-An emerging engineering material. Jom, 54(3), 40-43.

56. Louzguine, D. V., \& Inoue, A. (2002). Crystallization behaviour of Al-based metallic glasses below and above the glass-transition temperature. Journal of Non-crystalline Solids, 311(3), 281-293.

57. Yuan, Y. B., Wang, Z. W., Zheng, R. X., Hao, X. N., \& Ameyama, K. (2014). Effect of mechanical alloying and sintering process on microstructure and mechanical properties of Al-Ni-Y-Co-La alloy. Transactions of Nonferrous Metals Society of China, 24(7), 2251-2257.

58. Sheng, H. W., Luo, W. K., Alamgir, F. M., Bai, J. M., \& Ma, E. (2006). Atomic packing and short-to-medium-range order in metallic glasses. Nature, 439(7075), 419.

59. Bian, X. F., Sun, B. A., Hu, L. N., \& Jia, Y. B. (2005). Fragility of superheated melts and glass-forming ability in Al-based alloys. Physics Letters A, 335(1), 6167.

60. Freitag, J. M., Koknaev, R. G., Sabet-Sharghi, R., Koknaeva, M., \& Altounian, Z. (1996). Mechanical properties of Al-Y-Ni amorphous ribbons. Journal of Applied Physics, 79(8), 3967-3970.

61. Fan, G. J., Löser, W., Roth, S., \& Eckert, J. (2000). Glass-forming ability of REAl-TM alloys ( $\mathrm{RE}=\mathrm{Sm}, \mathrm{Y}$; $\mathrm{TM}=\mathrm{Fe}, \mathrm{Co}, \mathrm{Cu})$. Acta Materialia, 48(15), 38233831 . 
62. Qiu, K. Q., Zhang, H. F., Wang, A. M., Ding, B. Z., \& Hu, Z. Q. (2002). Glassforming ability and thermal stability of $\mathrm{Nd}_{70-\mathrm{x}} \mathrm{Fe}_{20} \mathrm{Al}_{10} \mathrm{Y}_{\mathrm{x}}$ alloys. Acta Materialia, 50(14), 3567-3578.

63. Wu, J., Wang, Q., Qiang, J. B., Chen, F., Dong, C., Wang, Y. M., \& Shek, C. H. (2007). Sm-based Sm-Al-Ni ternary bulk metallic glasses. Journal of Materials Research, 22(3), 573-577.

64. Chen, D., Takeuchi, A., \& Inoue, A. (2007). Gd-Co-Al and Gd-Ni-Al bulk metallic glasses with high glass forming ability and good mechanical properties. Materials Science and Engineering: A, 457(1-2), 226-230.

65. Du, X. H., Huang, J. C., Liu, C. T., \& Lu, Z. P. (2007). New criterion of glass forming ability for bulk metallic glasses.

66. Xu, X., Chen, L. Y., Zhang, G. Q., Wang, L. N., \& Jiang, J. Z. (2007). Formation of bulk metallic glasses in $\mathrm{Cu}_{45} \mathrm{Zr}_{48-\mathrm{x}} \mathrm{Al}_{7} \mathrm{Re}_{\mathrm{x}}(\mathrm{Re}=\mathrm{La}, \mathrm{Ce}, \mathrm{Nd}, \mathrm{Gd}$ and $0 \leq \mathrm{x} \leq 5$ at. \%). Intermetallics, 15(8), 1066-1070.

67. Sheng, H. W., Cheng, Y. Q., Lee, P. L., Shastri, S. D., \& Ma, E. (2008). Atomic packing in multicomponent aluminum-based metallic glasses. Acta Materialia, 56(20), 6264-6272.

68. Liang, X., Chen, J., Mora, M. T., Urdaneta, J. F., \& Zeng, Q. (2017). Effect of precipitation on the hardness of ternary metallic glass. Advances in Materials Physics and Chemistry, 7(06), 255.

69. Kim, Y. C., Na, J. H., Park, J. M., Kim, D. H., Lee, J. K., \& Kim, W. T. (2003). Role of nanometer-scale quasicrystals in improving the mechanical behavior of Ti-based bulk metallic glasses. Applied Physics Letters, 83(15), 3093-3095.

70. Belov, N., Naumova, E., \& Akopyan, T. (2017). Eutectic alloys based on the Al$\mathrm{Zn}-\mathrm{Mg}-\mathrm{Ca}$ system: microstructure, phase composition and hardening. Materials Science and Technology, 33(6), 656-666.

71. Muñoz-Morris, M. A., Calderón, N., Gutierrez-Urrutia, I., \& Morris, D. G. (2006). Matrix grain refinement in Al-TiAl composites by severe plastic deformation: Influence of particle size and processing route. Materials Science and Engineering: A, 425(1-2), 131-137.

72. Li, S., Wang, R. J., \& Wang, W. H. (2006). Bulk metallic glasses based on rareearth elements in lanthanum series. Journal of Non-crystalline Solids, 352(36-37), 3942-3946. 
73. Johnson, W. L. (1996). Fundamental aspects of bulk metallic glass formation in multicomponent alloys. In Materials Science Forum (Vol. 225, pp. 35-50). Trans Tech Publications.

74. Wang, W. H. (2007). Roles of minor additions in formation and properties of bulk metallic glasses. Progress in Materials Science, 52(4), 540-596.

75. Bhugra, C., \& Pikal, M. J. (2008). Role of thermodynamic, molecular, and kinetic factors in crystallization from the amorphous state. Journal of pharmaceutical sciences, 97(4), 1329-1349.

76. Cahn, J. W., \& Allen, S. M. (1977). A microscopic theory for domain wall motion and its experimental verification in $\mathrm{Fe}-\mathrm{Al}$ alloy domain growth kinetics. Le Journal de Physique Colloques, 38(C7), C7-51.

77. Liao, J. P., Yang, B. J., Zhang, Y., Lu, W. Y., Gu, X. J., \& Wang, J. Q. (2015). Evaluation of glass formation and critical casting diameter in Al-based metallic glasses. Materials \& Design, 88, 222-226.

78. Dulikravich, G. S., Egorov, I. N., \& Colaco, M. J. (2008). Optimizing chemistry of bulk metallic glasses for improved thermal stability. Modelling and Simulation in Materials Science and Engineering, 16(7), 075010.

79. Mao-Guo, G., Li-Cheng, J., Dong-Dong, Y., \& Wen-Ping, M. (2009). Evolutionary multi-objective optimization algorithms.

80. Egorov, I., Kretinin, G., Leshchenko, I., \& Kuptzov, S. (2002, September). IOSO optimization toolkit-novel software to create better design. In 9th AIAA/ISSMO Symposium on Multidisciplinary Analysis and Optimization (p. 5514).

81. Egorov, I. N., Kretinin, G. V., Leshchenko, I. A., \& Kuptzov, S. V. (2007). Multiobjective approach for robust design optimization problems. Inverse Problems in Science and Engineering, 15(1), 47-59.

82. Guo, S., Lu, Z. P., \& Liu, C. T. (2010). Identify the best glass forming ability criterion. Intermetallics, 18(5), 883-888.

83. Falcão de Oliveira, M. (2012). A simple criterion to predict the glass forming ability of metallic alloys. Journal of Applied Physics, 111(2), 023509.

84. Park, E. S., \& Kim, D. H. (2005). Design of bulk metallic glasses with high glass forming ability and enhancement of plasticity in metallic glass matrix composites: A review. Metals and Materials International, 11(1), 19-27. 
85. Park, E. S., \& Kim, D. H. (2005). Design of Bulk metallic glasses with high glass forming ability and enhancement of plasticity in metallic glass matrix composites: A review. Metals and Materials International, 1(11), 19-27.

86. Zhang, Z., Xiong, X. Z., Yi, J. J., \& Li, J. F. (2013). Crystallization behavior and thermal stability of Al-Ni-RE metallic glasses. Acta Physica Sinica, 62(13), 136401

87. Song, K., Bian, X., Lv, X., GuO, J., Li, G., \& Xie, M. (2009). Compositional dependence of glass-forming ability, medium-range order, thermal stability and liquid fragility of Al-Ni-Ce-based amorphous alloys. Materials Science and Engineering: A, 506(1-2), 87-93.

88. https://pdfs.semanticscholar.org/86e4/c652f6b3bac7ddb38d5bc6871360befc189f. pdf.

89. Luo, Q., Zhao, D., Pan, M. and Wang, W. (2006). Magnetocaloric effect in Gdbased bulk metallic glasses. Applied Physics Letters, 89, 081914.

90. Louzguine, D. V. and Inoue, A. (2001). Electronegativity of the constituent rareearth metals as a factor stabilizing the supercooled liquid region in Al-based metallic glasses. Applied Physics Letters. 79, 3410-3412.

91. Rosenflanz, A., Frey, M., Endres, B., Anderson, T., Richards, E., \& Schardt, C. (2004). Bulk glasses and ultrahard nanoceramics based on alumina and rare-earth oxides. Nature, 430(7001), 761

92. Inoue, A. (2000). Stabilization of metallic supercooled liquid and bulk amorphous alloys. Acta Materialia, 48(1), 279-306.

93. Telford, M. (2004). The case for bulk metallic glass. Materials Today, 7, 36-43.

94. Löffler, J. F. (2003). Bulk metallic glasses. Intermetallics, 11, 529-540.

95. Wang, W.-H., Dong, C. and Shek, C. (2004). Bulk metallic glasses. Materials Science and Engineering: R: Reports, 44, 45-89.

96. Johnson, W. L. (1999). Bulk glass-forming metallic alloys: Science and technology. MRS Bulletin, 24, 42-56.

97. Gu, J., Song, M., Ni, S., Guo, S. and He, Y. (2013). Effects of annealing on the hardness and elastic modulus of a $\mathrm{Cu}_{36} \mathrm{Zr}_{48} \mathrm{Al}_{8} \mathrm{Ag}_{8}$ bulk metallic glass. Materials \& Design, 47, 706-710. 
98. Singh, D., Singh, D., Mandal, R., Srivastava, O. and Tiwari, R. (2014). Glass forming ability, thermal stability and indentation characteristics of $\mathrm{Ce}_{75} \mathrm{Al}_{25-\mathrm{x}} \mathrm{Ga}_{\mathrm{x}}$ metallic glasses. Journal of Alloys and Compounds. 590, 15-20.

99. Zeng, Q. S., Fang, Y. Z., Lou, H. B., Gong, Y., Wang, X. D., Yang, K., \& Yu, X. H. (2010). Low-density to high-density transition in $\mathrm{Ce}_{75} \mathrm{Al}_{23} \mathrm{Si}_{2}$ metallic glass. Journal of Physics: Condensed Matter, 22(37), 375404

100. Singh, D., Singh, D., Srivastava, O. and Tiwari, R. (2016). Microstructural effect on the low temperature transport properties of $\mathrm{Ce}-\mathrm{Al}(\mathrm{Ga})$ metallic glasses. Scripta Materialia, 118, 24-28.

101. Duarte, M. J., Bruna, P., Pineda, E., Crespo, D., Garbarino, G., Verbeni, R., Zhao, K., Wang, W. H., Romero, A. H. and Serrano, J. (2011). Polyamorphic transitions in Ce-based metallic glasses by synchrotron radiation. Physical Review B. 84, 224116.

102. Duarte, M. J., Bruna, P., Pineda, E., Crespo, D., Garbarino, G., Verbeni, R., \& Serrano, J. (2011). Polyamorphic transitions in Ce-based metallic glasses by synchrotron radiation. Physical Review B, 84(22), 224116.

103. Xie, S. and George, E. P. (2008). Hardness and shear band evolution in bulk metallic glasses after plastic deformation and annealing. Acta Materialia, 56, 5202-5213.

104. Oliver, W. C. and Pharr, G. M. (1992). An improved technique for determining hardness and elastic modulus using load and displacement sensing indentation experiments. Journal of Materials Research, 7, 1564-1583.

105. Cheng, G., Barker, E. I., Stephens, E. V., Choi, K. S. and Sun, X. (2016). Quantifying Grain Level Stress-Strain Behavior for AM40 via Instrumented Microindentation. MRS Advances, 1, 761-772.

106. Cheng, G., Zhang, F., Ruimi, A., Field, D. P. and Sun, X. (2016). Quantifying the effects of tempering on individual phase properties of DP980 steel with nanoindentation. Materials Science and Engineering a-Structural Materials Properties Microstructure and Processing, 667, 240-249.

107. Cheng, G., Choi, K. S., Hu, X. and Sun, X. (2016). Determining individual phase properties in a multi-phase Q\&P steel using multi-scale indentation tests. Materials Science and Engineering: A, 652, 384-395.

108. Cheng, G., Sun, X., Wang, Y., Tay, S. L. and Gao, W. (2017). Nanoindentation study of electrodeposited Ag thin coating: An inverse calculation of anisotropic 
elastic-plastic properties. Surface and Coatings Technology, 310, 43-50.

109. Mao, W. L., Struzhkin, V. V., Baron, A. Q., Tsutsui, S., Tommaseo, C. E., Wenk, H. R., Hu, M. Y., Chow, P., Sturhahn, W. and Shu, J. (2008). Experimental determination of the elasticity of iron at high pressure. Journal of Geophysical Research: Solid Earth, 113.

110. Wojdyr, M. (2010). Fityk: a general-purpose peak fitting program. Journal of Applied Crystallography, 43, 1126-1128.

111. Rice, P. M. and Stoller, R. E. (2000). Correlation of nanoindentation and conventional mechanical property measurements. MRS Proceedings: Cambridge University Press; 2000. p. Q7. 11.

112. Rodriguez, R. and Gutierrez, I. (2003). Correlation between nanoindentation and tensile properties Influence of the indentation size effect. Materials Science and Engineering: A. 361, 377-384.

113. Armstrong, R. W. (2014). 60 Years of Hall-Petch: Past to Present Nano-Scale Connections. Materials Transactions. 55, 2-12.

114. Inoue, A., Zhang, T., Kita, K., \& Masumoto, T. (1989). Mechanical strengths, thermal stability and electrical resistivity of aluminum-rare earth metal binary amorphous alloys. Materials Transactions, JIM, 30(11), 870-877.

115. Lewandowski, J. J. (2001). Effects of annealing and changes in stress state on fracture toughness of bulk metallic glass. Materials Transactions, 42(4), 633-637.

116. Shen, T. D., He, Y., \& Schwarz, R. B. (1999). Bulk amorphous Pd-Ni-Fe-P alloys: preparation and characterization. Journal of Materials Research, 14(5), 2107-2115.

117. Inoue, A., Kato, A., Zhang, T. G. K. S., \& Masumoto, T. (1991). Mg-Cu-Y amorphous alloys with high mechanical strengths produced by a metallic mold casting method. Materials Transactions, JIM, 32(7), 609-616.

118. Shen, B. L., Koshiba, H., Mizushima, T., \& Inoue, A. (2000). Bulk amorphous $\mathrm{Fe}-\mathrm{Ga}-\mathrm{P}-\mathrm{B}-\mathrm{C}$ alloys with a large supercooled liquid region. Materials Transactions, JIM, 41(7), 873-876.

119. Chen, H. S. (1974). Thermodynamic considerations on the formation and stability of metallic glasses. Acta Metallurgica, 22(12), 1505-1511.

120. Dulikravich, G. S., Egorov, I. N., \& Colaco, M. J. (2008). Optimizing chemistry of bulk metallic glasses for improved thermal stability. Modelling and Simulation 
in Materials Science and Engineering, 16(7), 075010.

121. Inoue, A., Ohtera, K., Tsai, A. P., Kimura, H., \& Masumoto, T. (1988). Glass transition behavior of Al-Y-Ni and Al-Ce-Ni amorphous alloys. JapaneseJjournal of Applied Physics, 27(9A), L1579.

122. Rios, C. T., Suriñach, S., Baró, M. D., Bolfarini, C., Botta, W. J., \& Kiminami, C. S. (2008). Glass forming ability of the Al-Ce-Ni system. Journal of NonCrystalline Solids, 354(42-44), 4874-4877.

123. Song, K., Bian, X., Lv, X., GuO, J., Li, G., \& Xie, M. (2009). Compositional dependence of glass-forming ability, medium-range order, thermal stability and liquid fragility of Al-Ni-Ce-based amorphous alloys. Materials Science and Engineering: A, 506(1-2), 87-93.

124. Tang, C., Du, Y., Xu, H. H., Xiong, W., Zhang, L. J., Zheng, F., \& Zhou, H. Y. (2008). Experimental investigation of the Al-Ce-Ni system at $800^{\circ}$ C. Intermetallics, 16(3), 432-439.

125. Wang, R., Chen, W., Zhang, L., Liu, D., Li, X., Du, Y., \& Jin, Z. (2013). Diffusivities and atomic mobilities in the Al-Ce-Ni melts. Journal of NonCrystalline Solids, 379, 201-207.

126. Inoue, A., \& Takeuchi, A. (2002). Recent progress in bulk glassy alloys. Materials Transactions, 43(8), 1892-1906.

127. Qiu, X., Thompson, J. W., \& Billinge, S. J. (2004). PDFgetX2: a GUI-driven program to obtain the pair distribution function from X-ray powder diffraction data. Journal of Applied Crystallography, 37(4), 678-678.

128. Hayes, T. M., Allen, J. W., Tauc, J., Giessen, B. C., \& Hauser, J. J. (1978). Shortrange order in metallic glasses. Physical Review Letters, 40(19), 1282.

129. Yang, H., Wang, J. Q., \& Li, Y. (2008). Influence of TM and RE elements on glass formation of the ternary Al-TM-RE systems. Journal of Non-Crystalline Solids, 354(29), 3473-3479.

130. Maurya, R. S., \& Laha, T. (2015). Effect of rare earth and transition metal elements on the glass forming ability of mechanical alloyed Al-TM-RE based amorphous alloys. Journal of Materials Science \& Technology, 31(11), 1118-1124.

131. Saporiti, F., Boudard, M., \& Audebert, F. (2010). Short range order in Al-Fe-Nb, $\mathrm{Al}-\mathrm{Fe}-\mathrm{Ce}$ and $\mathrm{Al}-\mathrm{Ni}-\mathrm{Ce}$ metallic glasses. Journal of Alloys and Compounds, 495(2), 309-312. 
132. Hsieh, H. Y., Toby, B. H., Egami, T., He, Y., Poon, S. J., \& Shiflet, G. J. (1990). Atomic structure of amorphous A1 90 Fe x Ce 10- x. Journal of Materials Research, 5(12), 2807-2812.

133. Senkov, O. N., \& Miracle, D. B. (2001). Effect of the atomic size distribution on glass forming ability of amorphous metallic alloys. Materials Research Bulletin, 36(12), 2183-2198

134. Schroers, J. (2005). The superplastic forming of bulk metallic glasses. Jom, 57(5), 35-39.

135. Egorov, I. N., Kretinin, G. V., Leshchenko, I. A., \& Kuptzov, S. V. (2002, July). Robust design optimization strategy of IOSO technology. In Fifth World Congress on Computational Mechanics, Vienna, Austria.

136. Palomino, R. M.,et al. (2017). New in-situ and operando facilities for catalysis science at NSLS-II: The deployment of real-time, chemical, and structure-sensitive X-ray probes. Synchrotron Radiation News, 30(2), 30-37. 
VITA

\section{XUE LIANG}

\section{Born, Shanxi, China}

2002-2006

B.A., Materials Science

Beijing University of Technology

Beijing, China

2009-2013

Stonybrook University, New York

2016

Doctoral Candidate

Florida International University

Miami, Florida

Graduate Assistant

Mechanical and Materials Engineering Department

Miami, Florida

\section{PUBLICATIONS AND PRESENTATIONS}

Liang, X., Chen, J., Mora, M. T., Urdaneta, J. F., \& Zeng, Q. (2017). Effect of precipitation on the hardness of ternary metallic glass. Advances in Materials Physics and Chemistry, 7(06), 255.

Chen, J., Liang, X., Yang, B., Girard, J., Drozd, V., \& Liu, Z. (2016). Band Gap of Semiconducting High Pressure Phase of Boron. DEStech Transactions on Materials Science and Engineering, (msce).

Xue Liang, Jose Fernanedz, Jiuhua Chen, Crystallization and Indentation Characteristics of $\mathrm{Ce}_{75} \mathrm{Al}_{23} \mathrm{Si}_{2}$ Metallic Glass, COMPRES Annual Meeting 2016, Tamaya, NM

Xue Liang, Jiuhua Chen, Maria Mora, J.Fernanedz, Qiaoshi Zeng, Effects of Precipitation on the Hardness of Ternary Rare Earth-based Metallic Glass, COMPRES Annual Meeting 2017, Tamaya, NM

Xue Liang, Jiuhua Chen, Qiaoshi Zeng, Maria Teresa Mora, Effects of temperature on the short-range order of ternary metallic glass, COMPRES Annual Meeting 2018, Tamaya, NM

Xue Liang, Jiuhua Chen, Optimizing Chemistry of Al-based Ternary Metallic Glass for Improved Mechanical Property, COMPRES Annual Meeting 2019, Big Sky, MT 
Liang, X., Ruiz-Osés, M., Ben-Zvi, I., Schubert, S., Smedley, J., Attenkofer, K., ... \& Padmore, H. A. (2013). Preparation and investigation of antimony thin films for multialkali photocathodes (No. BNL-100967-2013-CP). Brookhaven National Laboratory (BNL).

Liang, X., Ben-Zvi, I., Ruiz-Oses, M., Smedley, J., Attenkofer, K., Vecchione, T., ... \& Schubert, S. (2012). Deposition and in-situ characterization of alkali antimonide photocathodes (No. BNL-96798-2012-CP). BROOKHAVEN NATIONAL LABORATORY (BNL).

Wang, E., Liang, X., Belomestnykh, S., McIntyre, G., Ruiz-Osés, M., Xie, H., ... \& Smedley, J. (2014). Fabrication of alkali antimonide photocathode for SRF gun. 